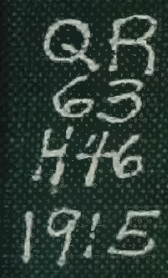


$Q R$

$$
\begin{aligned}
& 63 \\
& 1446 \\
& 1915
\end{aligned}
$$

\section{Líbrare}

$$
\text { OF THE }
$$

New Dork Itate Veterinary College 


\section{OR 63.H46 1915}

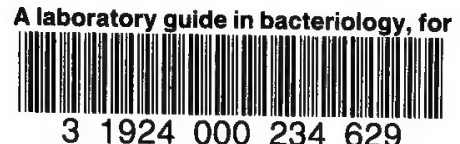

31924000234629 


\section{Cornell University Library}

The original of this book is in the Cornell University Library.

There are no known copyright restrictions in the United States on the use of the text.

http://www.archive.org/details/cu31924000234629 


\section{A LABORATORY GUIDE IN BACTERIOLOGY}


THE UNIVERSITY OF CHICAGO PRESS

CHICAGO, ILLINOIS

\section{Agnentr}

THE CAMBRIDGE UNIVERSITY PRESS

LONDON AND EDINBURGH

THE MARUZEN-KABUSHIKI-KAISHA

TOKYO, OSARA, Ктото

KARL W. HIERSEMANN

LEIPZIG

THE BAKER \& TAYLOR COMPANY

NEW YORE 


\title{
A LABORATORY GUIDE
}

IN

\section{BACTERIOLOGY}

FOR THE USE OF STUDENTS, TEACHERS

AND PRACTITIONERS

\author{
BY \\ PAUL G. HEINEMANN, Ph.D. \\ Instructor in Hygiene and Bacteriology \\ The University of Chicago
}

THIRD REVISED EDITION

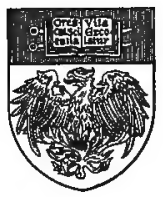

THE UNIVEERSITY OF CHICAGO PRESS

CHICAGO, ILLINOIS

\section{$Z$.}




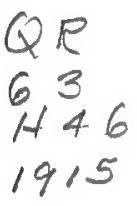

QR

63

1915

\section{CoPyright I \\ The University of Chicago}

First Edition June 1905

Second Edition June I9I I

Second Impression October IgIr

Third Impression October rgr 3

Third Edition September I 915

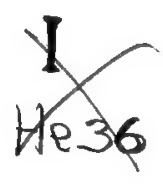




\section{PREFACE TO FIRST EDITION}

The considerations which led the writer to add this laboratory guide of bacteriology to the number of such guides already in existence were of various nature and may be briefly set forth here.

Probably no branch of biological science has advanced so rapidly during the past few years as the science of bacteriology, and it is difficult even for an active laboratory worker to keep abreast of this advance. A textbook or guide fixes the status of the science at the time of its writing, but almost before it leaves the press it becomes antiquated. Revisions, corrections, and additions are necessary at short intervals in order to keep a publication of this kind approximately up to date. There is, therefore, almost at any given moment room for a new publication to fill the want of a progressive instructor for a guide that gives the latest accepted rules and practices of the laboratory. The value of such a publication will Be enhanced by a plan and arrangement of sufficient flexibility and latitude to allow the instructor and the student to enter such additions and corrections as serve to bridge over the time between editions.

Medical students entering on a course in bacteriology often have had too little previous laboratory training in methods of precision. It is a matter of importance for the instructor to put himself in the attitude of mind of the student and to try to appreciate his difficulties in understanding details. Many of 
the pieces of apparatus employed in a bacteriological laboratory are novel even to the student trained in chemistry and biology, and it has been thought best to exhibit these, to the smallest detail, by means of illustrations-a feature not sufficiently considered in other guides.

The formulae for stains and the methods of staining have not been collected in one chapter, as is usually the practice, because this tends to confuse the student. They are described during the progress of the course, as occasion offers to put them to practical use.

Culture-description charts have not been included in this volume. A beginner naturally makes incomplete descriptions and many alterations, and thus defaces the book and impairs its future utility. A sufficient number of loose charts perforated for binding should be furnished to the student at a nominal figure.

A point of inestimable importance is how best to stimulate the student to consult textbooks, special monographs, and other references, as often and as freely as possible. This guide has been written with the aim of not only not interfering in any manner with the reading, through including such points and characteristics as might make a textbook superfluous in the judgment of the inexperienced, but also of making it necessary for the student to read the best textbooks with freedom and understanding. Cultural and morphological features are left entirely to the actual observation of the student, supplemented by instruction and the reading of textbooks.

The course, as outlined, is identical with the medical course given at the University of Chicago, with a few 
additional chapters which may be used during courses for non-medical students. A chapter containing a fairly complete list of formulae for culture media employed in advanced work has been added with the object of making them easily accessible to those engaged in advanced work.

The laboratory guides of Novy, Eyre, Frost, Gorham, Kanthack and Drysdale, and Connell, and the American edition of the Manual of Bacteriology of Muir and Ritchie have been freely consulted. I take this occasion of expressing my deep gratitude to Professor Edwin O. Jordan and Dr. Norman MacLeod Harris for their invaluable help and suggestions in the preparation of this guide.

Chicago, Ill.

PaUl G. HeinemanN

June, I905 



\section{PREFACE TO SECOND EDITION}

The influence of applied bacteriology is extending rapidly, and while formerly the science of microorganisms was chiefly confined to the medical field, it has become of vast industrial importance. The gigantic interests of fermentation industries, of the dairy, of agriculture, of municipal sanitation, and of water purification are largely controlled by bacteriologists. A knowledge of the principles of bacteriology is becoming more and more desirable to the student of general science, and teachers of domestic science in some institutions are required to take an elementary course.

The second edition of this laboratory guide has been revised and enlarged with the view of meeting modern requirements. The first edition was devoted chiefly to medical bacteriology. This has been partly rewritten, and in addition courses in general bacteriology, in the bacteriology of water, in the bacteriology of milk, in soil bacteriology, and a course on molds, yeasts, and acetic-acid bacteria have been outlined. This change of plan necessitated an entirely new arrangement of the material. The preparation of culture media, of stains, etc., has been incorporated in a separate part, and reference to this part is made at the beginning of each special part. The course in the bacteriology of water is calculated to be combined with the physical, chemical, and microscopic examination, the student being thus prepared for sanitary water analysis. Similarly, the course on the bacteriology of milk is to be given in 
connection with the physical and chemical examination of milk.

The author hopes that, by the radical changes indicated, the usefulness of the book may be extended, and that the study of applied bacteriology may be encouraged. I am under special obligations to Professor Edwin O. Jordan for advice and suggestions as to the general plan of the book, to Dr. Mary Hefferan for critical reading of the manuscript and the proof, and to Dr. R. E. Buchanan for valuable advice in outlining the course in soil bacteriology.

Paul G. Heinemann

June, IgII

\section{PREFACE TO THIRD EDITION}

In this third edition the general plan of the book has not been changed. The progress of science necessitated alterations and additions which have been incorporated in the text. A fermentation chart of cardboard has been added to the colony counter in the back cover.

The author is under obligations to Professors Edwin O. Jordan and Norman MacLeod Harris for valuable suggestions.

Paul G. Heinemann

June, I9I5 


\section{INTRODUCTION}

The advent of bacteriology into the realm of the biological sciences not only brought with it a new conception of the nature of many complicated phenomena, such as fermentation and disease, but also placed in the hands of experimental workers a new tool. The method of sterilization, of asepsis, made it possible for the first time to attack problems hitherto incapable of solution, or even of approach. This development of bacteriological technic, of rigid and undeviating adherence to definite rules and principles, is not likely to be passed over lightly by the historian of nineteenthcentury science. The art of practical medicine and theoretical medical research alike owe much of their recent brilliant success to a ready adoption of the new method.

At the present time an active campaign is being set on foot by public health authorities against several widespread and serious diseases of the human race. In various parts of the world malaria, tuberculosis, and typhoid fever are being fought energetically and with much success. In these systematic and organized movements the resources of bacteriology are being utilized as never before, and a full understanding of technical procedure and devices is deemed essential by all workers in this subject. The problems of watersupply and sewage disposal, of urban infantile mortality, and of the control of contagious diseases are all bound up with the intelligent application of bacteriological methods. 
In the almost untilled field of industrial bacteriology there is need for a fuller appreciation of the value of bacteriological methods and principles. Many great industries are based wholly upon the proper selection and adaptation of micro-organisms, and a timely and discriminating utilization of their products. Loose and empirical methods have been in force in the past, but these must eventually give way to a more precise and truly bacteriological technic.

Agricultural bacteriology is just now much in the public eye, and it would be gratuitous to prophesy the results that may reasonably be anticipated in this direction. Here again crude, rule-of-thumb, "practical" ways of doing things are being supplanted by the scientific, the reasoning, and the precise.

To the student, whether in medical, hygienic, or industrial bacteriology, proper technical methods of work must always have a peculiar value, since without their aid advance is impossible, and stumbling and disastrous missteps are certain. A comprehensive outline of modern bacteriological methods, therefore, is a necessary adjunct to obtaining a true and full understanding of the underlying principles and tendencies of the science. The technic of bacteriology is one of its greatest contributions to both science and art, and the use of so valuable and simple a tool should be mastered not only by the biological teacher and investigator, but by practical workers in medicine, hygiene, and many other fields.

EDWIN O. JORDAN 


\section{TABLE OF CONTENTS}

Part I. Bacteriological Technic

PAGE

Section I. Laboratory Rules . . . . . . 3

Section 2. General Directions . . . . . . . 4

Section 3. Preparation and Cleaning of Glassware . 8

Section 4. Methods of Sterilization . . . . . Io

Section 5. Preparation of Culture Media . . . 18

Section 6. Preparation of Staining Solutions . . 43

Section 7. The Microscope . . . . . . . 45

Section 8. Scheme for Routine Study of Bacteria . 50

Section 9. Method of Describing Cultures . . . 53

Section ro. Directions for Filling out Culture Charts $5^{8}$

\section{Part II. General Bacteriology}

Section I. Preparation of Culture Media . . . 69

Section 2. Collecting and Cultivating Micro-organisms from the Air . . . . . . . 70

Section 3. Study of Molds, Yeasts, and Torulae : $\quad 78$

Section 4. Bacteriological Examination of Water, Air, and Milk . . . . . . . . 84

Section 5. Exercises on Infection and Sterilization . $9 \mathrm{I}$

Section 6. Influence of Disinfectants, Light, and Heat on the Growth of Micro-organisms 94

Section 7. Study of Chromogenic Bacteria . . . 97

Section 8. Study of Micrococci . . . . . . 100

Section 9. Study of Intestinal Bacteria . . . . IOI

Part III. Important Pathogenic Bacteria

Section I. Preparation of Culture Media . . . I05

Section 2. The Pyogenic Group . . . . . . 105

Section 3. The Group of Colon-Typhoid Bacilli II

Section 4. The Proteus Group . . . . I2I

Section 5. The Capsulated Group . . . . . I23

Section 6. The Diphtheria Group . . . . . . 124 
Section 7. The Hemorrhagic Septicemia Group . . 127

Section 8. The Anthrax Group . . . . . . I27

Section 9. The Spirillum Group . . . . . . I29

Section Io. The Group of Acid-proof Bacilli . . . I3I

Section II A and B. Miscellaneous Organisms . I32, I33

Section I2. Pathogenic Trichomycetes . . . . I34

Section I3. The Group of Anaërobic Bacilli . . . I34

Section I4. Isolation of Unknown Bacteria from a Mixture : . . . . . . . . . I39

Part IV. The Bacteriological Examination of Water AND SEWAGE

Section r. Preparation of Culture Media and of Dilution Flasks . . . . . . . . I44

Section 2. Bacteriological Examination of Water . I45

Section 3. Examination of Sewage . . . . . I48

Section 4. Determination of Anaërobes in Sewage . I49

Section 5. A Study of B. coli and Streptococci . . I49

Section 6. Isolation of B. typhosus from Water . I5O

Section 7. Study of Reaction of Bacteria on Neutralred Broth . . . . . . . . . I50

Part V. The Bacteriological Examination of MilK

Section I. Preparation of Culture Media and of Dilution Flasks . . . . . . . . I54

Section 2. Quantitative Bacteriological Examination of Milk . . . . . . . . . I54

Section 3. Examination of Market Milk for Tubercle Bacilli . . . . . . . . . I55

Section 4. A Study of the Acid Fermentation of Milk I55

Section 5. Determination of B. coli and Streptococci in Milk . . . . . . . . . . I57

Section 6. Study of the Effects of Pasteurization and So-called Sterilization of Milk . . $15^{8}$

Section 7. A Qualitative and Quantitative Study of Anaërobes in Milk . . . . . 158

Section 8. A Study of Some Organisms Causing Abnormal Fermentations in Milk . . . 159 
Section 9. Examination of Milk for Molds and Yeasts . . . . . . . . 160

Section ro. Examination for Leukocytes in Milk . 160

Section II. A Study of Groups of Bacteria in Milk . I62 Part VI. The Bacteriological Examination of SoIL

Section r. Quantitative Determination of Bacteria and Spores in Soil . . . . . . . 165

Section 2. A Study of the Peptonization of Proteins by Soil Bacteria . . . . . . . I68

Section 3. The Formation of Amido Compounds and Ammonia . . . . . . . . I70

Section 4. The Formation of Nitrites from Ammonia and Isolation of Nitrite Bacteria . . . I7I

Section 5. The Formation of Nitrates from Nitrites and Isolation of Nitrate Bacteria . . . I74

Section 6. The Assimilation of Free Atmospheric Nitrogen and Isolation of the Bacteria . I75

Section 7. The Reduction of Nitrates to Nitrites and Isolation of the Bacteria . . . . . I77

Section 8. The Reduction of Nitrates to Free Nitrogen . . . . . . . . . . . I77

Section 9. Growing Legumes in Sand and in Sand Inoculated with Legume Bacteria . . I78

Part VII. Molds, Yeasts, Torulae, and Acetic-Acm BACTERIA

Section I. Preparation of Culture Media . . . I8I

Section 2. A Study of Molds . . . . . . . 182

Section 3. A Study of Yeasts . . . . . . . 185

Section 4. Examination of Baker's Yeast . . . Igo

Section 5. Examination of Yeast of Salt-rising Bread IgI

Section 6. A Study of Torulae . . . . . . Igz

Section 7. A Study of Acetic-Acid Bacteria . . . I92

\section{APPENDIX}

Dilution Tables . . . . . . . . . . . I97

Table of Weights and Measures . . . . . . . I98

Table of Centigrade and Fahrenheit Thermometers . Ig8 INDEX . . . . . . . . . . . . . . 203 

PART I

BACTERIOLOGICAL TECHNIC 



\section{SECTION I}

\section{LABORATORY RULES}

I. Familiarize yourself with the laboratory rules. Upon their careful observance depend good work and your own safety.

2. Food must not be eaten in the laboratory; pencils, labels, or fingers must not be moistened with the tongue.

3. If any portion of a culture is spilt by accident upon the desk or floor, it should be covered immediately with a germicide $\left(\mathrm{HgCl}_{2} \mathrm{I}: 1000\right.$, or carbolic acid in 5 per cent solution). After this germicide has acted for ro or I 5 minutes, wipe it up and throw the cloth or paper into a waste jar.

4. In case the hands should come in contact with infectious material, they should be washed with one of the above mentioned germicides, and then scrubbed with soap and water.

5. The platinum needles used in making cultures should be sterilized in a flame before and after use, and before they are laid down. When the needles are covered with viscous material, as milk, for instance, they should be held at the side of the flame until dry before being sterilized. This will avoid the danger of scattering infectious material about the desk.

6. All possible care should be observed in handling apparatus, etc. Solid material should not be put into sinks. Burned matches, paper, cotton, broken glass, 
etc., should be put into crocks and not on the floor or into the sink.

7. Discarded cultures should be killed in the autoclave $\left(5\right.$ minutes at $120^{\circ} \mathrm{C}$.) before being emptied into the crocks.

8. See that the air inlets of Bunsen burners are open before lighting, and relight if the flame strikes back.

9. Always return stockbottles to the proper places on the shelves.

Io. At the close of the day's work the desks should be washed off with corrosive sublimate, and the hands cleaned by thorough washing.

II. Before leaving the laboratory, see that the gas is shut off under all apparatus, that water faucets are closed, and that all glassware, etc., is replaced in the lockers. Culture tubes containing media or cultures should be replaced in their proper places, in order to avoid settling of dust or other foreign material on the stoppers. Dust and air draughts are frequently the cause of contaminations, and in order to avoid these the utmost cleanliness should be observed. A bacteriological laboratory should present an orderly appearance at all times.

\section{SECTION 2 \\ GENERAL DIRECTIONS}

The following directions should be followed in all the work outlined in this guide:

I. After obtaining the key to a locker, the student should examine the outfit, check all apparatus, and see that everything is in good condition. 
2. The student should familiarize himself with the program before him for each day, as this will facilitate intelligent and systematic work.

3. The student should procure description charts and fill them out carefully according to directions.

4. Store cover slips in a stender dish and cover them with alcohol. A soft linen cloth should be used for cleaning.

The following outfit will be needed for each course. Additions to this outfit will be designated as required in the respective courses.

200 culture tubes.

20 potato tubes.

I2 fermentation tubes.

20 petri dishes.

3 Erlenmeyer flasks, one $I, 000$ c.c., two 500 c.c. each.

2 glass funnels, one 4 inches, one 6 inches.

4 bottles for staining tluids.

I balsam bottle.

I stender dish.

3 staining dishes.

I saltcellar.

I glass rod.

2 platinum needles. Turn the end of one of the needles around a sharp pencil point so as to form a closed loop.

8 tin cups or glass tumblers, the bottoms of which should be covered with a layer of cotton.

4 wire baskets.

I Bunsen burner.

I saucepan and cover, or better, a double boiler.

3 graduates, one 500 c.c., one roo c.c., and one ro c.c.

I pinchcock.

I pipette and hose attached.

I magnifier (hand lens).

I tripod. 


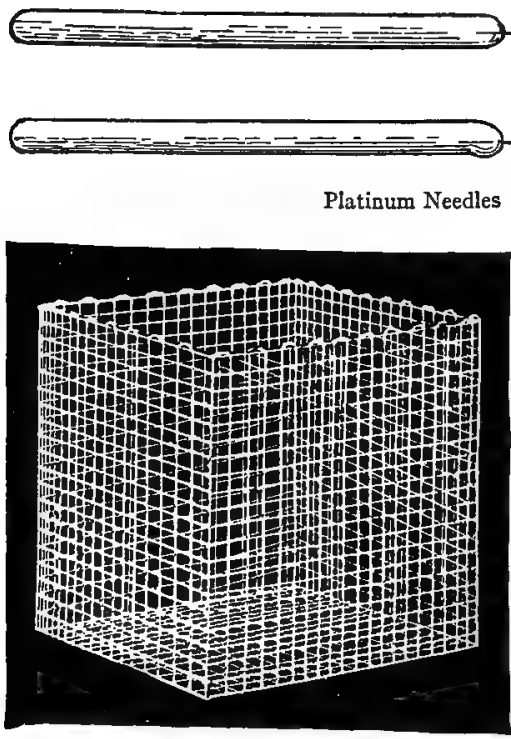

Wire Basket

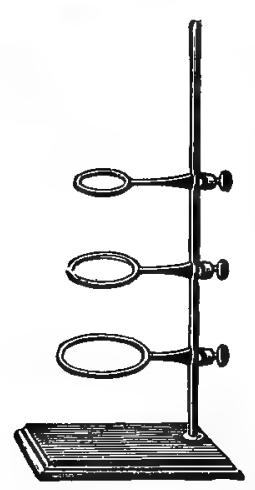

Retort Stand

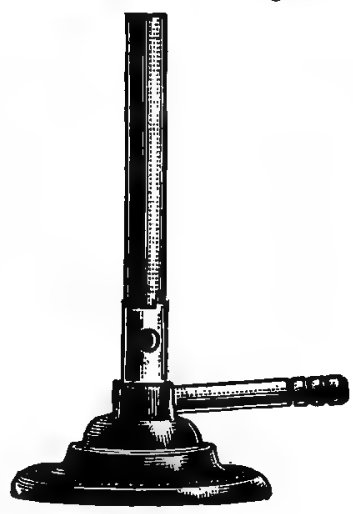

Bunsen Burner Fic. ,

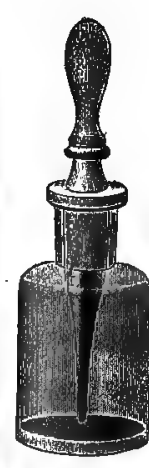

Bottle for Staining Fluid

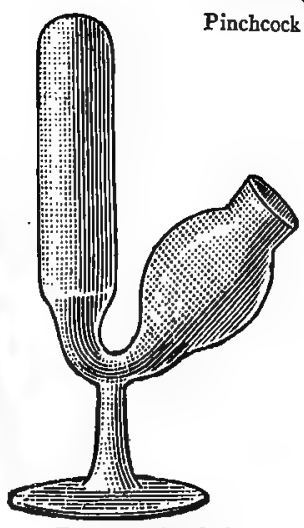

Fermentation Tube

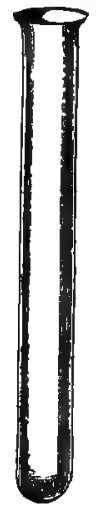

Culture Tube

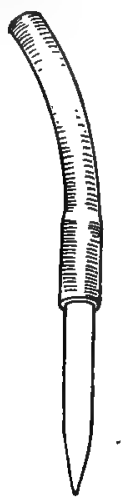

Pipette 


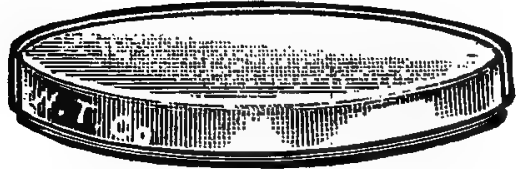

Petri Dish

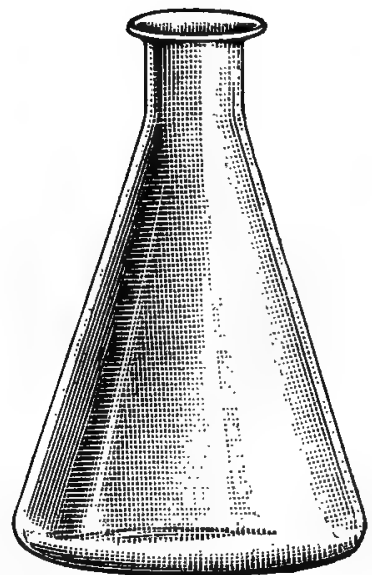

Erlenmeyer Flask

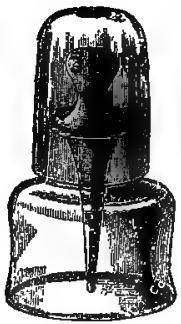

Balsam Bottle

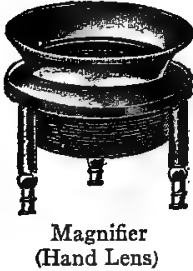

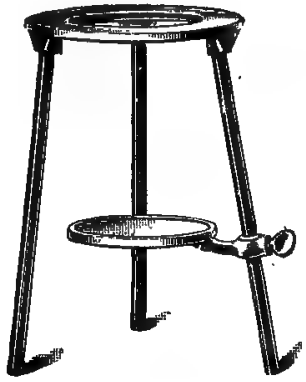

Tripod

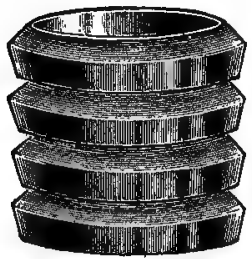

Staining Dishes

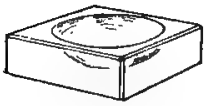

Saltcellar

FIG. I 
I retort stand with three rings.

I thermometer in case.

I box matches.

40 grams pepton.

I 20 grams gelatin.

$5^{\circ}$ grams agar.

6 sheets filter paper.

5o glass slides.

I camel's-hair brush.

50 cover glasses.

2 towels.

I tube brush.

5o labels.

I box for slides.

3 hollow-ground slides.

I glass pencil.

I pair forceps.

2 pairs cover-slip forceps.

\section{SECTION 3}

PREPARATION AND CLEANING OF GLASSWARE

Culture tubes, flasks, fermentation tubes, and petri dishes must be free from organic matter, acids, and alkalis. They should be cleaned as follows:

I. Immerse them in a vessel containing soapsuds or soap powder, boil Io to I 5 minutes, then clean them with a tube brush. Or immerse them for an hour in a solution of potassium bichromate and sulphuric acid:

Potassium bichromate............. 60 parts

Water....................... 300 parts

Concentrated sulphuric acid......... 460 parts

The sulphuric acid should be added slowly with constant stirring.

2. Rinse in tap water. 
3. Again use tube brush, and soap and water if necessary.

4. Rinse again in water to remove every trace of acid or soap.

5. Place the tubes in a wire basket, mouth down, and heat in a hot-air sterilizer for 20 minutes or longer until dry.

All other glassware should be treated in the same manner, excepting fermentation tubes, which should not be heated in the hot-air oven, as this would be likely to cause breakage.

The tubes should be plugged with cotton. Nonabsorbent cotton is suitable for this purpose. The cotton plug allows free communication with the air, admitting oxygen, which is necessary for the growth of many bacteria; at the same time the admitted air is filtered germ-free and contamination of cultures is avoided.

Various metho'ds for plugging tubes are employed in different laboratories. The simplest method is as follows: Take a small amount of cotton and push it gently into the tube with a glass rod. The cotton should reach into the tube for about $\frac{3}{4}$ of an inch and be sufficiently firm to support the weight of the tube (Fig. 2). The cotton may also be rolled into a cylinder of thickness equal to that of the tube and then pushed into the mouth.

The plugged culture tubes should be placed in a hot-air oven

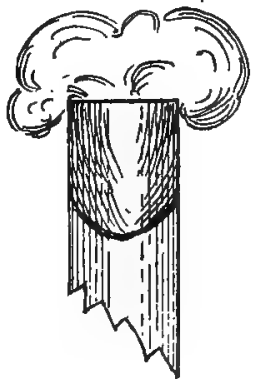

FIG. 2

Plugged Culture Tube 
at a temperature of $150^{\circ} \mathrm{C}$. for about 30 minutes, or until the plugs are slightly browned. The tubes are not necessarily sterile, but the plugs have become set so as to fit the mouth of the tube, and may be removed and replaced readily.

\section{SECTION 4 \\ METHODS OF STERILIZATION}

Sterilization is the process of removing all living organisms. This may be accomplished by heat, by

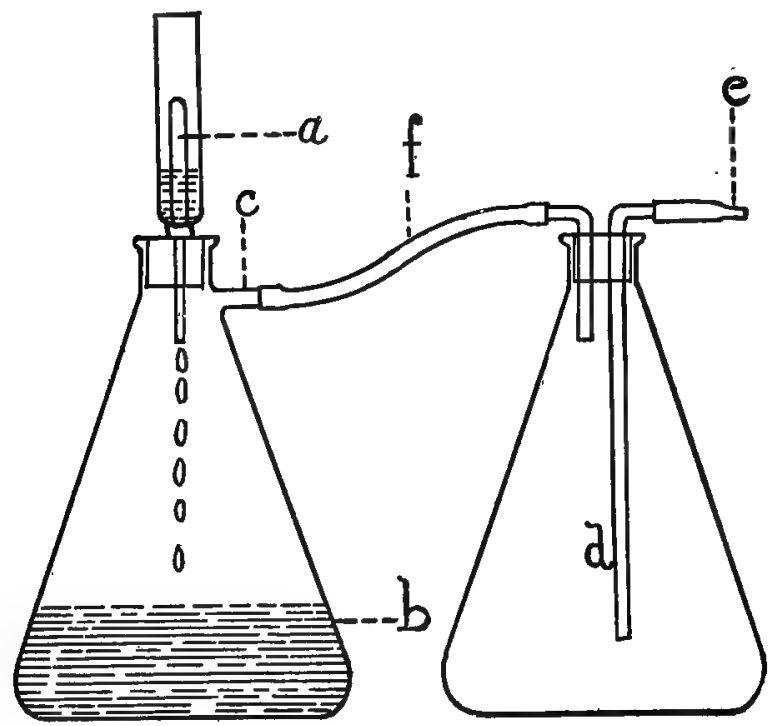

FIG. 3

Berkefeld Filter
a. Berkefeld filter
d. Intercepting flask
b. Filtered liquid
e. Connection with aspirator
c. Side tube with cotton filter
f. Rubber hose 
certain chemicals, or by filtration. Chemicals are used chiefly for sterilizing the skin, surgical instruments, and cultures which have been accidentally spilt. Filters for sterilization are made of some porous material, either infusorial earth or unglazed porcelain. Substances which may be injured by heat are sterilized in this manner. Positive or negative pressure is necessary for this kind of sterilization (Fig. 3).

Sterilization by dry heat. - Sterilization by dry heat is applicable to the sterilization of most glassware. This method of sterilization is carried out by means of hot-air sterilizers (Figs. 4 and 5). These hot-air sterilizers are

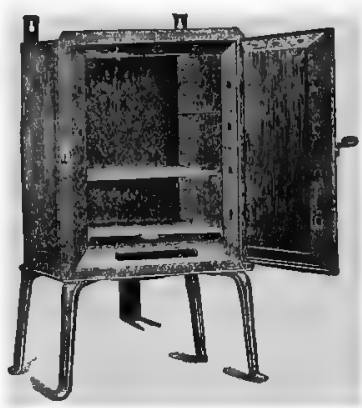

FIG. 4

Koch's Hot-Air Sterilizer boxes with double walls of sheet iron. The bottom shelf should always be covered with a piece of asbestos, to prevent heating the apparatus too rapidly. The temperature is maintained at $160^{\circ}$ or more for one hour. The flame enters a hole provided at the bottom of the box. Care should be taken to avoid the possibility of the flame becoming luminous, otherwise the g]assware will be covered with soot.

Culture media and all substances liable to be injured by heat of $160^{\circ} \mathrm{C}$. or over must be sterilized by the application of moist heat. Experience has taught that hot steam has greater germicidal powers than air of the same temperature. Hot steam, therefore, is the most common means of sterilizing culture media. 
Steam is applied in two ways. The first method is that of exposing media to steam of $100^{\circ} \mathrm{C}$. for $20 \mathrm{~min}$ utes. This is done in an apparatus generally known as the Arnold steam sterilizer. The usual form is illustrated in Figs. 6 and 7. Fig. 6 shows the appearance

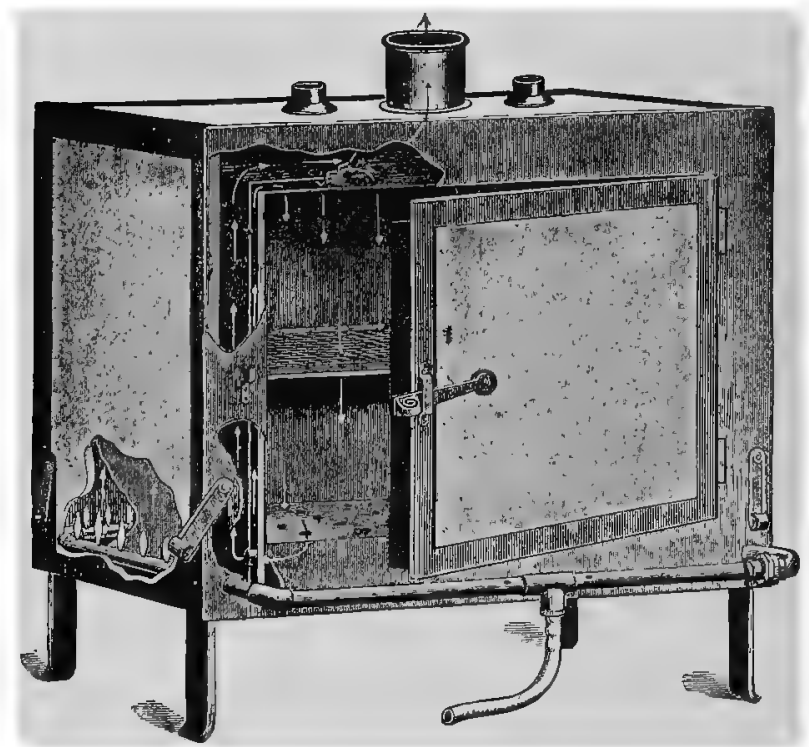

Fig. 5

Lautenschlager Hot-Air Sterilizer

of the ordinary form with the hood off. Fig. 7 shows the inside arrangement. The two compartments, $a$ and $b$, are connected by small holes, and a certain amount of water has to be kept here. The water is brought to a boil and the steam rises through a number of holes in the bottom $(c)$ into the chamber $(d)$. The steam condenses at the top and returns between two 
sheet-copper walls $(e, e)$ to the large compartment (b). Larger forms on the same principle are in use (Fig. 8).

The media to be sterilized are placed in the large chamber ( $d$, Fig. 7). The water is then heated until steam is generated, and the action of the steam on the media is continued for 20 minutes from the time steam

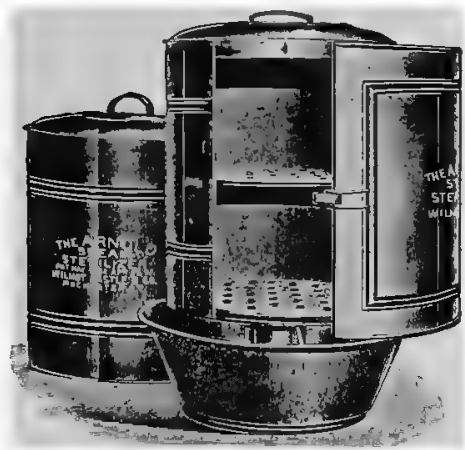

FIG. 6

Arnold Steam Sterilizer

The hood is taken off and the door opened, showing inside arrangement

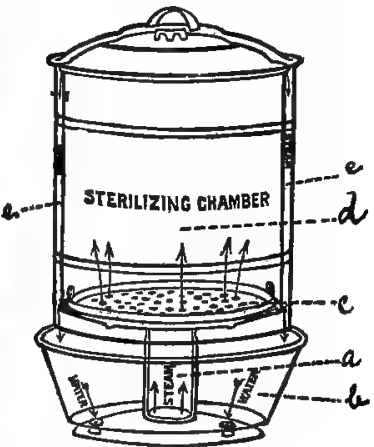

FIG. 7

Arnold Steam Sterilizer

a. Inner water compartment

b. Outer water compartment

c. Perforated bottom

d. Sterilizing chamber

e. Sheet-copper walls

begins to rise. This process is repeated on two succeeding days, so that the media have been exposed to the steam for three days. On the first day all vegetative forms are killed. The media are then kept at room or incubator temperature, so that spores which may be present and are not killed by the first exposure may develop into vegetative forms and be killed by the second exposure. If after this any spores should 


\section{4}

survive, they will develop in the next 24 hours, and the third exposure to steam will complete sterilization.

Sterilization is accomplished in a shorter time by the use of steam under pressure. The autoclave is the usual apparatus used for this purpose. Certain bacteria, some of which are widely distributed in nature,

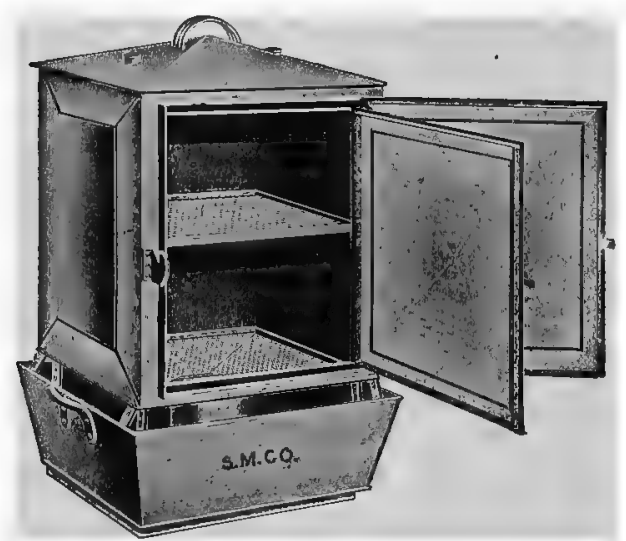

FIc. 8

Arnold Sterilizer

have the faculty of forming spores. These spores are highly resistant to heat and do not lose their vitality either by boiling or by application of steam under ordinary atmospheric pressure. By adding the pressure of one atmosphere to ordinary pressure, the boiling point is raised to $\mathrm{I} 2 \mathrm{I} .4^{\circ} \mathrm{C}$. $120^{\circ} \mathrm{C}$. is sufficient to kill all spores during an exposure of 5 minutes, if the media are in tubes. Larger amounts of media require a proportionately longer exposure.

The autoclave consists of a strong cylinder made of 
iron. Some forms have a cover, others a door on one side. A basket, or a set of shelves, is on the inside. A gauge indicates the pressure and temperature. A safety valve opens automatically when the desired pressure is reached. Two forms are illustrated in Figs. 9 and io.

Before using the autoclave the inside should be examined. It must be clean and contain a suffcient quantity of clean water. Water containing impurities is liable to foam up when boiling, wet the plugs, and ruin the media. If the lid is on top, it should be fastened carefully by tightening the thumbscrews. In order to distribute the pressure of the lid uniformly the diametrically opposite screws should be tightened simultaneously. The valve should be open and left open until the steam has escaped for about one minute. Then the valve

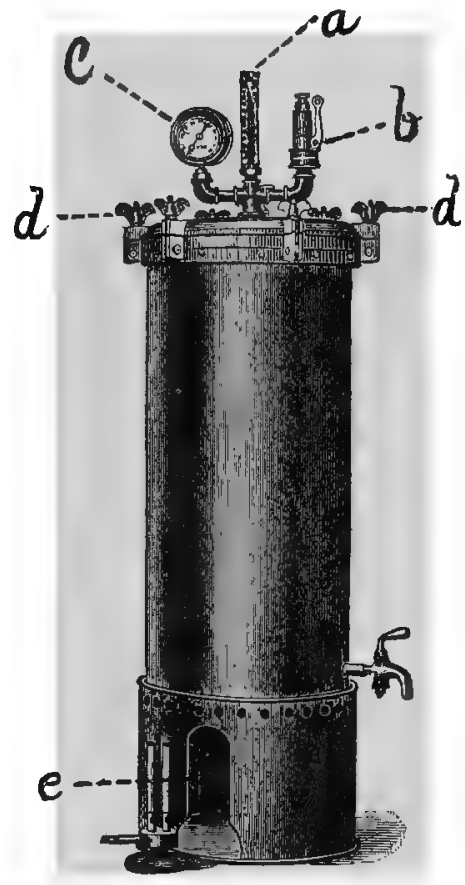

Fig. 9

Autoclave
a. Steam valve
b. Safety valve
c. Gauge is closed and when the desired pressure has been reached, the gas should be turned down so as to maintain pressure for the requisite length of time. 
At the end of this period the gas is shut off and the pressure allowed to decrease gradually. The valve should not be opened, nor the lid removed, until atmospheric pressure has been restored, otherwise the sudden release of pressure would cause the media to boil suddenly and push

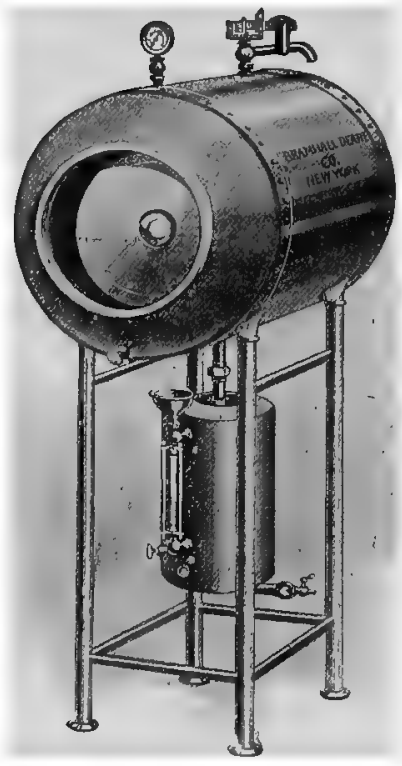

Fig. 10

Autoclave the plugs out of place.

When large autoclaves are used (Fig. Io) provision must be made for proper circulation of air, or "air cushions" form and media will not be sterilized. If an aperture remains in the outlet the discharge of air is facilitated. Attachment of a vacuum pump is often desirable to remove all air.

Blood serum or egg media are the most difficult to sterilize. The temperature of coagulation of these media is relatively low, and sudden heating causes the mass to break up, form bubbles, and become useless for cultural purposes. The Koch inspissator may be used, or, with certain precautions, the autoclave. The Koch inspissator (Fig. II) allows the tubes to rest in an inclined position and to be heated gradually to $75^{\circ} \mathrm{C}$. This temperature is maintained 
for one hour. This process has to be repeated for five or six successive days, before sterilization is complete. If the autoclave is to be used, the tubes are placed in the autoclave in an inclined position. Good results are obtained by this method:

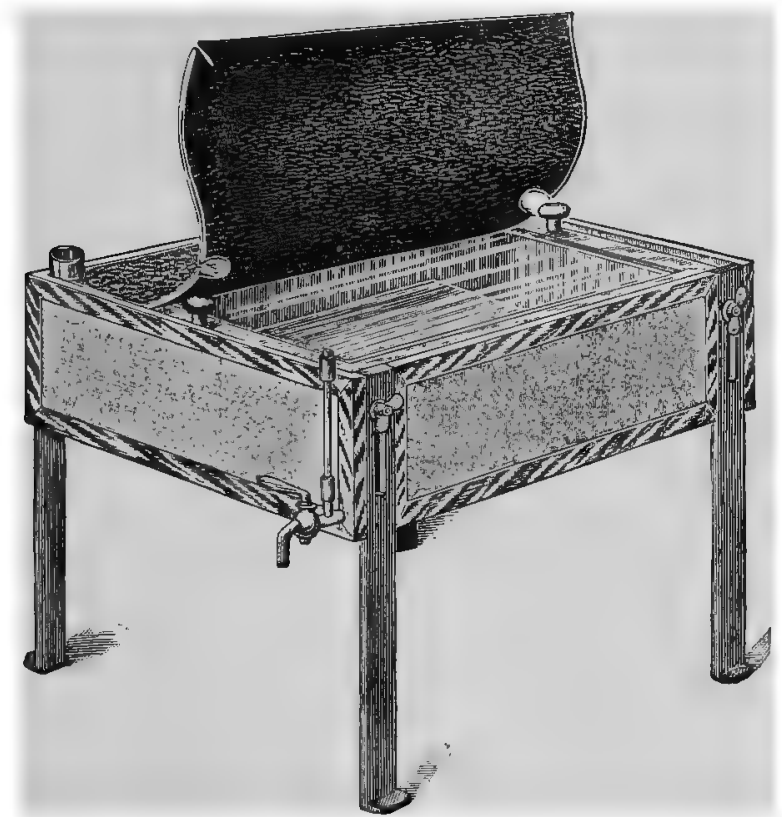

FIG. II

Koch Inspissator

r. Close the lid and the steam outlet.

2. Admit steam. After reaching 3 pounds pressure, keep this pressure for 5 minutes.

3. Increase the pressure slowly to 5 pounds and keep there for 5 minutes. 
4. Increase to Io pounds and hold for 5 minutes.

5. Increase to I 5 pounds and hold for 5 minutes.

6. Open the steam outlet and keep at I $_{5}$ pounds pressure for 20 minutes.

It is advisable to sterilize the tubes again on the following day by slowly bringing the pressure to 15 pounds with the steam outlet slightly open and keeping at this pressure for 20 minutes.

\section{SECTION 5}

\section{PREPARATION OF CULTURE MEDIA}

EXERCISE I. PREPARATION OF DUNHAM'S PEPTON SOLUTION AND OF PEPTON BROTYH (BOUILLON)

r. Weigh the saucepan, measure into it r,ooo c.c. of tap water, and heat over a flame or a water bath.

2. Dissolve in this, when hot, but not boiling, ro grams Witte's pepton.

3. When dissolved, replace the evaporated amount of water and divide into two equal parts of 500 c.c. each.

4. One-half is then filtered until perfectly clear, tubed, and sterilized in the autoclave for 5 minutes at $120^{\circ} \mathrm{C}$. 'This is Dunham's Pepton Solution.

5. Dissolve 1.5 grams extract of beef in the remaining $500 \mathrm{c.c}$.

6. Adjust the reaction with phenolphthaleïn paper or by titration against $\mathrm{n}$. NaOH.

Note.-The reaction of culture media is a matter of vital importance. Bacteria, especially pathogenic bacteria, grow preferably in a medium which is neutral or slightly acid to phenolphthalein. The neutral point of litmus is about 2 per 
cent more alkaline than the neutral point of phenolphthalein, so that a medium which is neutral to phenolphthalein is about 2 per cent alkaline to litmus. It has been found that about I per cent acid to phenolphthalein is the most favorable reaction for the growth of pathogenic bacteria. A medium of this reaction is still alkaline to litmus.

7. -After neutralization fill into an Erlenmeyer flask and autoclave for ro minutes at $120^{\circ} \mathrm{C}$.

8. Keep the sterilized broth for 24 hours and then filter until clear and distribute into culture tubes, .which have to be autoclaved again.

Note. - The reason for exposing broth to a heat of $120^{\circ} \mathrm{C}$. twice is this: The solution contains substances which are precipitated by heat and appear as a sediment after cooling. As it is important to have a perfectly clear broth in tubes, these substances are precipitated by the first heating, and, if tubed later, the second sterilization will not affect the appearance of the medium.

For ordinary purposes it is sufficient to neutralize media by means of phenolphthalein paper. This is prepared by soaking filter paper in a I per cent solution of phenolphthaleîn in 50 per cent alcohol and then allowing the paper to become dry. A 2 per cent or 4 per cent solution of sodium hydrate is added to the medium to be neutralized until a faint, but decided, pink appears on phenolphthaleĩn paper.

A more precise method is as follows: Measure by means of a pipette 5 c.c. of the medium into a white porcelain evaporating dish, add 45 c.c. of distilled water and I c.c. of a I per cent solution of phenolphathalein in 50 per cent alcohol. Heat the mixture to boiling and slowly add from a graduated burette I-2oth normal $\mathrm{NaOH}$ until a faint but decided and stable pink appears in the liquid. The amount of $\mathrm{NaOH}$ is read from the burette and the amount for neutralization of the whole volume calculated. It is desirable to make another titration after the $\mathrm{NaOH}$ has been added. The amount to be added to the medium has to be varied according to the reaction desired. If it is to be neutral, 
the above proceeding will accomplish the object. If it is desired to have a medium which has a reaction of I per cent acid, a proportionate amount should be deducted from the total amount of $\mathrm{NaOH}$ calculated.

Example.-By reading the burette we find that it takes 3 c.c. I-2oth normal $\mathrm{NaOH}$ to neutralize 5 c.c. of the medium. This means that 60 c.c. I-2oth $\mathrm{n}$. $\mathrm{NaOH}$ will neutralize roo c.c. medium, or 600 c.c. I-20th n.NaOH will neutralize 1,000 c.c. medium. To find the requisite amount of n.NaOH divide the above figure by 20 . Then 3 c.c. n.NaOH will neutralize 100 c.c. and 30 c.c. n. $\mathrm{NaOH}$ will neutralize $\mathrm{I}, 000$ c.c. If the reaction is to be I per cent acid, deduct Io c.c. from $30=20$ c.c. If 20 c.c. normal $\mathrm{NaOH}$ are added to each liter the reaction should be I per cent acid. This should be ascertained by a second titration.

A normal solution is the equivalent weight in grams (GramMolecule) dissolved in distilled water and made up to I,000 c.c. In the case of monovalent chemicals the molecular weight is taken, if bivalent the molecular weight is divided by two, etc.

All media should be prepared with the utmost care and should be perfectly clear.

EXERCISE 2. PREPARATION OF NUTRIENT AGAR-AGAR

Agar-agar (or called simply "agar") is a watery extract of certain seaweeds found on the Pacific coast of Asia. A solution of agar containing about I. 5 per cent forms a firm jelly, which melts near the boiling point of water, and on cooling solidifies at about $39^{\circ}$. Gelatin solidifies at much lower temperature, and cannot be kept solid at body temperature. The use of agar is, therefore, of great importance in the study of pathogenic bacteria, a large number of which prefer body temperature for growth.

I. Weigh a saucepan, or, if available, a double boiler. Note the weight.

2. Measure I,000 c.c. of tap water into the sauce- 
pan. It is advisable to add about 200 c.c. of water to this to allow for evaporation.

3. Cut and shred I5 grams of agar, add this to the water, bring to the boiling point, and keep at this temperature until the agar is completely dissolved. Violent boiling should be avoided and the mixture should be stirred, so as to prevent overheating.

NotE. - The agar may be soaked in cold water over night. This removes some of the impurities and renders the agar more readily soluble.

4. Add 3 grams extract of beef and ro grams Witte's pepton.

5. Adjust the reaction.

6 . Adjust the weight. Place $I, 000$ grams weight and the weight of the saucepan on one side of the scales and then add enough water to make the saucepan with the agar balance. If the weight is too high, it should be boiled gently until the weight has been brought down to the proper amount.

7. Make a paper filter as described below and arrange a retort stand as illustrated in Fig. I2.

8. When at the boiling point filter the agar and distribute into culture tubes.

9. The tubed agar should be sterilized in the autoclave for 5 minutes.

For agar slants each tube should contain about 7 c.c. or be filled one-third of the length of the tube. For plating, the tube should be half filled and contain ro c.c. Slants are prepared by allowing the agar after sterilization to cool in a slanting position. If it is desired to slant a large number a whole basket may be put in a slanting position. When a few tubes only 
are required they may rest with the plugged end on a glass rod or rubber hose until the agar has solidified.

For the purpose of filtering media heavy filter paper (Schleicher and Schüll No. 598) of the best quality only should be used. This is especially important when filtering agar or gelatin. After the filter

FIG. 12

Apparatus for Filtering Media

a. Filter

b. Large funnel

c. Small funnel

d. Rubber hose

e. Pinchcock

f. Pipette

g. Culture tube

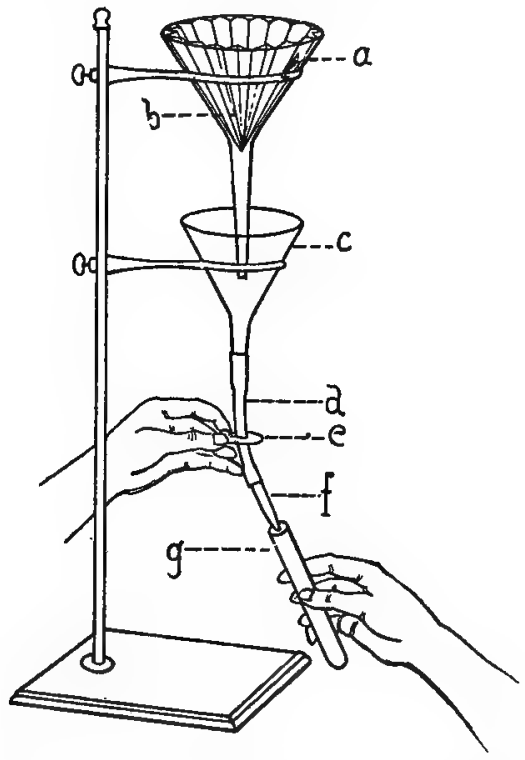

has been folded and inserted into the funnel hot water should be run through the filter, until it is soaked and warm.

Method of folding filters (Fig. I3).-- $a$ and $b$ ) Take a square piece of filter paper twice as wide as the depth of the funnel and fold to half the size so as to make No. I cover No. 2. (Compare with Fig. I3.) 
c) Fold this to make I cover 2 and 3 cover 4 (result Fig. I $3 c$ ). It consists of four layers and forms a square.

d) Fold the upper part, consisting of two layers, from I to 2 (Fig. $\mathrm{r}_{3} d$ ). The shaded triangle, $2-3-4$, now has six layers; the other, $\mathrm{I}-3-4$, two layers.
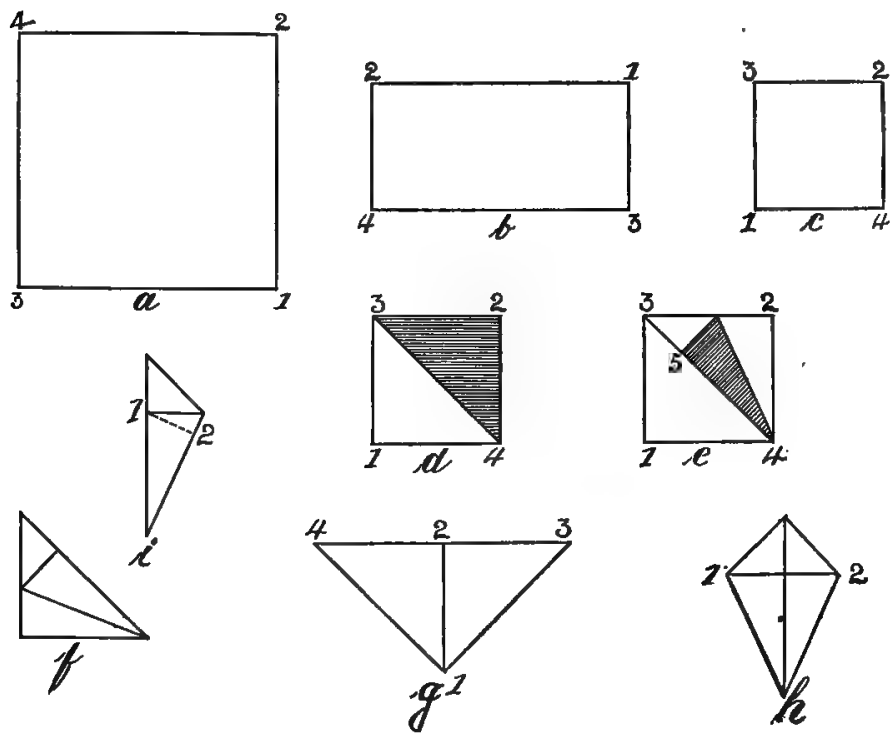

FIG. 13

Method of Folding Paper Filter

(For reference letters see text)

e) Fold the upper double layer so as to make 2 cover a point in the diagonal at 5 , taking care to make a sharp point at 4 (result Fig. I $3 e$ ). The shaded part is now eight layers deep.

f) Turn the folded part face down and repeat 
operations exactly on the other side as in $d$ and $e$ (result Fig. I $3 f$ ).

g) Take up and open the large middle fold (result Fig. I3g). The two halves must now be symmetrical.

h) Fold so as to make the lines $I-3$ and $I-4$. meet at the center line $\mathrm{r}-2$ (result Fig. $\mathrm{r}_{3} h$ ).

i) Now pick up and fold backward so as to have I cover 2 in the back (Fig. I3i).

j) Cut through the line $I-2$ and open up. The extreme ends will be found without a fold and may be folded so as to make 9 sharp edges.

This filter is inserted evenly into the funnel, spreading the folds at a distance from each other as nearly alike as possible. Care should be taken to make the folds and the point sharp, as this insures rapid filtration and prevents the filter from tearing.

If a vacuum pump is available, the medium may be filtered rapidly by the use of suitable apparatus, as illustrated in Fig. I4. At the connection with the vacuum pump a valve should be inserted or a flask arranged as in the illustration, to prevent the water from entering the flask if the water pressure should be reduced suddenly.

If some precautions are properly observed, chiefly the making of a good filter with sharp edges and a sharp point, and the soaking of this in hot water, there is no difficulty in filtering agar or gelatin successfully in a short time. There is some danger of the point of the filter breaking when the hot medium is poured on. This may be avoided by folding ${ }^{\circ}$ a second filter of about two inches diameter and fitting this small filter on the bottom and outside of the larger one. 
The basket which is to receive the tubes after filling should be placed in an inclined position, as this facilitates the proper arrangement of the tubes. In filling the tubes the pipette at the end of the rubber hose

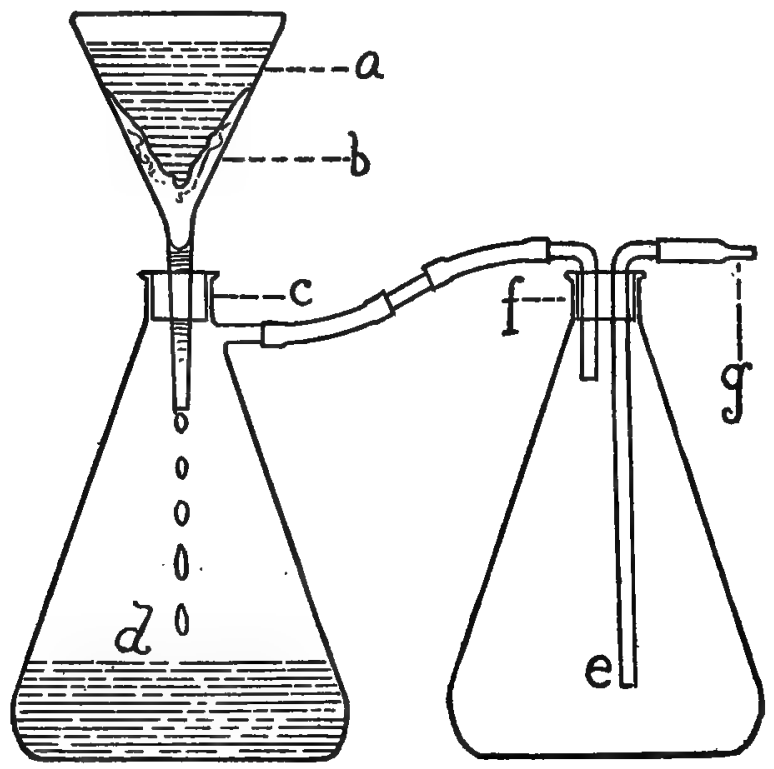

Fig. I4

Filtering Media by Means of Vacuum Pump
a. Liquid medium
b. Absorbent cotton
c. Rubber stopper
d. Filtered medium

e. Reflux flask

f. Rubber stopper with two holes

g. Connection with aspirator

should be inserted to a depth of at least two inches and when the proper amount has been discharged should be removed carefully so as to avoid wetting the mouth of the tube. A wet tube-mouth will cause 
the cotton plug to stick to the glass, and later not only occasion much annoyance to the person using the tube but expose the medium in it to danger of contamination.

EXERCISE 3. PREPARATION OF DEXTROSE AGAR

Dextrose is added to agar for the demonstration of gas-forming organisms. Dextrose is decomposed by these bacteria with gas formation, the gas appearing as bubbles in the medium.

Dextrose agar is prepared by adding a definite amount of dextrose, usually I per cent, to filtered agar.

Nore.-Dextrose agar cannot be distinguished from plain agar by appearance. It is therefore necessary either to label the tubes or to separate dextrose agar tubes from plain agar tubes in a basket by tying a piece of string or inserting a piece of paper between.

\section{EXERCISE 4. PREPARATION OF PEPTON GELATIN}

I. Weigh the saucepan and measure I,000 c.c. of tap water into it. To this 200 to 300 c.c. of water should be added to allow for evaporation.

2. Dissolve 3 grams extract of meat and Io grams pepton.

3. When boiling dissolve ro per cent gelatin in cold weather and I 2 per cent in hot weather. The gelatin must be of the best quality (gold label) and should be dissolved slowly, taking a few leaves at a time, and with constant stirring.

4. When completely dissolved, adjust the reaction as directed in the preparation of agar. Gelatin contains an appreciable amount of acid and it will require more $\mathrm{NaOH}$ solution for neutralization than agar. 
5. Cool to about $60^{\circ} \mathrm{C}$. Dissolve the whites of two or three eggs, or about Io grams of pure powdered egg albumin in about Ioo c.c. of tap water. Mix this solution with the gelatin and heat slowly to the boiling point, placing a piece of asbestos under the pan unless a double boiler is used. Boil gently until the egg white or egg albumin has coagulated and a solid film has formed which mechanically incloses the impurities.

6. Adjust the weight to $I, 000$ grams, allowing for the weight of the pan. Filter and tube, as in the preparation of agar.

7. Sterilize in the autoclave for $5^{-8}$ minutes at $120^{\circ} \mathrm{C}$., or in the arnold for three successive days.

If sterilized in the autoclave, care should be taken not to allow the temperature to go beyond $120^{\circ} \mathrm{C}$., and gelatin should not be permitted to remain at this temperature beyond the prescribed time. Gelatin is readily decomposed by heat and then does not solidify after cooling.

EXERCISE 5. PREPARATION OF LITMUS MILK

Milk is one of the most important culture media. Only the cleanest milk obtainable should be used. "Certified milk" is most suitable. In many cases commercial milk powder may be used. If certified skimmed milk or fat-free milk is available step I is omitted.

I. Separate five-sixths of the cream from the milk.

2. Add a sufficient quantity of tincture of litmus to impart a decided blue color to the milk. If a solution of Merck's pure extract of litmus I:I00 is at hand about 5 per cent of this will be sufficient.

3. Distribute in culture tubes and sterilize in the 
autoclave for 5 minutes at $120^{\circ} \mathrm{C}$. After sterilization the blue is usually more or less lost, but returns upon standing.

\section{EXERCISE 6. PREPARATION OF POTATO}

r. Select several large potatoes, and cleanse by brushing the dirt off, cutting out the eyes and other blemishes, and washing in water.

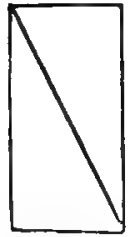

FIG. 15

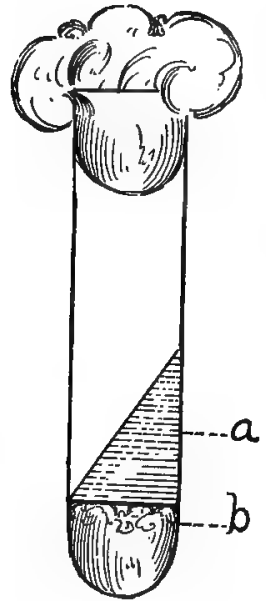

FrG. I6

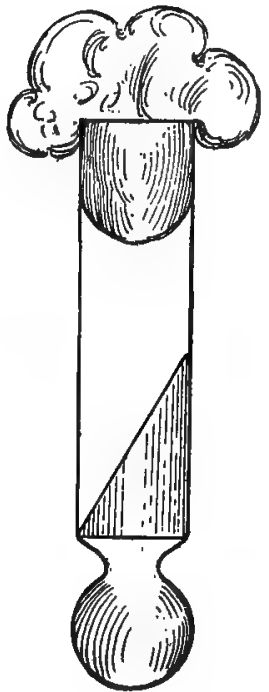

FIG. I7

Potato Cylinder Ordinary Style of Potato Tube Potato Tube (showing diagonal for cutting)

2. Punch out cylinders with a borer of suitable size, trim them, and cut each cylinder into two equal parts on a diagonal line (Fig. I5). 
3. Immerse the pieces in running water for 24 hours.

4. Trim the pieces of potato so they slide down the tube and insert one half-cylinder into each potato tube. The wide end rests on the constriction of the tube. Pour a small amount of water into it, and fill about one-half of the part of the tube below the constriction. Large culture tubes without constrictions may be used. A small amount of cotton should be pushed to the bottom of these and the cotton soaked with water. The potato then rests on the cotton (Figs. I6, I 7 ).

5. Sterilize in the autoclave for 8 to ro minutes at $120^{\circ} \mathrm{C}$, , or in the arnold for three consecutive days.

Nore.-Potatoes usually harbor a spore-bearing bacillus, the spores of which are highly resistant. Therefore a longer exposure in the autoclave is necessary to insure sterilization.

SUBSTITUTE FOR POTATO

I. Dissolve I5 grams agar in 600 c.c. water and filter.

2. Dissolve the following salts in 200 c.c. water:

Asparagin................. 5 grams

$\mathrm{K}_{2} \mathrm{HPO}_{4} \ldots \ldots \ldots \ldots \ldots \ldots \ldots \ldots \ldots \ldots \ldots \ldots \ldots \ldots$

$\mathrm{Na}_{2} \mathrm{HPO}_{4} \ldots \ldots \ldots \ldots \ldots \ldots \ldots \ldots \ldots \ldots \ldots \ldots$

$\mathrm{MgSO}_{4} \ldots \ldots \ldots \ldots \ldots \ldots \ldots \ldots \ldots \ldots \ldots \ldots \ldots \ldots$

$\mathrm{CaCl}_{2} \ldots \ldots \ldots \ldots \ldots \ldots \ldots \ldots \ldots \ldots$ grams

Ammonium lactate.............. 2 grams

3. Add the solution of salts to the hot agar.

4. Dissolve ro grams pepton.

5. Adjust the reaction to the neutral point with phenolphthaleîn.

6. Suspend 30 grams washed starch in water.

7. Add the starch suspension slowly with constant stirring to the previous mixture. 
The weight of the mixture should be I,000 grams. Tube hot, without filtration, through a pipette with a wide aperture. Autoclave for five minutes at $120^{\circ} \mathrm{C}$., and allow to cool in a slanting position.

EXERCISE 7. STANDARD METHOD OF PREPARING BROTH, NUTRIENT GELATIN, AND NUTRIENT AGAR

STANDARD METHODS FOR TBE EXAMINATION OF WATER AND SEWAGE. AMERICAN PUBLIC̨ HEALTH ASSOCIATION, 75.5 BOYLSTON STREET, BOSTON, MASS.

\begin{tabular}{|c|c|c|}
\hline Broth & Gelatin & Agar \\
\hline I. & & $\begin{array}{l}\text { Boil Io or I5 g. thread agar } \\
\text { in } 500 \text { c.c. water for balf an } \\
\text { hour and make up weight } \\
\text { to } 500 \mathrm{~g} \text {., or digest for Io } \\
\text { minutes in the autoclave. } \\
\text { Let this cool to about } 60^{\circ} \text {. }\end{array}$ \\
\hline $\begin{array}{l}\text { z. Infuse } 500 \mathrm{~g} \text {. lean meat } 24 \\
\text { hours with I,000 c.c. of dis- } \\
\text { tilled water in refrigerator. }\end{array}$ & Ditto. & $\begin{array}{l}\text { Infuse } 500 \mathrm{~g} \text {. lean meat } \\
24 \text { hours with } 500 \text { c.c. of } \\
\text { distilled water in refriger- } \\
\text { ator. }\end{array}$ \\
\hline $\begin{array}{l}\text { 3. Make up any loss by evap- } \\
\text { oration. }\end{array}$ & Ditto. & Ditto. \\
\hline $\begin{array}{l}\text { 4. Strain infusion through } \\
\text { cotton flannel. }\end{array}$ & Ditto. & Ditto. \\
\hline 5. Weigh filtered infusion. & Ditto. & Ditto. \\
\hline 6. Add I \% Witte's pepton. & $\begin{array}{l}\text { Ditto. } \\
\text { And ro \% gold } \\
\text { label sheet gel- } \\
\text { atin. }\end{array}$ & Add $2 \%$ Witte's pepton. \\
\hline $\begin{array}{l}\text { 7. Warm on water bath, stir- } \\
\text { ring till pepton is dis- } \\
\text { solved, and not allowing } \\
\text { the temperature to rise } \\
\text { above } 60^{\circ} \text {. }\end{array}$ & $\begin{array}{l}\text { Warm on water } \\
\text { bath until pep- } \\
\text { ton and gela- } \\
\text { tin are dis- } \\
\text { solved, not } \\
\text { above } 60^{\circ} \text {. }\end{array}$ & $\begin{array}{l}\text { Warm on water bath until } \\
\text { pepton is dissolved, not } \\
\text { above } 60^{\circ} \text {. }\end{array}$ \\
\hline 8. & & $\begin{array}{l}\text { To } 500 \text { g. of meat infusion } \\
\text { add } 500 \text { c.c. of the } 3 \% \\
\text { agar, keeping the tem- } \\
\text { perature below } 60^{\circ} \text {. }\end{array}$ \\
\hline
\end{tabular}

9. Titrate after boiling one minute to expel carbon dioxid.

ro. Adjust reaction to $\mathrm{I} \%$ acid by adding normal bydrochloric acid or sodium bydrate as required.

II. Heat over boiling water (or steam) bath for 40 minutes.

I2. Restore loss by evaporation. 
EXERCISE 8. PREPARATION OF BROTH FROM FRESH MEAT

The following method has some advantages over the previous method and is specially adapted to the preparation of diphtheria toxin:

I. Clean one pound beef or veal of adhering fat, etc., and grind in a meat chopper.

2. Cover with one liter of water and digest over night at room temperature.

3. Heat to $60^{\circ} \mathrm{C}$. and digest at this temperature for two hours.

4. Boil for 30 minutes.

5. Press the liquid from the meat in a meat press (Fig. I8). Mix the meat with some more water, press out again, and bring the volume of the two combined liquids to I liter.

6. Dissolve in this 20 grams pepton and 5 grams sodium chlorid.

7. Adjust the reaction to I. 2 per cent acid with phenolphthalein as indicator.

8. Filter until perfectly clear and sterilize in the autoclave.

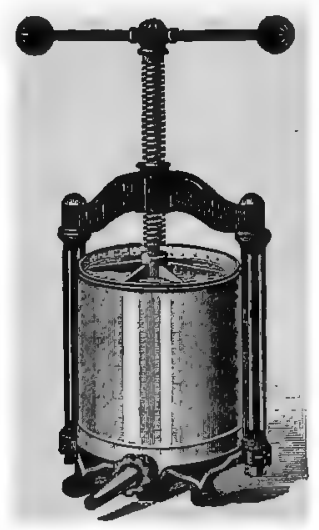

FIG. 78

Meat Press

EXERCISE 9. PREPARATION OF BLOOD SERUM

I. Fresh ox blood, horse blood, or dog's blood, collected in sterile containers, is set aside in an ice chest until the serum has separated. 
2. Three parts of serum are mixed with I part broth containing $\mathrm{I} .5$ per cent dextrose.

3. The mixture is filtered and tubed.

4. Place in a Koch inspissator (Fig. II).

5. Incline the inspissator to the proper angle, so as to produce a large sloping surface of the serum.

6. Heat slowly to the boiling point and boil for 5 minutes. This process is to be repeated on three or four successive days.

Note. -25 c.c. water should be placed in the inspissator with the tubes, so as to keep the air in the inspissator saturated. Blood serum may be sterilized in a shorter time by the use of the autoclave (see p. I6).

EXERCISE IO. PREPARATION OF BEERWORT MEDIA

Hopped beerwort may be obtained from a brewery. Beerwort media are used chiefly for the cultivation of yeasts and molds, these preferring media of the acidity of beerwort. Beerwort should be autoclaved, cooled, and filtered before tubing, otherwise a precipitate will form in the tubes.

Liquid beerwort.-Place about 7 c.c. of beerwort in culture tubes and sterilize at $120^{\circ} \mathrm{C}$. for five minutes.

Beerwort gelatin.-Dissolve Io to I 2 per cent gold label gelatin in beerwort and sterilize at $120^{\circ} \mathrm{C}$. in the autoclave.

Beerwort agar.-Dissolve I . 5 per cent agar in beerwort and sterilize at $120^{\circ} \mathrm{C}$. in the autoclave.

EXERCISE II. PREPARATION OF YEAST-WATER MEDIA

Yeast water.-One liter of washed yeast or one pound of pressed yeast is boiled in two liters of water for one hour. The reaction is made neutral to phenol- 
phthalein, the solution is then filtered and sterilized in the arnold for three successive days.

Dextrose yeast water.-Dissolve Io to I 5 per cent dextrose in yeast water without adjusting the reaction.

EXERCISE 12. PREPARATION OF MEDIA FOR THE DIFFERENTIATION OF B. coli AND B. typhosus

\section{MacConkey's bile-salt agar-}

Nutrient agar. . ........... Ioo c.c.

Sodium taurocholate.......... 0.5 per cent

Pepton................. 2 per cent

Boil and filter, add 2 per cent lactose, tube and sterilize in the arnold.

MacConkey's bile-salt broth-

Sodium taurocholate.......... 0.5 per cent

Pepton.................. 2 per cent

Dextrose................. 0.5 per cent

Dissolve in beef broth by boiling, filter, and add litmus solution. Sterilize in the arnold.

Aesculin bile-salt agar-

Agar.

Commercial bile-salt. ...........

Pepton (Witte) . . . . . . . . . .

Distilled water
I5 grams

2.5 grams

Io grams

I,000 c.c.

Boil until dissolved and neutralize with n. $\mathrm{NaOH}$. Cool to $60^{\circ} \mathrm{C}$., add the whites of two eggs or a solution of egg albumin, bring to boiling point, and filter when the albumin has coagulated. Neutralize again, if necessary, and add to the hot filtrate I gram aesculin and I gram iron citrate in scales. The final reaction should be 0.6 per cent acid. 
Drigalski and Conradi's medium (modified by Harris)-

Dextrose-free broth. . . . . . . . 2,000 c.c.

Nutrose................ 20 grams

Agar.................. 40 grams

Boil, dissolve, neutralize to phenolphthaleïn, autoclave at $120^{\circ} \mathrm{C}$. for 5 minutes. Clarify with whites of four eggs (or powdered egg albumin), and filter. Then add after dissolving separately in water:

Lactose.................. 30 grams

Litmus solution (see p. 35\% .......... 260 c.c.

Crystal violet ( 0.1 per cent solution) 20 c.c.

Tube and sterilize in the arnold.

\section{Parietti's solution-}

Carbolic acid.................. 5 c.c.

Hydrochloric acid.............. 4 c.c.

Water....................... I00 c.c.

Phenol media.-One part carbolic acid (phenol) is added to I,O00 parts medium.

Hiss's plating medium for colon-typhoid differentiation-

Agar................... I5 grams

Gelatin. . . . . . . . . . . . . 5 grams

Extract of meat.............. 5 grams

$\mathrm{NaCl} \ldots \ldots \ldots \ldots \ldots \ldots \ldots \ldots \ldots, 5$ grams

Dextrose................... Io grams

Distilled water.............. r,000 c.c.

Hiss's tube medium-

Agar................. 5 grams

Gelatin................ 80 grams

Extract of meat........... 5 grams

$\mathrm{NaCl} \ldots \ldots \ldots \ldots \ldots \ldots \ldots \ldots \ldots . \ldots \ldots \ldots \ldots$

Dextrose.................. Io grams

Distilled water............. r,000 c.c. 


\section{Hesse's medium-}

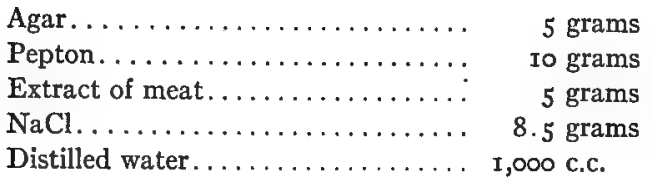

Capaldi's medium-

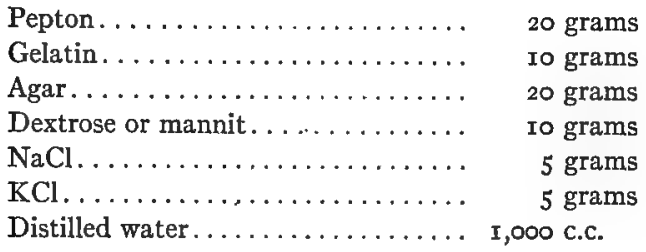

Malachite green media.-Two to 3 c.c. of a 2 per cent solution of "Höchst 120 " malachite green solution is added to broth (alkaline to litmus).

Ox-bile medium.-This culture medium is used for the detection of B. coli in water. Dissolve I per cent lactose and I per cent pepton in fresh ox bile, filter and fill in fermentation tubes and sterilize in the arnold for three successive days.

EXERCISE I3. PREPARATION OF MEDIA FOR WATER AND MILK EXAMINATION

Litmus solution.-Dissolve I part Merck's pure extract of litmus in Ioo parts of water, filter, and sterilize in the autoclave for 5 minutes at $\mathrm{I} 20^{\circ} \mathrm{C}$.

Litmus lactose agar and litmus dextrose agar.Dissolve I per cent lactose or dextrose in sugar-free agar. The litmus should be added in the petri dish before use from a sterile tube of litmus solution by means of a sterile I c.c. pipette. 
Litmus lactose gelatin and litmus dextrose gelatin.-Dissolve I per cent lactose or dextrose in sugarfree gelatin, containing 13 per cent gelatin. The tubes should contain 8 c.c. of the medium. After adding I c.c. litmus solution and I c.c. of the material to be plated the medium will contain ro per cent gelatin and remain solid.

Mannit agar.-Dissolve I per cent mannit in sugarfree agar.

EXERCISE I4. PREPARATION OF WHEY MEDIA

Litmus whey (Petruschky, modified by Durham).Caseïn is precipitated from milk with rennet extract. The whey is neutralized with 4 per cent citric acid solution and heated on the water bath for half an hour. It is then filtered, and litmus solution added until a decided blue color is obtained. Sterilize in the autoclave.

Whey gelatin.-Add ro per cent gelatin to clarified whey.

Whey agar.-Add a few drops acetic acid to boiling milk until the casein is precipitated. Neutralize, or bring to a reaction of I per cent acid if desired, and dissolve I per cent pepton, 2 per cent dextrose, and I. 5 per cent agar. Filter, tube, and sterilize in the autoclave.

EXERCISE I5. PREPARATION OF GLYCERIN MEDIA

Glycerin broth.-Add 6 per cent pure glycerin to ordinary broth.

Glycerin agar.-Add 6 per cent pure glycerin to nutrient agar. 
Glycerin egg medium.-Add 6 per cent glycerin to the egg mixture before heating.

Glycerinated potato.-Prepare potatoes in the usual manner and soak for 24 hours in a 25 per cent glycerin solution in distilled water.

Substitute for glycerinated potato.-Mix 6 per cent glycerin with the substitute for potato described on $\mathrm{p}$. 29.

EXERCISE I6. PREPARATION OF EGG MEDIA

Dorset's egg medium.-Eggs are broken into a flask and the yolks broken with a platinum needle or glass rod. The flask is gently shaken until the yolks and whites are thoroughly mixed. Foam formation should be avoided. Distribute in culture tubes and sterilize in a Koch inspissator or autoclave in the same manner as blood serum.

Dorset's egg-yolk medium.-Add 5 to to c.c. of sterile distilled water to the yolks of three or four eggs, and treat the same as in the above egg medium.

Capaldi's egg medium.-A few loopfuls of egg yolk are added to a tube of liquefied agar, previously cooled to 45 to $47^{\circ} \mathrm{C}$.

EXERCISE 17. MEDIA FOR THE STUDY OF SOIL BACTERIA

\section{Winogradsky's solution-}

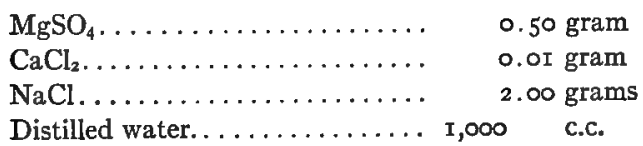


Solution for nitrite formation-

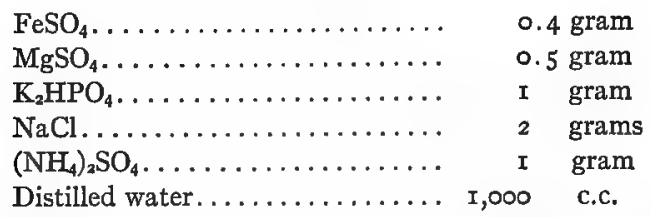

Dissolve 20 grams agar in the above solution. After solution add Io grams precipitated $\mathrm{CaCO}_{3}$. Shake and tube. Sterilize in the autoclave.

Preparation of silica jelly.-Mix roo c.c. $\mathrm{HCl}$, specific gravity I. 10 Beaumé's scale at $60^{\circ} \mathrm{F}$., with Io० c.c. sodium silicate, specific gravity I . $\circ 9$ Beaumé's scale at $60^{\circ} \mathrm{F}$. Place in collodion sacs and dialyze in running water for I2 hours. Prepare the following solution:

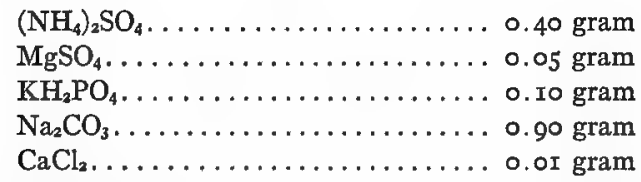

Dissolve these salts in the smallest amount of distilled water possible. Heat both the salt solution and the silica jelly to boiling, cool rapidly without stirring. Mix and pour on petri dishes or tubes and sterilize in the autoclave at $110^{\circ} \mathrm{C}$. The tubes should be placed in a slanting position.

Synthetic agar for plating-

Dextrose............... Io grams

$\mathrm{MgSO}_{4} \ldots \ldots \ldots \ldots \ldots \ldots \ldots \ldots \ldots \ldots$

$\mathrm{K}_{2} \mathrm{HPO}_{4} \ldots \ldots \ldots \ldots \ldots \ldots \ldots \ldots$ 0.5 gram

Pepton............... 0.05 gram

Agar.................. 2o grams

Distilled water............. I,000 c.c.

Dissolve, filter, tube, and sterilize in the autoclave. 
Solution for testing the formation of nitrates-

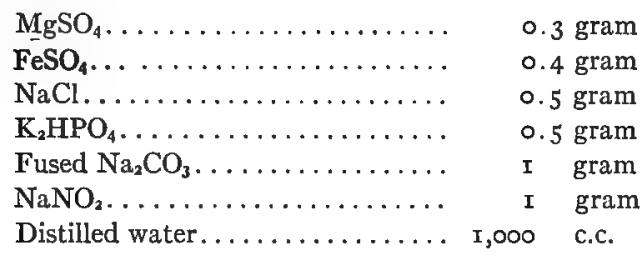

Dissolve 20 grams agar in the above solution. Sterilize in the autoclave. The salt solution may also be added to the silica jelly. For plating fill in culture tubes.

Solution for testing the assimilation of atmospheric nitrogen-

I. Solution

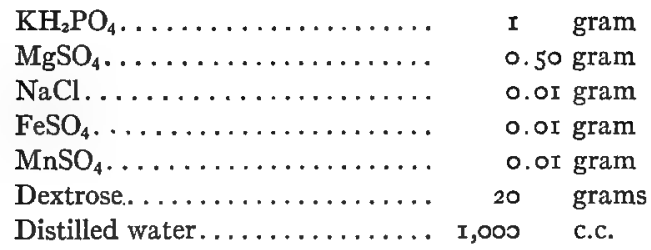

Dissolve 20 grams agar in this solution if intended for plating and tubing. Sterilize in the autoclave.

2. Mannit Solution

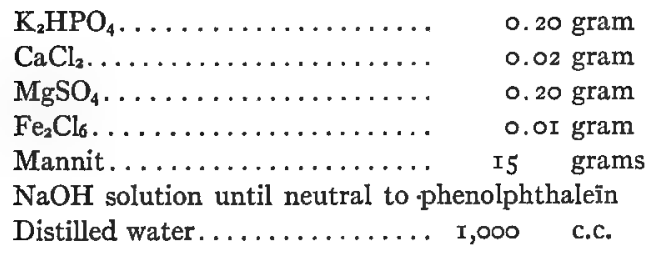

Dissolve 20 grams agar in this solution if intended for plating and tubing. Sterilize in the autoclave. 
Solution for testing the denitrification of nitrates to free nitrogen (Giltay solution) -

Solution I

Dextrose................... Io grams

Distilled water.............. 250 c.c.

Solution 2

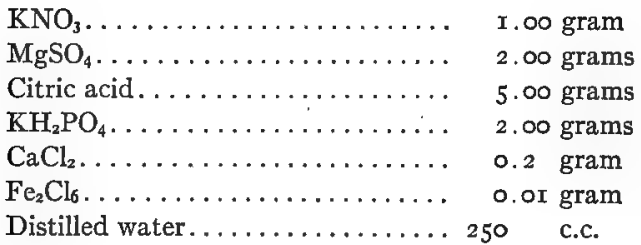

Make solution I neutral to phenolphthaleïn with Io per cent $\mathrm{NaOH}$ or $\mathrm{KOH}$ solution. Mix solutions I and 2 and make up to $I, 000$ c.c. Dissolve 20 grams agar in the solution, tube, and sterilize in the autoclave.

Synthetic agar for quantitative examination of soil--

Dextrose.............. Io grams

$\mathrm{MgSO}_{4} \ldots \ldots \ldots \ldots \ldots \ldots \ldots \ldots \ldots \ldots \ldots \ldots$

$\mathrm{K}_{2} \mathrm{HPO}_{4} \ldots \ldots \ldots \ldots \ldots \ldots \ldots \ldots$ 0.5. gram

Pepton............... 0.05 gram

Agar................. 20 grams

Distilled water............ I,000 c.c.

Pepton solution for ammonification-

Distilled water.............. I,000 c.c.

Pepton................ Io grams

Dissolve and sterilize in the autoclave.

EXERCISE I8. PREPARATION OF MISCELLANEOUS MEDIA

Blood agar.-Fresh blood obtained under aseptic precautions is smeared over the surface of agar, or 
blood may be mixed with agar, previously liquefied and cooled to $50^{\circ}$, in various proportions. The agar should contain 2 to 3 per cent agar according to the amount of blood to be added.

Bread-paste medium.-Bread is cut into slices, dried in an oven, pulverized, and distributed in roo c.c. flasks until the layer on the bottom of the flask is about half an inch thick. Water is added gradually until the surface of the bread is moist. Sterilize in the arnold.

Hay infusion.- Io grams of chopped hay are macerated in $I, 000$ c.c. water in the water bath for three hours. Filter and sterilize in the autoclave.

Wine must. -Wine must is diluted with four times its volume of water. Dissolve 0.5 per cent ammonium tartrate, macerate in the water bath for I hour, filter and sterilize in the arnold for three successive days.

Acid broth.-Add 0.5 per cent acetic acid to ordinary broth.

Calcium carbonate broth. - A few lumps of marble added to ordinary broth.

\section{NITRATE MEDIA}

Nitrate broth.-Add 5 parts potassium nitrate to each liter of ordinary broth.

Nitrate solution. -5 c.c. of a 2 per cent aqueous potassium nitrate solution are added to a solution of I gram pepton and I gram dextrose in I,000 c.c. water. 
EXERCISE I9. PREPARATION OF NON-PROTEIN MEDIA (SYNTHETIC MEDIA)

Jordan's non-protein medium-

Redistilled water............. I,000 c.c.

Asparagin................ 2 grams

$\mathrm{MgSO}_{4} \ldots \ldots \ldots \ldots \ldots \ldots \ldots \ldots \ldots \ldots \ldots$

$\mathrm{K}_{2} \mathrm{HPO}_{4} \ldots \ldots \ldots \ldots \ldots \ldots \ldots \ldots$ I gram

Dissolve and sterilize in the autoclave.

Uschinsky's medium (Fränkel's modification)-

Water...................... I,000 c.c.

Asparagin.............. 4 grams

Ammonium lactate. ........... 6 grams

$\mathrm{Na}_{2} \mathrm{HPO}_{4} \ldots \ldots \ldots \ldots \ldots \ldots \ldots . \ldots \ldots$

$\mathrm{NaCl} . \ldots \ldots \ldots \ldots \ldots \ldots \ldots \ldots \ldots \ldots$ grams

Dissolve and sterilize in the autoclave.

Raulin's solution for the cultivation of molds-

Distilled water............ I,500 c.c.

Cane sugar.............. to grams

Tartaric acid............. 4 grams

Ammonium nitrate......... 4 grams

Potassium carbonate........ 0.6 gram

Ammonium phosphate....... 0.6 gram

Magnesium carbonate........ 0.4 gram

Ammonium sulphate........ 0.25 gram

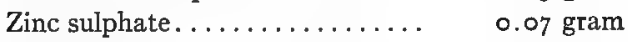

Iron sulphate........... 0.07 gram

Potassium silicate......... 0.07 gram

Note.-Culture media should be stored in a dark, cool place. If they are to be kept for a considerable length of time, the tubes should be sealed with paraffin or with rubber caps. They should be protected from dampness, as mold fungi are apt to alight on the cotton stoppers and send their filaments into the tubes. Before inoculation each tube should be examined, and those which are cloudy or contain colonies of bacteria or molds should 
be rejected. If the medium has shrunk from the effects of evaporation it should be rejected, or the evaporated water may be replaced and the medium sterilized again.

\section{SECTION 6}

\section{PREPARATION OF STAINING SOLUTIONS}

Saturated alcoholic solutions of stains are prepared by covering the anilin dye with absolute or 96 per cent alcohol and allowing it to stand with frequent agitation until no more stain is dissolved. Other solutions for the preparation of stains are:

I. Solution of potassium hydrate in water $\mathrm{I}: \mathrm{ro}, 000$.

2. Solution of carbolic acid in water ( 5 per cent).

3. Anilin water, prepared by shaking 2 c.c. anilin oil with roo c.c. water and filtering through filter paper until clear.

The following four stains are most commonly in use for morphological studies of bacteria:

\section{Löffler's methylene blue-}

Saturated alcoholic solution of methylene blue...... 30 c.c. Potassium hydrate in distilled water $\mathbf{r}: 10,000 \ldots \ldots$. . 70 c.c.

\section{Ziehl-Neelsen's carbol-fuchsin-}

Saturated alcoholic solution of fuchsin............ Io c.c. 5 per cent solution carbolic acid in distilled water...... 9० c.c.

\section{Ehrlich's anilin gentian violet-}

Saturated alcoholic solution of gentian violet....... 25 c.c. Anilin water (2 per cent)................. 75 c.c.

\section{Gram's iodin solution-}

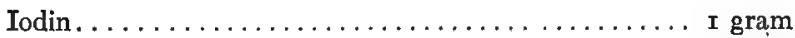

Potassium iodid.................... 2 grams

Dissolve in a few cubic centimeters of distilled 
water. After solution add enough distilled water to bring the volume to 300 c.c.

Other useful stains are the following:

Delafield's hematoxylin-

Hematoxylin crystals.......... 4 grams

Alcohol.................... 25 c.c.

Ammonia alum............. 50 grams

Water.................... 400 c.c.

Glycerin.................. I00 c.c.

Methyl alcohol............... I00 c.c.

Alum hematoxylin-

I. Hematoxylin............ 2 grams Absolute alcohol............. roo c.c.

2. Ammonia alum............ 2 grams Water.................. roo c.c.

Mix I and 2 and add-

Glycerin................. 850 c.c.

Glacial acetic acid............. roo c.c.

Allow to stand for one month before using.

Bismarck brown-

Bismarck brown............ 0.5 gram

Water................. too c.c.

Safranin-

Safranin............... 0.5 gram

Water................... roo c.c.

Carbolic thionin blue (Nicollé) -

Thionin blue............... I gram

Carbolic acid.............. 2.5 grams

Water.................. roo c.c.

Alum carmin-

Alum................. 2.5 grams

Carmin.................. I. 0 gram

Water.................. 100 c.c. 
Kühne's methylene blue-

Methylene blue............. r.5 grams

Absolute alcohol.............. Io c.c.

Carbolic acid solution (5 per cent) .. too c.c.

Carbolic gentian violet (Nicollé)

Gentian violet (sat. alcoh. sol.).... Io c.c.

Carbolic acid................ I gram

Water................... go c.c.

\section{Pappenheim's Stain-}

Sat. aqueous solution of methyl green $3 \sim 4$ parts

Sat. aqueous solution of pyronin..... I-I.5 parts

Mix previous to staining. Apply for 20 seconds. The mixture is dependable for a few weeks only.

\section{SECTION 7}

THE MICROSCOPE

(Fig. I9)

The compound microscope is a necessary adjunct to any kind of bacteriological work. For this work three objectives (Leitz No. 3, No. 6, or No. 7 and $\frac{1}{12}$ oil immersion, Zeiss No. A or No. AA, No. D or No. DD, and $2 \mathrm{~mm}$. oil immersion) and two oculars (Nos. 2 and 4) are indispensable. For the intelligent manipulation of the microscope it is useful to understand the underlying optical principles, which may be studied from special works on the subject.

\section{References-}

S. H. Gage, The Microscope.

Carpenter and Dallinger, The Microscope and Its Revelations.

For use in the laboratory it will be sufficient to call attention to some of the most important points to be observed. 
The usual pattern of microscope consists of two main parts: the stand, and the optical parts (Fig. I9) which are attached to the stand.

The stand consists of a body tube, draw tube, coarse adjustment, fine adjustment (micrometer screw) in a pillar, nose-piece, stage with clips for holding the object, main pillar, and the horseshoe base. At the junction of the main pillar and the fine-adjustment pillar is the inclination joint.

The draw tube, regulating the focal length, which varies in different instruments, should be raised to $\mathrm{I} 6$ or I7 mm. If a nose-piece is attached, the width of this must be deducted from the tube length.

The optical parts are the oculars, the objectives, the substage condenser, and the mirror. The ocular is a combination of lenses, which slips into the top of the draw tube and is nearest the eye. The objective is a combination of lenses which is screwed into the nosepiece and fits to the lower end of the draw tube. The substage condenser fits under the stage: It concentrates the light on the object and is raised for high powers or lowered for low powers. At the lower end of this condenser is the iris diaphragm, which is regulated by a small lever with a milled head, and serves the purpose of regulating the light supply. The mirror has two sides, a concave and a flat one.

In the manipulation of the compound microscope the following points should be observed:

I. Keep the instrument clean. When not in use, lock it in the case or cover it with a bell-jar.

2. When carrying the instrument, grasp it by the main pillar underneath the stage, not by the fine- 


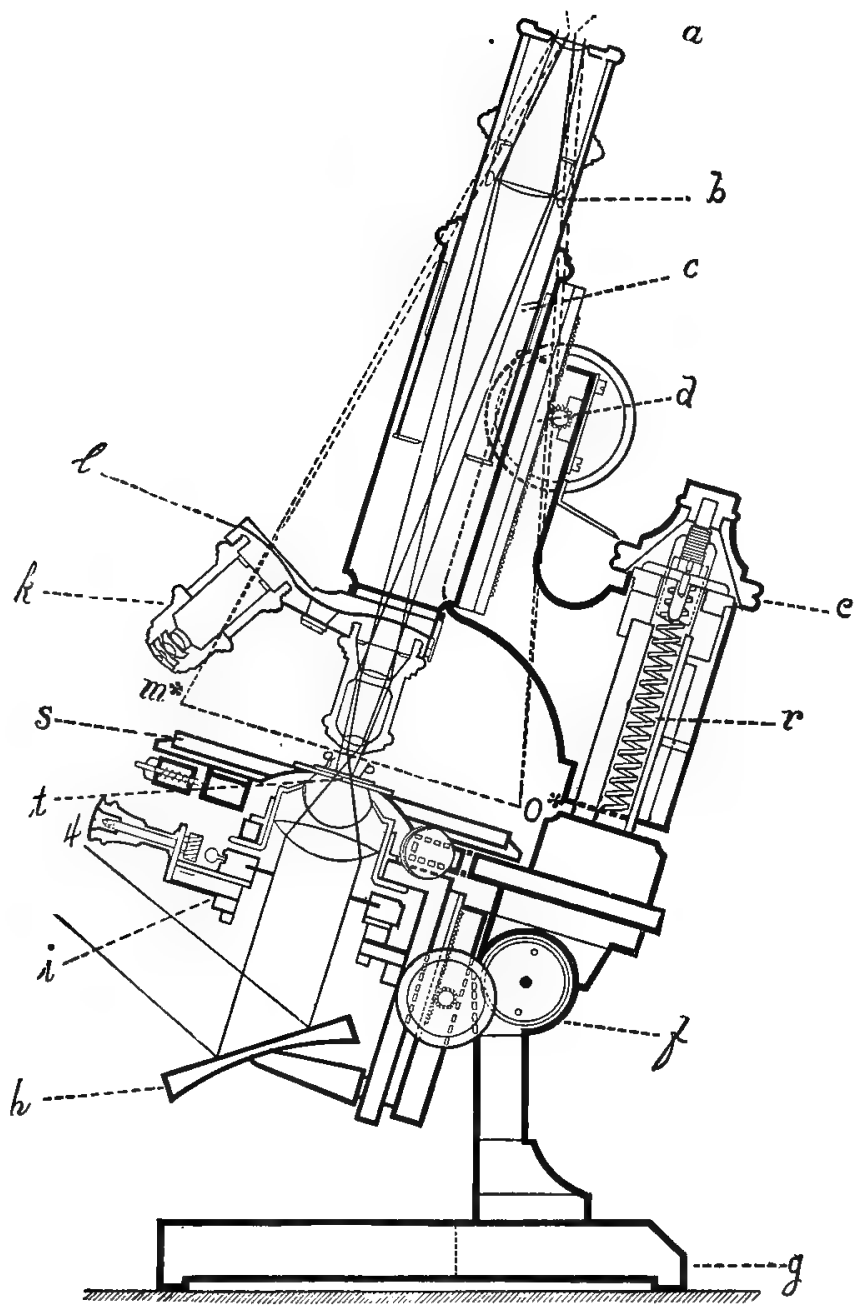

Fig. I9

Microscope (after E. Leitz)

a. Ocular

$b$. Place where virtual picture is formed

c. Body tube

$d$. Coarse adjustment

c. Micrometer screw

$f$. Inclination joint

g. Horseshoe base

h. Mirror

i. Iris diaphragm and condenser

$k$. Objective

i. Nose-piece

$m-0$. Picture as it appears to the eye $p$-q. Object (cover slip)

†. Adjustment spring

s. Stage

t. Object (slide) 
adjustment pillar. The fine adjustment consists of a delicate screw-thread, which is easily damaged.

3. The lenses, condenser, and mirror, when necessary, should be wiped with Japanese lens paper, never with any coarse material.

4. For cleaning use a damp cloth. For wiping the lenses use water or xylol. Never use alcohol, as this dissolves the cement holding the lenses in place and also injures the lacquer.

5. Do not take the instrument apart. The working parts are of delicate nature and easily injured. Be careful not to drop the oculars or objectives.

6. The inclination joint can be used only with dry lenses and dry objects, not with the oil-immersion or hanging-drop preparations.

7. After placing the object on the stage, focus with a low power and the coarse adjustment. With high powers use the coarse adjustment first and the fine adjustment afterward. The free use of the fine adjustment saves the accommodation of the eye. As the eye is capable of accommodating itself to distances, it may, with an effort, distinguish a picture which is not in perfect focus. This effort is saved by using the fine adjustment.

8. Raise the draw tube by means of the coarse adjustment before changing the objectives or examining a different preparation.

9. Before focusing, obtain as good light as possible by turning the mirror, and then regulate the supply by the diaphragm. Always use reflected light, never direct sunlight.

Io. When focusing an object, lower the draw tube until the lens almost touches the cover glass. This 
can be seen by looking at the instrument from one side and watching the reflection of the objective in the cover glass. Then, with the eye at the ocular, slowly focus up. Do not focus down with the eye at the ocular, as the lens may then come into violent contact with the object, destroying the latter and injuring the lens.

Ir. For living or transparent objects use as little light as possible. For stained or opaque objects more light is necessary.

I2. Do not use higher powers than are necessary.

I3. To use the oil-immersion lens, place a drop of clear cedar oil, free from dust and air bubbles, on the cover glass, which must be perfectly dry. In this case, by careful manipulation, the objective, after being brought in touch with the oil by means of the coarse adjustment, may be gradually lowered by the fine adjustment until the object is focused; or better, lower the objective until almost in touch with the cover glass, and focus up. High powers require the use of a homogeneous liquid between the cover glass and the front lens of the objective, to avoid loss of light by refraction. As a bundle of rays disperses when entering a thinner medium from a denser one, there is not sufficient light entering the objective to make objects discernible, when using high powers without oil. By the insertion of a liquid (inspissated oil of cedar) of nearly the same refractive index as glass, a homogeneous connection is established between the cover glass and the objective, thus avoiding loss of light and allowing a bundle of light of sufficient power to enter the objective. $^{\mathbf{x}}$

${ }^{2}$ For detailed description and diagrams see S. H. Gage, The Microscope. 
14. After using the oil-immersion lens, wipe the oil off with lens paper. If the oil sticks to the lens, wipe it off with xylol, never with alcohol. At the same time wipe the oil off the cover slip.

I5. The microscope should stand on a firm table, to avoid being shaken. The table should be low enough so as not to necessitate bending the body.

I6. Always keep both eyes open. This saves the eyesight. Beginners find this a difficult rule to apply, but with very little practice and persistence it is easily accomplished. Also use both eyes alternately.

I7. It is well to move the object while bringing it into focus. It is then easy to feel when the lens touches the glass, and a moving object is seen more readily than a stationary one.

I8. Use the plane mirror in combination with the condenser, and the concave mirror without the condenser or with artificial light.

I9. In preparing stained preparations, it may happen that a small amount of stain remains on the upper side of the cover slip. Care must be taken to focus for a plane below this.

\section{SECTION 8}

SCHEME FOR ROUTINE STUDY OF BACTERIA

This scheme is to be followed strictly in the study of all organisms, except when special instructions are given, and the student should familiarize himself with the different steps.

r. The inoculation of one slant agar tube from each culture supplied. These inoculated agar tubes are to 
be incubated at $37^{\circ}$ for 24 hours, unless otherwise instructed.

2. At the end of $\mathbf{2 4}$ hours make from each agar tube:

a) A physical description of the culture (see Section 9).

b) A hanging-drop examination.

c) A Gram stained preparation.

d) An ordinary stained preparation.

All stained preparations and all Gram stains should be preserved.

3. Transfer from agar culture to the following media:

Dextrose agar.

Gelatin.

Potato.

Broth.

Litmus milk.

Dunham's solution, if a test for indol is to be made.

These transfers, excepting gelatin, are to be placed in the thermostat, unless otherwise ordered.

4. An accurate description and sketches are to be made of each culture (see Section 9). These descriptions should be made complete after 24 hours, and any changes should be noted after 48 hours and after 6 days. (See culture charts.)

5. Plates are to be made in agar from a $24-48$-hourold broth culture of each culture, unless otherwise directed. These plates are to be described once after 24-48 hours. (See Section 9.)

Nore.-The thermostat or incubator (Fig. 20) is a box made of copper and having double walls, between which water 


\section{LABORATORY GUIDE IN BACTERIOLOGY}

circulates. The outer surface is usually covered with asbestos or linoleum, so as to hold the heat. The thermostat is provided with two doors, the inner one of glass so as to enable the observer to look inside without causing a drop in temperature by admitting

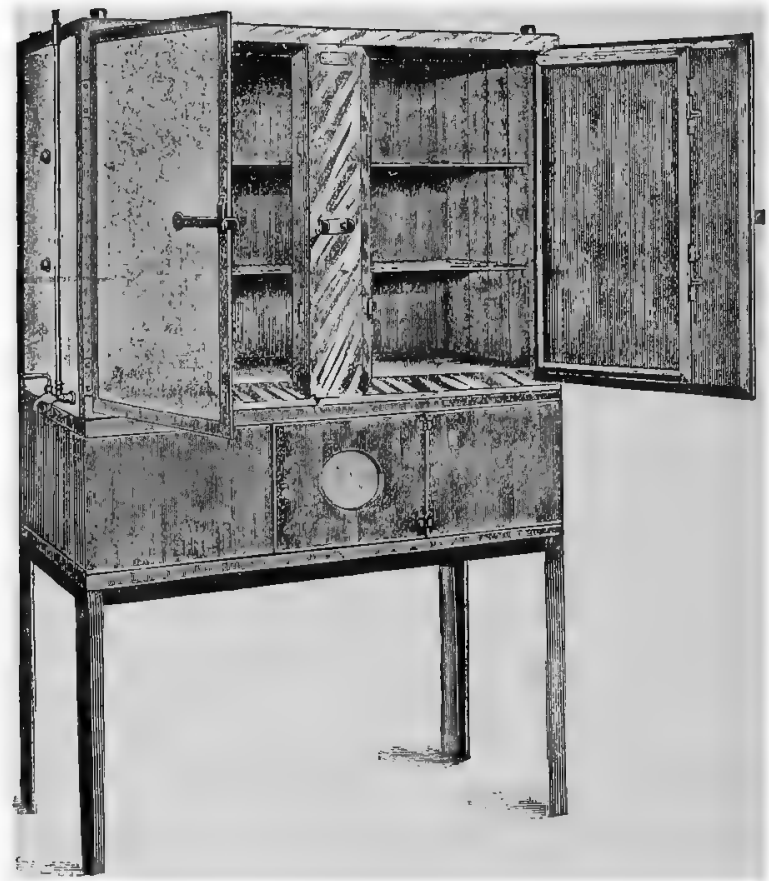

FIG. 20

Thermostat or Incubator

the cooler air. The outer door is covered with asbestos like the walls. A thermometer reaches through the upper part, provided with several air holes which permit free circulation of air. The gas supply is shut off automatically, if it should accidentally become extinguished. The necessary heat may also 
be obtained successfully by electric devices. For class use large incubators are constructed on similar principles, with a number of separate compartments for the accommodation of large numbers of students.

\section{SECTION 9}

METHOD OF DESCRIBING CULTURES

The following method of describing cultures should be carefully studied, and each suggestion should be considered in the description. It is of prime importance that cultures should be closely observed, in all media, and accurately described and sketched, as this is the only method which furnishes the proper means of studying and determining the different species of bacteria. By keeping this scheme in sight while making a description, it will be possible after some practice to make perfect descriptions without its aid. After growth has taken place the culture should be compared with a sterile tube of the same batch of culture medium.

I. Morphological characters of bacterium. Size.

Facility and mode of staining.

Gram stain.

Special staining qualities.

Motility.

Present or absent.

Sluggish or active movement.

Flagella present or absent.

Capsules present or absent.

Spores present or absent.

Involution forms. 
Make a sketch of part of a field under the microscope.

II. Plate cultures.

I. Naked-eye appearance.

a) Surface colonies.

If colonies are too small to make observations with the naked eye, this fact should be stated.

Color by reflected light.

Approximate size.

Elevation or depression.

Translucency.

Moist appearance.

Smoothness.

Luster.

Liquefaction (in gelatin plates only).

Consistency: soft, viscid, hard, chalky.

b) Deep colonies.

Color.

Shape.

2. Microscopic appearance under low power (No. 3 objective, Leitz). Use little light; the diaphragm should be almost closed.

a) Surface colonies.

Shape.

Color.

Translucency.

Thickness (in center and edges).

Nucleation.

Striation.

Granulation (if present, whether coarse or fine) or Homogeneity. 
Edge: entire or smooth, wavy, with pointed protuberances, serrate, dentate, lacerate, fringed, hairlike shoots, curled, tubercle-like appearance (tuberculated).

b) Deep colonies.

Shape: punctiform, lanceolate, oval, circular, spindle-shaped, conglomerate, irregular, branched, filamentous, rosette-shaped.

Color.

Translucency.

Granulation.

III. Agar slant culture.

Limitation: confinement to needle track or spreading. If "spreading, in what shape?

Vigor: luxuriant, fair, or scant.

Color: by reflected light.

Elevation or depression, more pronounced at edges or in center.

Translucency.

Moistness.

Smoothness.

Luster.

Coloration of medium.

Odor.

Gas formation: in culture or in medium.

IV. Stab culture in plain agar.

I. Surface growth (describe like agar slant). 
2. Stab growth.

Vigor.

Extent.

Color.

Granulation.

Outgrowths.

Coloration of medium.

Cloudiness.

Gas formation.

V. Stab culture in dextrose agar.

Describe like plain agar stab and in addition always note presence or absence of gas formation.

VI. Stab culture in gelatin.

Describe like agar stab, and in addition always note presence or absence of liquefaction. If liquefaction is present, it may be saucer-shaped, turnip-shaped, conical, funnel-shaped, horizontal (extending the whole diameter of tube), sack-shaped. Cloudiness and presence of sediment in liquefied area, and color and shape of sediment, should be described.

VII. Potato culture.

Describe like agar slant, adding to it the eventual discoloration of the medium, and presence of gas bubbles.

VIII. Litmus milk culture.

Reaction (acid, alkaline, or neutral, as indicated by color). 
Coagulation: present or absent.

Note, - If acid has formed but no coagulation is evident after six days, heat gently' and see whether coagulation then takes Ilace.

Whey: if present, clear or turbid.

Liquefaction of coagulum (proteolysis).

Gas formation.

Decoloration of litmus.

Color of cream ring.

Odor.

In milk the presence or absence of coagulation and proteolysis should be noted. Compare your culture with a sterile milk tube.

IX. Broth culture.

Cloudiness: degree and uniformity; scum (ring- or island-shaped).

Precipitate, observed by shaking. Amount, color, formation, diffusibility, viscidity, amount of precipitate.

X. Solidified blood serum.

Describe like agar slant, and note presence or absence of liquefaction.

XI. Fermentation tubes.

Gas formation in closed arm, percentage and relation of carbon dioxid to hydrogen expressed in simple figures by the formula $\frac{\mathrm{H}}{\mathrm{CO}_{2}}$.

Growth in both arms or in one arm only, observed by cloudiness.

Reaction: acid or alkaline to litmus. 


\section{SECTION IO}

DIRECTIONS FOR FILLING OUT CULTURE CHARTS (See chart on pp. 59-60.)

\section{First page-}

I. Name the group and organism.

II. Indicate the source and habitat from books and references.

III. Name the most important references, and read them.

IV. Morphological characters.

I. Describe the morphology opposite the medium from which obtained as observed from the stained preparation.

2. Size: approximate estimate in microns. Note whether large or small, thick or slender, round or square ends, etc.

3. Arrangement of bacteria: in groups, chains, bunches, pairs (diplococcus), sarcina form, filaments, branching, etc. Also note different arrangements, if observed, in different media.

4. Staining powers: Mark + for positive, - for negative stains. Special stains must be described more fully.

5. Motility: If absent, mark -; if present, + . In the latter case describe the character of the movement.

6. Spores: Absence noted by -; presence, by + . If present, mention the method of spore stain applied. 


\section{FROST'S CULTURE CHART (MODIFIED)}

Group.

Name of organism.

Source

Habitat.

References

1. Form:

a. On agar

RoD:

Coccus:

b. On other media

Size

3. Cell groupings

4. Staining powers

a. Anilin gentian violet

b. Löfler's methylene blue.

c. Gram stain.

d. Special stains, such as: (r) Flagella. (3) "Tubercle"

5. Motility: $(a)$ Flagellar

(4) Capsule

(2) Spore.

c. Character of movement

(b) Molecular

6. Spores

7. Special characters, such as: capsules, vacuoles, granules, pleomorphic and involution forms, etc

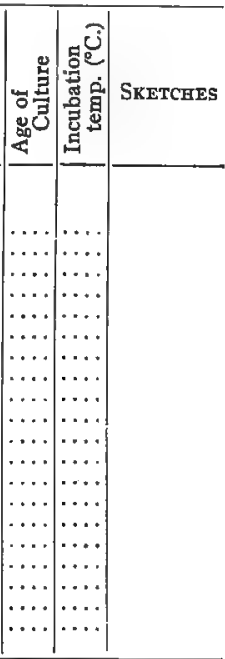

\section{Phystological Characters}

I. Relation to temperature: (a) Optimum... (b) Minimum...(c) Maximum. .

\section{Relation to free oxygen:.}

3. Relation to other agents such as:

desiccation, light, disinfectants, etc:

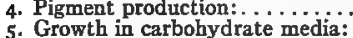

5. Growth in carbohydrate media:
a. Stab or shake culture (dextrose agar): gas production. . . . . . . . . .

b. Fermentation tube: ( $I$ ) growth in bulb:.. (2) growth in closed arm:

c. Percentage of gas produced in: fermentation tube......

After $\mathbf{2 4}$ hours

After 48 hours

Gas formula $\frac{\mathrm{H}}{\mathrm{CO}_{2}}$ in

\begin{tabular}{|c|c|c|}
\hline DEXTROSE & LACTOSE & SACCHAROSE \\
\hline$\cdots$ & $\cdots \cdots$ & $\cdots$ \\
\hline & & \\
\hline
\end{tabular}

\section{d. Reaction ( $\mathrm{I}$ ) in bulb.}

c. Acia or alkali production (in litmus milk)

7. Reduction of nitrales to nitrites.

7. Reduction of nitrales to nitrites............ to ammonia.

fecal odor; 24 hours.

9. Enzym production;

Io. Characteristic odor.

II. Agglutination

I2. Pathogenesis 
Culture Characters of $\ldots \ldots \ldots \ldots \ldots \ldots \ldots \ldots \ldots \ldots \ldots \ldots \ldots \ldots$

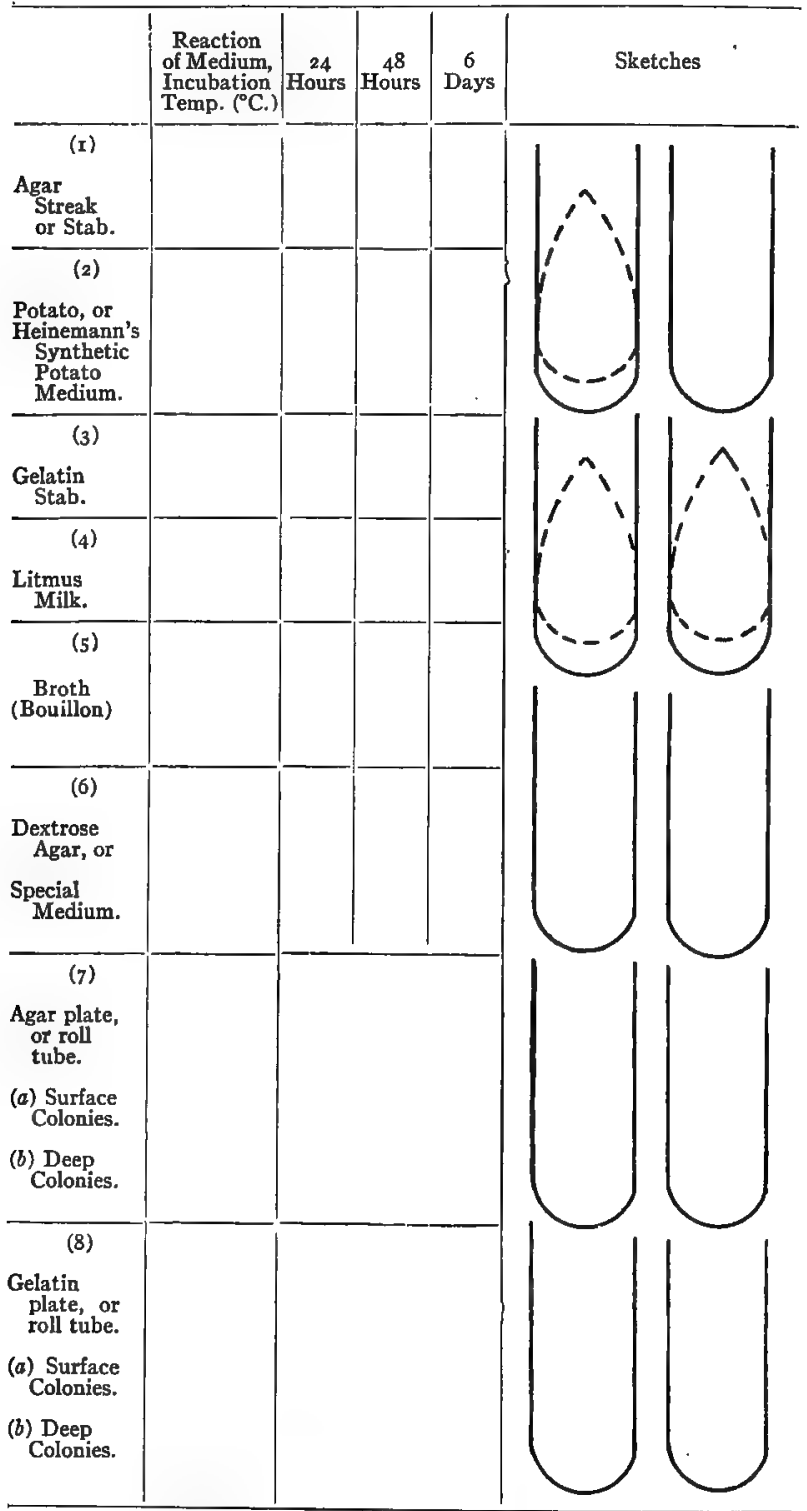

This Culture Chart is used in connection with "A Laboratory Guide in Bacteriolngy," by PAUI G. HeINEMANN, published by

The University of Chicago Press, Chicago, Illinois 
7. Note any peculiar appearance in the microscopical picture, especially involution forms and the presence or absence of capsules. If capsules are present, note the method of demonstration.

V. Physiological characters.

I. Relation to temperature: What is the optimum temperature?

2. Relation to free oxygen: aërobe, anaërobe, facultative aërobe, or anaërobe.

3. Relation to disinfectants, light, desiccation, heat (thermal death-point).

4. Pigment production: If present, + ; if absent, - In the former case, note the color, diffusibility, solubility, influence of acids and alkalis.

5. Gas production in glucose media: to be filled out only in case of actual observation. In fermentation tubes note the growth in either arm or both arms, recognized by turbidity. Note the total percentage of the gas formed in 24 and 48 hours. Reaction may be tested by the addition of litmus solution. Gas formula expressed: $\frac{\mathrm{H}}{\mathrm{CO}_{2}}$.

6. Acid or alkali production in litmus milk.

7. The production of indol or nitrites, or both, is tested on the sixth day of observation in a culture in Dunham's pepton solution or sugar-free broth.

Note,-Indol is a decomposition product of proteins and belongs to the aromatic series. Nitrites result from reduction of 
nitrates, or from oxidation of ammonia. The ability of organisms to produce these reactions is of great importance in their differentiation. A control test with a tube of sterile medium should be made.

8. Enzym production: Proteolytic enzym production noted by the liquefaction of gelatin or caseïn. Coagulative, recognized by precipitation of caseïn, if acid formation is absent, or present only in quantities less than 0.4 per cent. Amylolytic, by the digestion of starch (potato).

9. Characteristic odor.

Io. Pathogenesis: What pathogenic effect has the organism on man? What effect on animals, and which animals? What diseases are caused by the organism in man or animal?

Note.-The terms "proteolysis," "enzym production," and "coagulation" are frequently confusing to the beginner. The following brief explanation will aid in an intelligent interpretation of the reactions observed.

"Proteolysis" is the breaking up of complex nitrogenous compounds (proteins), rendering them soluble. This process is also expressed by the terms "peptonization" and "liquefaction." The liquefaction of gelatin is one kind of proteolysis. Gelatin is composed of nitrogenous matter (albuminoid or gelatinoid), and it is for this reason mainly that gelatin stab cultures are made. If the gelatin is liquefied, the assumption is that the organism is capable of producing a "proteolytic" or gelatinolytic enzym. In milk the process is more complex, and this medium, on account of its composition (fat, milk sugar, caseĩn, lactalbumin), offers excellent opportunities for the organism to develop different characteristics. Milk is one of the most important of media. The casein, contained in milk in colloid solution, may be precipitated by an enzym or by an acid. This precipitate forms the coagulum. At least 0.4 per cent of acid, which is largely 
lactic acid produced by splitting of milk sugar (lactose), is required for precipitation, and this amount of acid will turn the blue litmus to a decided red. A coagulum may also be produced by the presence of a "coagulative" or "rennet"-like enzym, which is the result of the metabolic activity of the organism. Such coagulation may take place in milk of amphoteric or alkaline reaction, as well as in milk of slightly acid reaction. The coagulum formed by any of the mentioned agents may gradually contract, and a straw-yellow, opalescent liquid will be squeezed out, called "whey." If the organism also produces a proteolytic enzym, this will attack the coagulum and gradually dissolve it (proteolysis, peptonization). At first the coagulum shows a broken-up edge; lumps separate and settle to the bottom, and finally the coagulum may disappear completely. Theoretically, coagulation is always necessary before proteolysis sets in, but in the case of some organisms the proteolytic enzym is so powerful as to produce immediate solution of the casein. (See Figs. 2I, $22,23,24$.)

Another phenomenon frequently observed in litmus milk is the decolorization of litmus, whether this be pink or blue. This is due to the fact that the organism takes up the oxygen necessary to maintain the coloration. It may be frequently observed that at the surface, where atmospheric oxygen has access, the color remains or is restored. The color may also be restored by shaking the milk vigorously, thus bringing it into intimate contact with the oxygen of the air.

The production of an amylolytic enzym (diastase, amylase) is demonstrated by gas production on potatoes. This medium contains starch in large amounts. The starch is converted into maltose by diastase (amylase). Maltose may then be split by the action of an inverting enzym into dextrose, which is then fermented with gas production.

\section{Second page-}

I. Note the reaction of the medium.

2. The incubation temperature may be $(a) 37^{\circ} \mathrm{C}$. (thermostat), (b) room temperature $\left(20^{\circ} \mathrm{C}.\right),{ }^{x}(c)$ ice chest.

s Gelatin cultures are to be incubated at room temperature. 

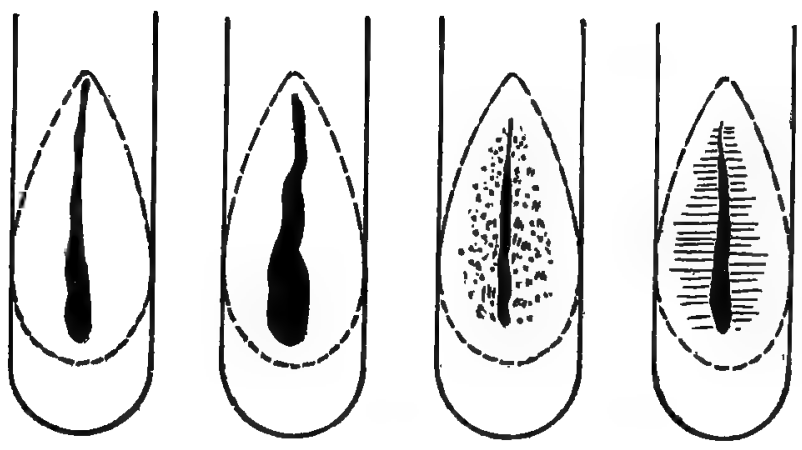

FIG, 2 I

Streak Cultures
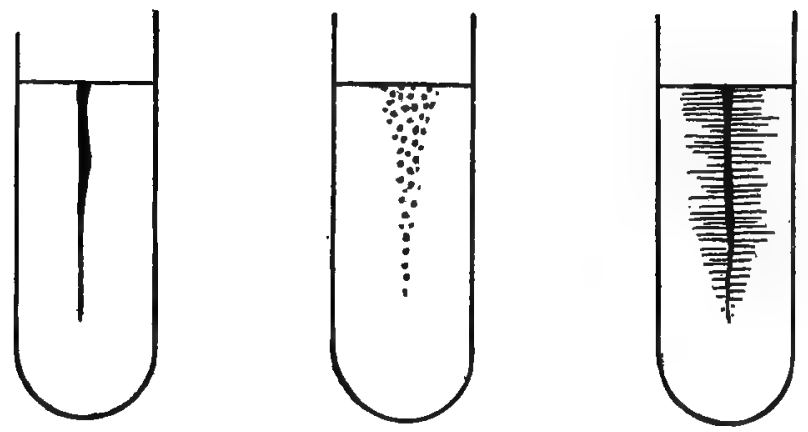

FIG. 22

Stab Cultures 

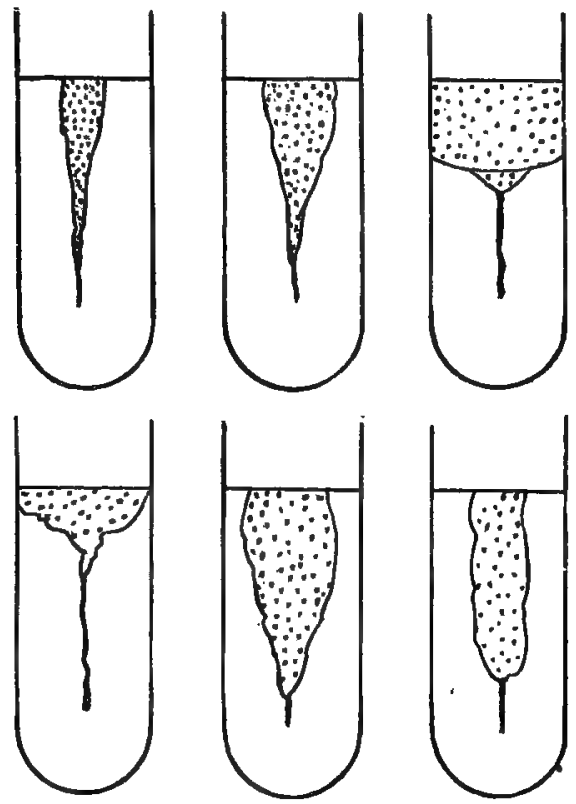

FIG. 23

Liquefaction of Gelatin
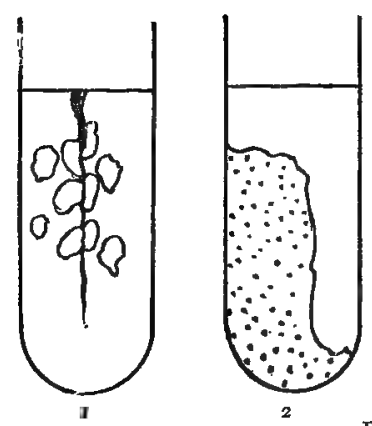

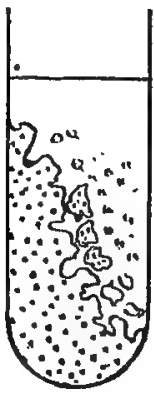

3

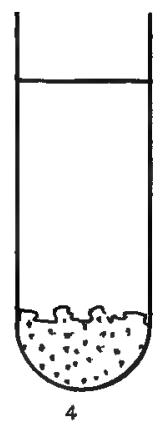

Fig. 24

I. Gas bubbles in glucose agar 2. Coagulation of milk

3. Coagulation and peptonization of milk 4. Complete peptonization of milk 
3. Plates are to be described only once after 24 or 48 hours, according to growth. Make notes in column 7 for agar plate; in column 8, for gelatin plate. Make sketches in the margins reserved for this purpose.

4. The growth on the media $I, 2,3,4,5$, and 6 is to be described fully according to the outline in the spaces under 24 hours. In the spaces under 48 hours and 6 days note only the changes from the first description.

5. Make sketches frequently and accurately, especially from milk and gelatin media, and any other noteworthy growth, in the columns reserved for this purpose; also a sketch of each organism from part of a field under the microscope.

These directions for filling out culture charts are applicable in the described manner to studies of cultures furnished by the laboratory. For determining any species of unknown bacteria, original researches must be made to cover all points, without the possibility of gathering this information from textbooks or references. On the accuracy of observation and description depends the success of bacteriological work and species determination. It is frequently necessary to employ special media, or inoculation of animals, or such biological reactions as the agglutination test, to determine what species one is dealing with.

The student will do well to familiarize himself with all directions and explanations given in this and the previous chapters. Find a characteristic for each item mentioned; otherwise the descriptions will be incomplete; and follow the instructions for routine work with all possible accuracy. 


\section{PART II}

\section{GENERAL BACTERIOLOGY}





\section{SECTION I \\ PREPARATION OF CULTURE MEDIA}

The following culture media are to be prepared for this work:

\section{First SET}

Wort agar.................... 20 tubes

Ten of these tubes should contain about 7 c.c. for slants, the other ten about ro c.c. for plating.

Wort gelatin................. Io tubes

Liquid wort.................. Io tubes

Fermentatioa tubes.............. 6 tubes

Two of the fermentation tubes to contain I per cent dextrose, two I per cent lactose, and the remaining two I per cent saccharose.

\section{SECONd SET}

Meat extract agar.............. 20 tubes

Ten of these for slants and tea for plating.

Pepton gelatin................. I5 tubes

Broth. .................. I5 tubes

Dextrose agar. ................. I5 tubes

Litmus milk.................. I5 tubes

Synthetic potato............... Io tubes

The beerwort media are to be prepared during the first waek, the other media later. 


\section{SECTION 2}

COLLECTING AND CULTIVATING MICRO-ORGANISMS FROM THE AIR

\section{EXERCISE I}

r. Sterilize all petri dishes in the hot-air sterilizer for one hour at $160^{\circ} \mathrm{C}$.

2. Melt two tubes of plain agar, one of dextrose agar, and two of beerwort agar, in a water bath. The water bath (Fig. 25) is a round copper vessel with a number of holes in the top. These holes are large enough to allow a culture tube to slip in. A thermometer is passed through a rubber cork with a hole in its center, and inserted into one of the holes in the water bath. Water is then poured into the apparatus until the level is slightly higher than the media in the tubes

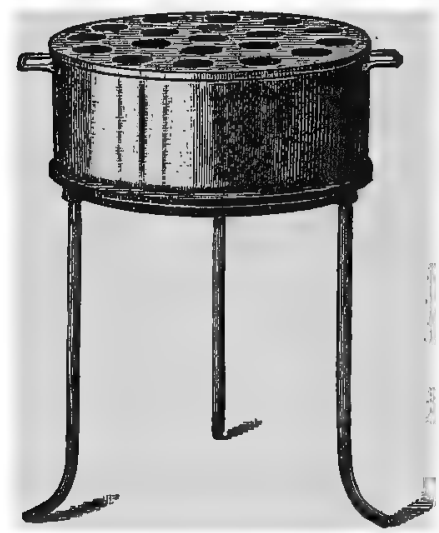

FrG. 25

Water Bath and the thermometer lowered until the mercury bulb is immersed in the water. The culture tubes are then slipped in, and the water heated to $100^{\circ} \mathrm{C}$.

3 . Singe the cotton stopper of the liquefied agar tubes in the flame, remove the cotton stopper, pass the mouth and about one inch of the tube through the flame, and pour the 
contents into a sterile' petri dish, carefully lifting the cover (Fig. 26) and quickly replacing it.

4. Repeat this operation with the other tubes, excepting glucose agar.

5. Place all petri dishes containing the liquid agar on a level surface.

6. When the agar has solidified, expose, by removing the cover, one dish of plain agar and one of wort agar to the air of the laboratory, and the other two outside on the window-sill, for 5 minutes.

7. Replace the cover and place in incubator.

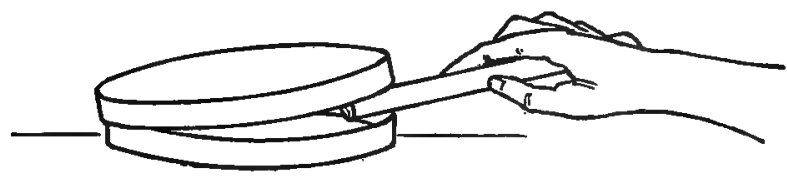

FIG. 26

Pouring Medium into Petri Dish

8. Cool the water bath to $43^{\circ} \mathrm{C}$, , and mix the scrapings from under a finger nail with the liquid glucose agar. Incubate at $37^{\circ} \mathrm{C}$.

9. Remove the plug of a tube of broth and place a hair in the liquid. Incubate at $37^{\circ} \mathrm{C}$.

Liquefied agar media should be inoculated at a temperature no higher than $43^{\circ} \mathrm{C}$. nor lower than $40^{\circ} \mathrm{C}$. Above $43^{\circ} \mathrm{C}$. the organisms are liable to be injured by heat; below $40^{\circ} \mathrm{C}$. the agar solidifies, and an even distribution is impossible. If gelatin is used, the latter precaution is not imperative, as gelatin solidifies at about $25^{\circ} \mathrm{C}$.

Observe and make notes on the appearance of these petri dishes after 24 hours. By this time it will be 
observed that a number of spots of different sizes, shapes, colors, etc., have formed on the surface of the medium.

The low power of the microscope will reveal a dark part in most of these spots. This dark part is a dust particle, which has carried micro-organisms to the surface of the agar, and thus opportunity is given for multiplication and formation of a "colony." A colony originating in this manner may or may not consist of one species of organism. By studying the organisms we will find that the colonies are composed of bacteria, yeasts, torulae, or molds. All or any of these may be carried by dust particles in the air.

EXERCISE 2

Inoculate two or three colonies on agar slants.

Method of inoculation-

I. Singe the cotton plug of a tube containing the medium. Organisms in the air are constantly alighting on the cotton, and bacteria may also be deposited on the cotton by handling it with the fingers. If these organisms are not killed by the process of singeing, they may drop on the medium after removal of the stopper, and thus ruin a pure culture.

2. Hold the tube (or, if a transfer is made, both tubes side by side) between the thumb and the forefinger, so that the end of the tube rests on one edge of the hand (Fig. 27), holding them at an angle of about $45^{\circ}$. If held horizontally, the condensation water, usually present at the lower end of the agar slant, will moisten the surface and destroy a characteristic growth 
along the needle track. If held in a vertical position, contamination from the air may take place.

3. Remove the cotton stoppers by taking hold of the singed portion, and hold also by the singed part between the other fingers. If the portion of cotton from the inside of the tube is touched by the fingers, or accidentally falls on the table or the floor, it becomes contaminated and must be singed before replacing.

4. Sterilize the straight platinum needle in the flame, holding it like a pencil. The platinum wire

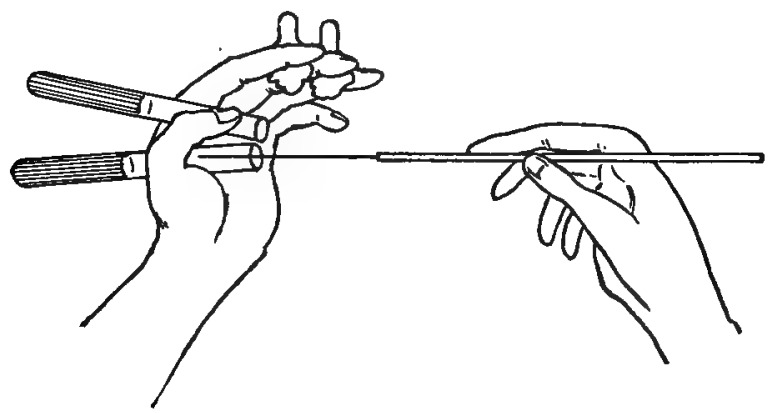

Fig. 27

Method of Inoculating Media

should be heated until red hot, and the glass end passed slowly through the flame once or twice.

5. After cooling the needle by plunging into the medium, take up a small portion of a colony or culture on the end of the needle by a lateral movement, and, when removing it from the tube, take care not to touch the walls of the tube. If any cotton accidentally sticks to the mouth of the tube, it should be burnt off with a hot platinum needle, and then the mouth of the tube passed through the flame before inserting the needle. 
6. Insert the needle with the culture into the sterile tube and draw along the surface of the slant, without puncturing the jelly, and turn the needle during the operation.

7. Replace the cotton plugs and sterilize the needle in the flame, as above.

A stab culture is made by puncturing the medium centrally by a quick, steady movement of the needle. Care should be taken not to let the needle touch the bottom of the tube, the object being to make a narrow puncture, and by touching the glass the needle would

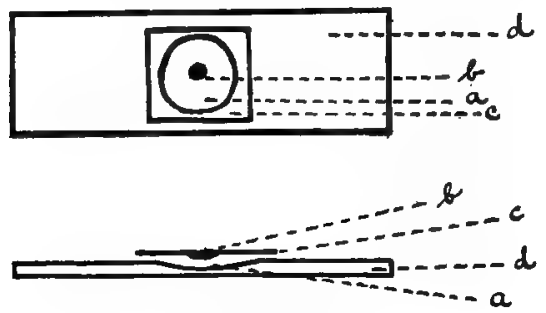

Fic. 28

Hanging Drop
4. Hollow
b. Drop
c. Cover slip
d. Slide

bend and make a ragged opening in the medium on withdrawing.

Inoculations of liquid media are made by rubbing the end of the needle against the glass below the surface of the liquid. The medium is then shaken. After inoculation liquid cultures should not be shaken again, as this might destroy a characteristic shape of the coagulum, break up the cream ring, or defeat sedimentation in broth. 
Inoculations from liquid media are made with the looped needle. This may also be used from a solid medium, if a considerable amount of growth is required. The contents of the loop are then spread over the whole surface.

\section{EXERCISE 3}

Describe the appearance of the colonies as outlined in Section 9.

\section{EXERCISE 4}

Examine as to motility in the hanging drop. Preparation of a hanging drop (Fig. 28):

I. Clean a cover slip in alcohol. Pass several times through the flame so as to burn the last traces of grease off the surface.

2. Place a loopful of pure water on the center of the cover slip.

3. Flame the straight platinum needle, and, after cooling, touch one of the colonies and mix lightly with the drop of water without spreading it. Take only a minute amount of culture, so as to produce a faint cloudiness in the water.

4. Smear vaselin around the depression in a hollowground slide, invert the cover slip over the depression, and gently press the margin on the vaselin.

5. Examine in oil, using very little light,

\section{EXERCISE 5}

Molecular movement.- - Rub a small amount of car$\min$ in a mortar with some water and make a hangingdrop preparation. When examining this through the oil-immersion lens, it will be observed that the small 


\section{LABORATORY GUIDE IN BACTERIOLOGY}

particles of carmin have a lively vibrating motion. This is called "molecular movement," "Brownian movement," or "pedesis." The particles scarcely change their relative position. Actively motile organisms, on the contrary, change their relative positions. The movement of these may be slow, snakelike, or like a fish swimming; or they may dart rapidly across the field.

Now observe and describe what changes have taken place in the tube of broth with the hair. Compare with a sterile tube, noting the turbidity, sediment, odor, etc. Also examine in hanging drop.

Examine the tube of glucose agar containing the nail scrapings. Describe the general appearance, and note whether gas bubbles are present.

EXERCISE 6

Make stained preparations of three different colonies, using the three stains: i.e., gentian violet, methylene blue, and carbol fuchsin, also a Gram stain.

Method of making stained preparations-

r. Clean and flame a cover slip, or, if preferred, a slide may be used for this purpose. Cover slips, if handled by the fingers, should be held by the edges. Use as much as possible the forceps made for that purpose. After handling, the forceps should be sterilized in the flame.

2. Place one loopful of water on the cover slip.

3. Take a small quantity of the colony or culcure on a platinum needle and mix with water until faintly cloudy. Burn the remainder of the culture off the needle. 
4. Spread over the cover slip by two or three sweeps of the needle. The water should spread easily and not run together. If the water does not spread well the cover slip has not been sufficiently cleaned.

5. Dry by moving high over the flame.

6. Pass rapidly three times back and forth through the flame. This process precipitates albuminous matter and causes the bacteria to adhere firmly to the glass.

Note.-The same object may be accomplished by allowing absolute alcohol to evaporate from the cover slip. This method has some advantages, since the bacteria do not shrink from the heat.

7. Cover with stain for Io-I 5 seconds.

8. Wash in water.

9. Blot with filter paper, dry in the air or high over the flame, and mount in Canada balsam.

ro. Label and preserve this preparation.

Try to avoid the mistake, made by most beginners, of taking too much growth on the needle. For hanging-drop preparations less material should be used than for stained preparations.

\section{EXERCISE 7}

Method of making preparations according to Gram-

I. Prepare a film of the organism to be examined, as for the ordinary stained preparation.

2. Cover with gentian violet for I minute.

3. Wash in water, and remove the water by means of filter paper, leaving the surface moist.

4. Cover with Gram's iodin solution for 2 minutes.

5. Pour Gram's iodin solution off and, without washing, place in a staining dish, film side up, and cover with 96 per cent alcohol. 
6. Allow to remain in alcohol, with occasional agitation, for at least 4 minutes, or until no more stain is taken up by the alcohol.

7. Dry without washing, and mount.

This stain is an important means of differentiating species of bacteria.

It is a positive Gram stain if by application of this method either the organism loses none of the stain or the stain is dark blue or dark slate blue. It is a negative stain if either the coloration is completely gone or only a light bluish tinge is left.

The preparation before mounting may be washed in water and counterstained with Bismarck brown. This method shows all foreign matter brown in contrast to the bacteria, and is especially adapted for staining bacteria in tissues, sputum, etc.

By mounting a Gram stain and a gentian violet stain of the same organism on the same slide both time and material are economized.

\section{SECTION $3_{3}$}

STUDY OF MOLDS, YEASTS, AND TORULAE

EXERCISE I. CULTURAL STUDIES

Yeasts, torulae, and molds grow better in a medium of acid reaction than in a neutral or alkaline medium. Media prepared from hopped beerwort are generally used for this purpose.

Make transfer of a stock culture of Saccharomyces cerevisiae or any other species of yeast which may have appeared on the plates prepared in the previous section. Also transfer two species of molds from these plates to slanted wort agar. 
Note.-Molds may be recognized by the filamentous, cottonlike form of the colonies. The hyphae extending into the air carry spores (conidia). By gently touching these with a sterile platinum needle, the spores may be transferred to an agar slant, and development will take place. Colonies of yeasts or torulae appear smooth, moist, opaque, elevated, and slightly yellowishwhite, or sometimes reddish. These may be transferred in the same manner as colonies of bacteria. Molds require careful handling for microscopical demonstration. They are usually examined in water or glycerin in the unstained condition.

\section{EXERCISE 2}

Method of preparing molds for microscopical examination-

I. Transfer some of the growth to alcohol (50 per cent).

2. When thoroughly moistened, transfer some of the growth to a drop of glycerin on a slide.

3. Spread carefully with a platinum needle.

4. Cover with a slip and examine.

5. If satisfactory, the preparation may be made permanent by painting a ring of asphalt around the edge of the cover slip.

Molds may also be stained in the following manner:

I. Place a small amount of mold on a slide.

2. Cover with alcohol and allow alcohol to evaporate.

3. Wash in water.

4. Stain with gentian violet or methylene blue.

5. Mount in glycerin.

\section{EXERCISE 3}

\section{Study of Yeasts-}

I. Examine a small amount of yeast taken from an agar slant in water under the high power of the micro- 
scope. Note the manner of reproduction by "budding."

2. Prepare a culture in liquid wort of Sacch. cerevisiae.

3. Pour the supernatant liquid of the 24 -hour-old culture off, and spread the sediment on a gypsum block with a looped needle.

Note.-Gypsum blocks may be prepared in the following manner: Gypsum (plaster of paris) is mixed with half its volume of water and quickly placed in a cylinder of paper. When dry, the paper is cut away and the block is placed in a suitable vessel (a stender dish or a deep, narrow petri dish, covered by an inverted tumbler). The block and vessel are then sterilized in the hot-air sterilizer for one hour at II $0^{\circ}$ to II $5^{\circ} \mathrm{C}$., or in the autoclave for 3 o minutes.

4. Pour enough distilled water around the gypsum block to submerge about one-half of it.

5. Incubate at $25^{\circ} \mathrm{C}$.

6. Set aside in a cool, dark place for 3 or 4 days.

7. Examine a small portion of the film on the surface of the gypsum under the microscope in water.

Note.-Under favorable conditions, and in the presence of oxygen, yeasts will develop spores. The porosity of the gypsum block, which admits free communication with the water, and the fact that the surface of the block is exposed to the air, offer favorable conditions for spore formation, which takes place in 3 or 4 days.

EXERCISE 4. CULTURE STUDIES OF YEASTS AND MOLDS

Make transfers from all agar cultures of yeasts to wort gelatin and liquid wort. Mark these cultures with labels or glass pencils on the side of the tube opposite to the slanted surface and just below the cotton 
stopper. Incubate the gelatin cultures at room temperature, all other cultures at 25 or $37^{\circ} \mathrm{C}$. in the incubator. Make descriptions after 24 hours, 48 hours, and 6 days, as outlined in Section 9 .

\section{EXERCISE 5}

Select two species of yeasts and inoculate three fermentation tubes with each species, using the looped needle, so as to have each species act on the three different sugars. Measure the gas evolved after 24 hours and after 48 hours by means of Frost's fermentation chart or gasometer (back cover). The chart is to be placed between the open arm and the bulb and moved until the extreme upper end of the closed arm is level with the top of the chart and parallel with the vertical lines on the chart. Express the results in percentages as read from the gasometer.

Gas production is not a constant accompaniment of fermentations. Carbohydrates are fermented by many organisms without gas formation, the usual product being an acid, often lactic acid. Such fermentations produce turbidity, but no gas. Growth therefore must be described and can be observed by turbidity, forming either in the closed arm, the bulb, or both. Observations are to be noted in the space for this purpose on the first page of the description charts.

\section{Analysis of gas produced in the closed arm-}

The gas consists chiefly of carbon dioxid and hydrogen, as may be proved by the following method: Fill the bulb with a 2 per cent solution of $\mathrm{NaOH}$, and close the mouth with the thumb, taking care not to leave any 
air between the thumb and the liquid. Now tilt.the gas back and forth slowly from the closed arm to the bulb and back to the closed arm five or six times, and finally allow the gas to collect again in the closed arm. The $\mathrm{NaOH}$ combines with the carbon dioxid, and consequently, on releasing the thumb, the volume of gas will become smaller in proportion to the amount of carbon dioxid absorbed. The percentage of gas is measured again with the chart, and the relation determined of the gas left in the arm to the original amount.

\section{Example-}

Total percentage of gas before addition of $\mathrm{NaOH} 45$

Percentage left after absorption by $\mathrm{NaOH}$.... 30

Difference...................... I5

$3^{\circ}$ per cent represents the amount of hydrogen and I5 per cent the amount of absorbed carbon dioxid. The proportion is expressed by the formula

$$
\frac{\mathrm{H}}{\mathrm{CO}_{2}}=\frac{30}{\mathrm{I} 5}=\frac{2}{\mathrm{I}} \text {. }
$$

The fact that the gas remaining in the closed arm is probably hydrogen may be proved by tilting it into the bulb, previously filled with water and closed by the thumb. Hold a burning match over the mouth and release the thumb. A slight explosion takes place from the combination of the hydrogen with the oxygen of the atmosphere.

The gas produced by yeasts usually consists chiefly of carbon dioxid; the gas produced by intestinal bacteria consists chiefly of two-thirds hydrogen and one-third carbon dioxid; and the gas produced by the proteus group consists chiefly of one-third hydrogen 
and two-thirds carbon dioxid. These proportions, obtained by the above-described method, are but approximations to the actual condition. Somewhat different results have been reported by Keyes (Jour. Med. Res., I9o9, N.S. I6, p. 69). For his experiments synthetic media and more precise methods for the control of conditions were employed.

Gas formation by bacteria does not necessarily depend on the presence of carbohydrates. Nitrogen may be produced from nitrites and nitrates, or urea, hydrogen sulphid, and ammonia from proteins during the process of putrefaction.

EXERCISE 6. STUDY OF THE GERMINATION OF MOLD SPORES

Transfer two species of molds from the air plates to slant wort agar and incubate at $37^{\circ} \mathrm{C}$.

After several days, when sufficient growth has taken place, remove spores from the surface of the hyphae by means of a straight needle and suspend these in a tube of liquid beerwort or broth. Transfer a loopful of this suspension to a cover slip and examine under the microscope, magnifying about 600 times. If only a few spores are discovered in a field invert this cover slip over the hollow of a hollow-ground slide and keep in place by painting a ring of vaselin around the hollow. If there are too many spores on the cover slip dilute the suspension with beerwort or broth. This hanging drop is incubated and observed daily under the microscope and sketches made of the appearance. In seven to ten days the spores should have produced the whole cycle of development of the mold and new spores should have formed. 


\section{SECTION 4}

BACTERIOLOGICAL EXAMINATION OF WATER, AIR AND MILK

EXERCISE I. BACTERIOLOGICAL ANALYSIS OF WATER References-

Prescott and Winslow, Elements of Water Bacteriology, New York, 1914 .

Savage, The Bacteriological Examination of Water Supplies, London, 1906.

A bacteriological examination of water is made for the purpose of determining-

r. Bacterial numbers.

2. Bacterial species.

3. Sewage pollution.

Collection of samples.-Procure wide-mouthed, glass-stoppered bottles, having a capacity of at least roo c.c. After cleaning and drying, tie lead foil or filter paper over the stopper, wrap the bottles individually in paper and sterilize in the hot-air oven for I hour at $160^{\circ} \mathrm{C}$.; then deposit them in a metal or wooden case. The samples from surface waters should be taken at least one foot below the surface, to avoid contamination with organisms from the air. If possible, samples should be plated on the spot or in the laboratory within an hour at the latest. But when a greater interval of time must occur, the samples should be taken to the laboratory packed in ice, despite the probability of thus partially altering the bacterial flora.

Method of examination.-A number of pipettes of various sizes (I c.c., 2 c.c., 5 C.c., and Io c.c.) are plugged 
with cotton and sterilized in the hot-air oven. Then a number of Erlenmeyer flasks are filled with roo c.c. of distilled water, and these are sterilized in the autoclave at $120^{\circ} \mathrm{C}$. for 5 minutes. During sterilization a small variable amount of water is lost. This has to be disregarded.

\section{Method of procedure-}

r. With a sterile pipette carry over to one of these flasks I c.c. of the sample after shaking. The dilution is now $\mathrm{I}:$ 100. Mark with a glass pencil.

2. With a sterile ro c.c. pipette remove ro c.c. from another dilution flask, and add to the remainder ro c.c. of the first dilution. We now have a dilution of $I: I, 000$. (See appendix.) Make a number of dilutions in this manner, carrying the dilutions higher in proportion to the quality of the water to be examined.

3. Melt a number of agar and gelatin tubes, corresponding to the number of dilutions made, and cool to $43^{\circ} \mathrm{C}$.

4. Transfer I c.c. of each dilution flask to a petri dish.

5. Pour the contents of one agar tube on the petri dish and mix this with the I c.c. of water by tipping the dish back and forth.

6. Incubate the agar plates at $37^{\circ} \mathrm{C}$. and keep the gelatin plates at room temperature.

Estimation of colonies.-The colonies are then counted after 48 hours, by means of a colony counter (see back cover). Plates should be counted which contain no more than 200-300 colonies. If it is necessary to count plates with a large number of colonies, an estimate must be made by counting different sec- 
tions of the plate counter and averaging the result for the whole plate.

Species determination.-If the different species of bacteria are to be studied, the colonies must be examined by the naked eye and the low power. Then those which appear to be different are transferred to slant agar tubes, and from these to the ordinary media.

Sewage contamination.-If Bacillus coli and streptococci are present in relatively large number, sewage pollution is indicated.

Method of examination for B. coli and streptococci-

I. I c.c. of the sample, or, if necessary, of the diluted sample, is added to each of a series of ten fermentation tubes, containing sterile I per cent dextrose broth.

2. Place in thermostat.

3. Examine after $\mathrm{I} 2-\mathrm{I} 8$ hours.

4. Examine a loopful of the sediment in a stained preparation.

Example.-If I c.c. of the sample is added to each fermentation tube, and six show gas formation, there would be six colon bacilli in each Io c.c. if undiluted water is employed. By this method number of B. coli per cubic centimeter may be estimated.

Formula for determining the number of B. coli present in water:

$\frac{N \times D}{I}=$ Number of B. coli in I c.c. water.

$\mathrm{N}=$ Number of tubes with gas; $\mathrm{D}=$ Dilution; $\mathrm{I}=$ Total number of tubes inoculated. 
The presence of streptococci is determined by making Gram stains from each of the fermentation tubes after two or three days. The number of streptococci can be determined approximately by the same method of calculation as for B. coli, by substituting the number of tubes containing streptococci for $\mathrm{N}$.

Isolation of B. coli and streptococci is accomplished by plating from the fermentation tubes in lactose litmus agar.

EXERCISE 2. THE BACTERIOLOGICAL EXAMINATION OF AIR

For precise methods see:

"Report of the Committee on Standard Methods for the Examination of Air," Am. Jour. Public Hygiene, 1910, 20, p. 346.

Rettger, Jour. Exp. Med., igro, 22, p. 46r.

An approximate determination of the number of bacteria in the air can be made by the following simple method: Place 50 c.c. of broth in an Erlenmeyer flask (Fig. 29, a). This flask is provided with a rubber stopper $(b)$ with two holes, through which two glass tubes ( $c$ with a wide opening and $d$ ) lead. Cotton plugs are then inserted at $c$ and $d$, and the apparatus is sterilized in the autoclave. A large bottle $(f)$, containing 5 liters of water, is then provided with a rubber stopper, and also with two glass tubes $(g$ and $h) ; h$ is connected with a short piece of rubber hose and a pinchcock (i). When the Erlenmeyer flask and contents are sterilized, the tube $d$ is connected, by means of the rubber hose $e$, with $g$, and the plug at $c$ is removed. By opening the pinchcock $i, 5$ liters of air are aspirated 
through the broth in flask $a$. The flask is then disconnected, and I c.c. is plated in agar and I c.c. in gelatin. The former is incubated at $37^{\circ} \mathrm{C}$., and the latter kept at room temperature. After 48 hours the colonies are counted, and the result is multiplied by 5o. This then represents the amount of bacteria in 5 liters of air.

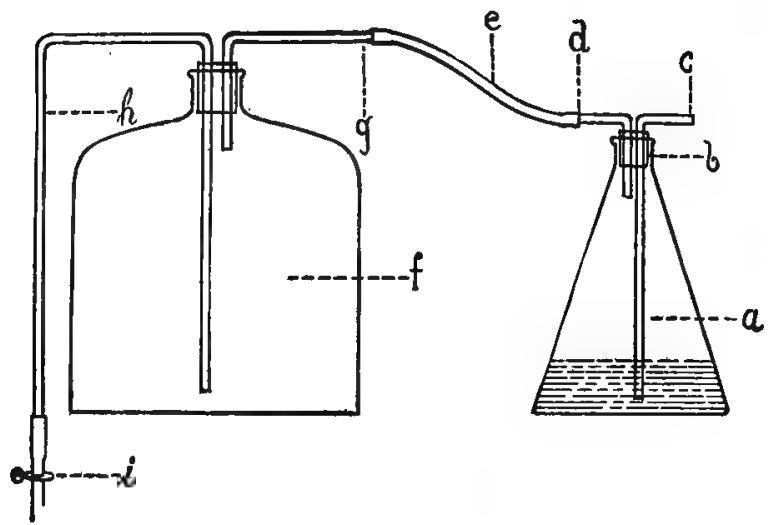

Fig. 20

Apparatus for Determining the Number of Bacteria in a Definite Volume of Air
a. Erlenmeyer flask
$f$. Five-liter flask
$b$. Rubber stopper
$c, d$. Glass tubes
$g, h$. Glass tubes
i. Pinchcock

EXERCISE 3. BACTERIOLOGICAL STUDY OF MILK

The method for determining the number of bacteria in milk is fundamentally the same as for water, except that dilutions must be carried higher, as milk generally contains larger numbers of bacteria.

Sterilization and pasteurization of milk.-Some of the germs in milk are saprophytes (which under favor- 
able circumstances produce disagreeable odors or tastes), and such pathogens as the bacillus of tuberculosis (which may be derived from the cow, or may be an accidental contamination), the typhoid bacillus, the bacillus of "summer complaint" in children (possibly identical with the bacillus of epidemic dysentery), the germs of cholera, diphtheria, and scarlet fever. All these, except B. tuberculosis, flourish in milk at its ordinary temperature.

None of the methods employed in sterilizing milk render it sterile in the bacteriological sense of the word, but by means commonly employed most of the nonsporing pathogenic bacteria are destroyed, along with a large number of saprophytes, thus rendering milk comparatively safe and less subject to ordinary fermentative changes.

I. Sterilization at $100^{\circ} \mathrm{C}$. for 30 minutes.-Such milk, if chilled and kept at a low temperature, will remain unchanged for more than a week, but, by heating, certain alterations have been produced in taste and appearance.

2. Pasteurizing milk.-The changes occurring in milk, as above mentioned, begin at about $80^{\circ} \mathrm{C}$. Pasteurization at a low temperature is accomplished by raising the temperature to $60-65^{\circ} \mathrm{C}$. for a period of 20 minutes. This has been shown to be sufficient to kill the germs of tuberculosis, typhoid fever, cholera, diphtheria, and pyogenic cocci. Spores are not killed. As shown by Theobald Smith, tubercle bacilli, when suspended in distilled water, physiological salt solution, broth, and milk, are destroyed at $60^{\circ} \mathrm{C}$. in $15^{-20} \mathrm{~min}$ - 
utes; but, if milk containing tubercle bacilli has its surface exposed to the air when heated to $60^{\circ} \mathrm{C}$., the pellicle which forms on its surface may contain living tubercle bacilli after an exposure of 60 minutes.

Study of the effect of the above two methods of sterilization as compared with each other and with unsterilized milk:

I. From the fresh milk provided make three agar plates, using $\mathrm{r}, 2$, and 3 loopfuls, respectively.

2. Fill about ro c.c. into each of ten sterile culture tubes, and keep one at room temperature and one in the thermostat.

3. Treat four of these tubes in the following manner: Place water in a saucepan sufficient to cover completely the milk when the tubes are immersed in it. Raise the temperature to $65^{\circ} \mathrm{C}$, and keep it there by regulating the flame. The tubes of milk are then immersed in the water, and kept there for 30 minutes, as it requires. about ro minutes for the milk in the tubes to reach the temperature of the water. The tubes are then taken out and cooled quickly by standing them in cold water. Place one of the tubes at incubator and the other at room temperature. Aërate the other two by shaking vigorously for $I \frac{1}{2}$ minutes. Keep one of these at room temperature, the other in the thermostat.

4. Place two more milk tubes in the arnold at $100^{\circ} \mathrm{C}$. for 30 minutes. Keep one at room temperature and one in the thermostat.

5. The remaining two tubes autoclave at $120^{\circ} \mathrm{C}$. for 5 minutes, and place one in the thermostat and keep the other at room temperature. 
6. Note the conditions of these ten tubes after 2 or 3 days. Compare the results, and tabulate them. Note especially coagulation, time elapsed before coagulation sets in, gas formation, condition of whey, film, and odor.

Plates in lactose litmus gelatin should be made from each of these tubes, and the colonies studied and counted. Subcultures on agar slants may also be made and the usual media inoculated from these, if the individual species are to be studied.

\section{SECTION 5}

EXERCISES ON INFECTION AND STERILIZATION

EXERCISE I. PHENOMENA OF INFECTION

I. Prepare three agar plates.

2. Touch the surface of the jelly in one plate with the tips of the fingers.

3. Touch the surface of the jelly of another plate with the tips of the fingers, after washing the hands.

4. Catch a fly and allow it to walk on the surface of the jelly of the third plate. Release the fly and replace the cover.

5. Place these three plates in a locker or thermostat for 24 hours. Observe and describe the results. Make hanging-drop and stained preparations of some of the colonies formed.

EXERCISE 2. PHENOMENA OF STERILIZATION

I. Make an infusion of hay in a flask with cotton stopper. (See p. 4r.)

2. Set the flask aside for 24 hours in a warm place, and observe the results. 
3. Expose a tube of unsterilized broth to steam in the arnold, another to steam in the autoclave, at I $20^{\circ} \mathrm{C}$. for 5 minutes each

4. Set aside in a thermostat, and observe the results.

EXERCISE 3. PHENOMENA OF STERILIZATION (CONTINUED)

Action of Berkefeld and cotton filters.-Berkefeld filters are made of diatomaceous earth, and are porous so as to allow the passage of fluids, while retaining suspended solids, bacteria, etc. Some bacteria, known as "ultramicroscopic bacteria," are so small that they pass through Berkefeld filters.

I. Arrange a Berkefeld filter so as to connect with a suction pump, and filter a quantity of unsterilized broth (Fig. 3).

2. Set aside, and observe results.

The filter $(a)$, after having been connected with the flask, is sterilized in the autoclave. The cotton plug $c$ prevents the air, which is sucked back, from carrying germs into the flask. The flask $d$ is an intercepting or reflux flask, which guards against the broth becoming contaminated from water being sucked back if the pressure suddenly diminishes.

\section{EXERCISE 4}

Arrange a cotton filter as shown in Fig. 30. Vessel $a$, provided with a rubber stopper $(b)$ with two holes, is arranged so as to have a glass tube $(c)$ reach to the bottom. This tube is provided with cotton at the top opening $(d)$ and some nutritive medium (broth, $e$ ) is placed inside. Through the other hole a bent glass tube leads out, and this tube is also provided with a 
cotton filter at $f$. The whole apparatus is then sterilized in the autoclave at $120^{\circ} \mathrm{C}$. for 5 minutes, and connection is made through the flask $(g)$ and the tube (h) with the aspirator. Now aspirate some air through the flask, disconnect at $f$, and set aside. Observe the

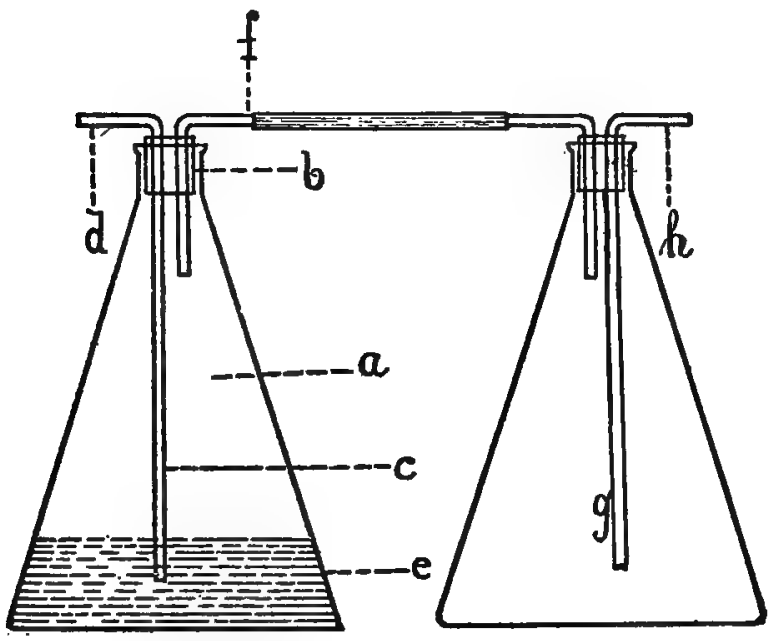

Fic. 30

Action of Cotton Filter

a Erlenmeyer flask

b. Rubber stopper

c. Glass tube

d. Cotton filter e. Broth

$f$. Bent glass tube with cotton filter at $f$

g. Erlenmeyer flask

h. Tube connecting with aspirator

results. Remove the cotton filter $(d)$, and drop it into a flask containing sterile broth; place in the thermostat for I8-24 hours; examine and note the conditions then present.

Results of the exercises in this chapter are to be observed by noting the appearance of colonies or 
turbidity, and by preparing stains with gentian violet from small amounts of the material in the culture media.

\section{SECTION 6}

INFLUENCE OF DISINFECTANTS, LIGHT, AND HEAT ON THE GROWTH OF MICRO-ORGANISMS

For precise methods see:

Anderson and McClintic, Hyg. Lab. Bull. 82, I912.

Amer. Jour. of Public Health, October, xgi 2.

Rideal and Walker, ibid., June, Igr3.

North Dakota Agricultural College, Special Bulletin, July, August, I9I3.

\section{EXERCISE I}

I. Prepare fifty-seven Hill's test rods. These are prepared in the following manner: Glass rods about two inches longer than ordinary culture tubes are marked with hydrofluoric acid or a glass cutter (diamond or file) by a circle one inch from the end. A wad of cotton is then wrapped around the middle of the rod, and inserted in a culture tube. The rod is then pushed down until it nearly reaches the bottom. That part of the rod which is free at the upper end is used for labeling. The whole apparatus is sterilized in the dry-air oven.

2. Fill two wide-mouthed flasks, one with roo c.c. of a 5 per cent solution of carbolic acid, the other with Ioo c.c. of a I per cent solution.

3. Fill two similar flasks, one with roo c.c. of a solution of mercuric chlorid $I: I, 000$, the other with a solution of $I: I 0,000$. 
4. Fill two similar flasks, one with Ioo c.c. of a Io per cent solution of formalin (40 per cent formaldehyd), the other with a I per cent solution.

5. Prepare 48-hour broth cultures of Staphylococcus aureus, Bacillus coli, and B. typhosus from stock cultures.

6. Dip nineteen of these rods into each of these cultures respectively, to the depth of one inch; set them aside in their tubes to dry over night in the thermostat after marking each tube.

\section{EXERCISE 2}

We have now six flasks containing different solutions of disinfectants.

r. Place in each one of these flasks nine of the prepared rods, three of which have been dipped in the Staph. aureus culture, three in the B. coli culture, and three in the B. typhosus culture.

2. Take three rods (one of each organism) out of each flask after the lapse of half a minute, wash by pouring sterile physiological salt solution over them into a dish containing mercuric chlorid solution $I: I, \infty 00$, and place each rod in a tube of sterile broth.

3. Repeat the proceedings of step 2 with a second series of rods after 2 minutes.

4. Repeat again after 5 minutes with the remaining series.

5. Place all tubes (fifty-seven) in the thermostat. Three of these tubes have not been dipped into any one of the six flasks containing antiseptics, and are incubated with the others as controls.

6. Observe the results on each of the four successive 
days, and on the last day prove the relative growth by making agar plates with I c.c. of each culture, and count the colonies after 24 hours.

7. Tabulate the results, and state conclusions.

EXERCISE 3. INFLUENCE OF SUNLIGHT

Experiment I-

I. Inoculate a flask containing roo c.c. of sterile water with B. coli.

2. After thoroughly shaking, take I c.c. by means of a sterile pipette, and plate in agar. Place the plate in the thermostat.

3. Expose the flask to sunlight for several hours.

4. Make another plate with I c.c. of the suspension; and place in a thermostat.

5. After 48 hours count both plates, and compare the results.

\section{Experiment 2-}

I. Melt a tube of agar and cool to $43^{\circ} \mathrm{C}$.

2. Inoculate with B. coli (or any other organism).

3. Pour into a sterile petri dish.

4. After solidification, turn bottom side up, and paste a strip of black paper on the glass, covering part of the surface.

5. Expose to direct sunlight for several hours, and note the resulț.

EXERCISE 4. INFLUENCE OF MOIST HEAT

Read the methods of determining the thermal deathpoint of bacteria in the textbook.

I. Prepare six broth cultures each of B. coli and B. subtilis. 
2. Place four cultures of each organism in the water bath and heat.

3. Remove one of each at $40^{\circ} \mathrm{C}$, , one of each at $60^{\circ} \mathrm{C}$, one of each at $80^{\circ} \mathrm{C}$., and keep one of each for Io minutes at $100^{\circ}$.

4. Place one tube of each organism in the autoclave, and heat to $120^{\circ} \mathrm{C}$. for 5 minutes.

5. Now place all twelve tubes in the thermostat, including one of each organism as a control.

6. After 24 hours, make plates of each tube in agar, and place them in the thermostat.

7. After 24 hours, count the colonies and compare the results.

\section{SECTION 7}

\section{STUDY OF CHROMOGENIC BACTERIA}

EXERCISE I. CULTURAL STUDIES

References to chromogenic bacteria, and the production and chemistry of pigments:

Fischer's lectures, Flügge, Die Mikroorganismen.

Lehmann and Neumann.

Members of this group are widely disseminated in the air, water, etc. A few representatives will be studied.

I. Inoculate agar slants from laboratory cultures of Bacillus prodigiosus, B. pyocyaneus, B. violaceus, and Sarcina lutea. Inoculate three slants each of $\mathbf{B}$. prodigiosus and B. violaceus, and one each of Sar. lutea and B. pyocyaneus. 
2. Label each tube with the name of the culture inoculated, and the date of inoculation.

3. Place one culture of each organism in the thermostat, one culture of $\mathbf{B}$. prodigiosus and $\mathbf{B}$. violaceus in the locker, and leave the others exposed to sunlight.

4. After 24 hours compare the growths of $\mathbf{B}$. prodigiosus and $\mathbf{B}$. violaceus, under the various conditions, in respect to-

a) Relative amount of growth.

b) Relative amount of pigment produced.

5. Note the characteristics of the pigments: Are they diffused through the medium, or are they confined to the growth?

6. Make descriptions of agar cultures; also hangingdrop, stained, and Gram preparations.

7. Transfer from 24-hour-old agar cultures of all organisms to all media. (See Section 8.) Potatoes may be inoculated with the looped needle, as the surface is too rough to allow of a smooth inoculation with the straight needle.

8. After all cultures have been incubated for 24 hours, make all descriptions as outlined on pp. $53 \mathrm{ff}$.

CaUtron.-Through oversight gelatin cultures are sometimes placed by students in the thermostat. This defeats the purpose of obtaining a stab growth, as the gelatin will melt. In order to avoid this mistake, it is recommended to label one tin cup or tumbler "Gelatin" in large letters. This will serve as a constant reminder that gelatin has to be kept at room temperature.

9. Make plate cultures of the four organisms.

Method of making plates-

I. Melt two agar tubes for each organism in the water bath and cool to $43^{\circ} \mathrm{C}$. 
2. Transfer $3-5$ loopfuls (according to the intensity of the growth, to be judged by the degree of cloudiness) of the broth culture to a sterile tube of Dunham's solution, or sterile physiological salt solution.

3. Shake well, avoiding air bubbles as much as possible.

4. Transfer 4 or 5 loopfuls from this suspension to a melted agar tube.

5. Shake this carefully by rolling the tube between the palms of the hand.

6. Transfer 4 or 5 loopfuls of this agar tube (2) to the second agar tube (3), and mix as above.

7. More tubes may be inoculated in the same way, resulting in still higher dilutions if this is desirable. In the meantime the inoculated tubes should be replaced in the water bath, so as to keep them liquid.

8. Pour the contents of the tubes, one after the other, into sterile petri dishes.

9. Tip the petri dishes so as to distribute the medium evenly over the bottom.

Io. Label them with the name of the organism and the date.

Ir. Set aside on a level place to solidify.

I2. When solidified, place them in the thermostat bottom up, in order to avoid moistening the surface of the agar by the condensation water dropping from the cover.

NoTE.--If the surface were moistened, the colonies would run together and the characteristic appearance be destroyed. Gelatin plates, on the contrary, are placed cover up. Condensation water does not form on these plates and gelatin may be liquefied by the organisms. The liquefied part would then fall from the medium on the cover and ruin the plate. 
The plates prepared in the above manner should be studied after 24 hours, or, if not sufficiently developed, after 48 hours, according to directions in Section 9.

\section{EXERCISE 2. STUDY OF PIGMENTS}

On the sixth day take agar slant or potato cultures of the four chromogenic bacteria, and proceed as follows: Pour 96 per cent alcohol on the cultures of B. prodigiosus, B. violaceus, and Sar. lutea. The pigment should dissolve. Filter the liquids into clean test tubes, and, by adding a few drops of 5 per cent hydrochloric acid, note the change in color. Then add an excess of a 2 per cent solution of sodium hydrate, and note whether or not the color returns and is changed again. Then pour chloroform on a culture of B. pyocyaneus. This will dissolve the bluish-green pigment (pyocyanin). Filter, and evaporate on the water bath. When almost dry, place a small amount on a slide, and observe the small crystals of pyocyanin under the microscope. Note also the aromatic odor given off by the pigment as the solvent evaporates.

\section{SECTION 8}

\section{STUDY OF MICROCOCCI}

Make transfers from laboratory cultures of Staphylococcus aureus and Streptococcus lacticus.

Follow the outline of routine work and make descriptions of these two organisms. 


\section{SECTION 9 \\ STUDY OF INTESTINAL BACTERIA}

EXERCISE I

Make transfers from laboratory cultures of B. coli, B. suipestifer, B. fecalis alkaligenes, and B. cloacae.

\section{EXERCISE 2}

In addition to the usual routine study prepare fermentation tubes in the following manner: Meat extract broth or meat infusion broth is inoculated with a culture of $\mathbf{B}$. coli to remove the muscle sugar and incubated at $37^{\circ} \mathrm{C}$. for 24 hours. The broth is then boiled, the reaction made I per cent acid, and the broth filtered until clear. Dissolve I per cent dextrose in one third, I per cent lactose in another third, and I per cent saccharose in the remaining third. Fill these solutions into fermentation tubes and sterilize in the arnold for three successive days. Any gas which accumulates during sterilization in the closed arm must be tipped out while the medium is hot. When cooled down, inoculate the fermentation tubes with the four organisms, incubate for 24 hours, and then measure the gas in the closed arm. Replace in the incubator and measure the gas again after 48 hours. Finally determine the composition of the gas as described on p. 8I.

In addition to the exercises outlined for this course demonstrations should be made of stains of tubercle bacilli in sputum, stains of diphtheria bacilli, methods of anaërobic cultivation of bacteria, and various ontfits used in municipal laboratories for diagnosis. 



\section{PART III}

IMPORTANT PATHOGENIC BACTERIA 



\section{SECTION I}

\section{PREPARATION OF CULTURE MEDIA}

The following amounts of culture media will be required in this work:

\begin{tabular}{|c|c|c|}
\hline Name of Medium & Amount & Number of Tubes? \\
\hline 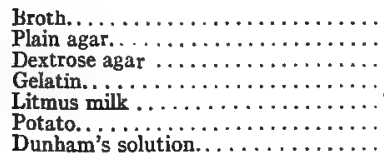 & $\begin{array}{l}300 \mathrm{c.c} . \\
\text { r,000 g. } \\
250 \mathrm{~g} . \\
300 \mathrm{~g} . \\
200 \mathrm{c.c} . \\
300 \mathrm{c.c} .\end{array}$ & $\begin{array}{l}25 \\
30 \\
20 \\
25 \\
25 \\
10 \\
25\end{array}$ \\
\hline 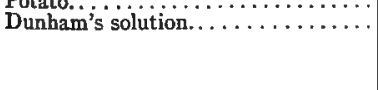 & . & 160 \\
\hline
\end{tabular}

The following staining solutions should be made up in sufficient quantities to fill ordinary staining bottles:

Löfller's methylene blue.

Ziehl-Neelsen's carbol fuchsin.

Ehrlich's gentian violet.

Gram's iodin solution.

The work in this course should begin with Part II, Section 7 , p. 97 .

\section{SECTION 2 \\ THE PYOGENIC GROUP}

EXERCISE I. THE PYOGENIC GROUP (SUBGROUP A) ${ }^{\mathrm{r}}$ Members-

Staphylococci, streptococci, Microc. tetragenus.

Inoculate agar slants from laboratory cultures of Staphylococcus aureus, Staph. albus, and Strepto-

s This subdividing of the pyogenic group is an arbitrary measure designed to facilitate study, the commoner pyogens being studied first. 
coccus pyogenes. These organisms arè pathogenic, and care must be taken to observe the rules of technic. Any carelessness may be followed by grave consequences. In case of accident, such as the spilling of a culture or infecting of the hands, disinfection--e.g., with a solution of mercuric chlorid ( $I$ : I, , ) - is necessary.

After 24 hours' incubation of three agar slants, proceed with the other media as outlined in the routine study (pp. 50 ff.).

Special study.--Inoculate a rabbit intravenously with a broth culture of Staph. aureus. The ear of the rabbit is shaved, and washed with mercuric chlorid solution, followed by alcohol. Then I or 2 c.c. of a 24-hour-old culture in broth is drawn up into a hypodermic syringe, which has been sterilized by immersion in boiling water for Io minutes. The mode of holding a rabbit is as follows: The left arm of an assistant rests against the hind-quarters of the rabbit on the table, while the two hands hold the fore-legs. If the animal struggles, force should not be applied, as this might cause injury. The struggles may be overcome by wrapping the animal in a towel or some other piece of cloth. The needle is then inserted into the lumen of the lower vein (ramus lateralis posterior of the vena auricularis posterior), which has been pinched between the fingers, or by means of a forceps, so as to arrest the circulation. No air should be injected with the culture, as this will kill the animal. The hypodermic syringe is then withdrawn and sterilized in boiling water for 15 minutes. 
After the death of the rabbit, study the lesions produced by the organism, and make cultures on slant agar, and smears from the heart's blood, spleen, and foci of suppuration.

DIRECTIONS FOR AUTOPSIES (SEE SKETCH, FIG. 3I)

See Mallory and Wright, Pathological Technique.

I. Have the instruments sterilized in boiling water.

2. Tie the animal by the extremities on a square board, with the abdomen upward.

3. Note the presence of any external lesions, such as swellings, ulcerations, etc.

4. Wash with a solution of mercuric chlorid $(I: I, \infty) 0)$ followed by alcohol.

5. Lift the skin over the pubes with the forceps, and with the scissors make an incision along the median line well above the sternal notch; then diagonal incisions extending along the fore- and hind-legs.

6. Cut the skin away with a moderately sharp knife, avoiding opening the abdominal cavity.

7. Open the abdomen by a median incision from the pubes to the sternum.

8. Remove the anterior thoracic wall by cutting away the ribs from below upward on each side to the thoracic apex.

The viscera are now exposed. Cultures and smears should be made from the heart's blood, peritoneal cavity, spleen, liver, and localized foci of suppuration.

Gram stains are of special value inasmuch as staphylococci are gram positive, while the tissues are more or less decolorized. 


\section{I08 LABORATORY GUIDE IN BACTERIOLOGY}

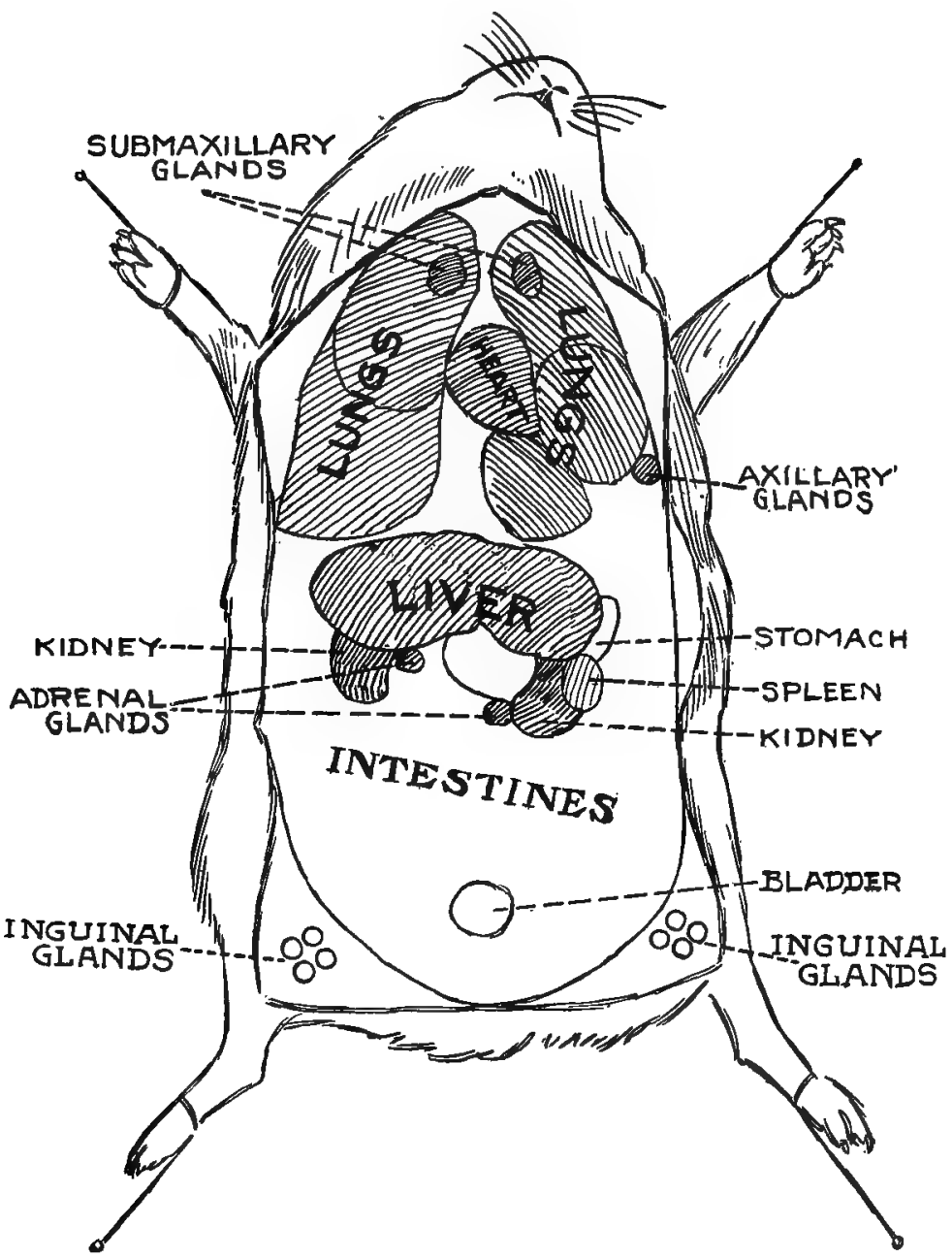

FIG. 3 I

Autopsy of a Guinea-Pig(Diagrammatic) 
EXERCISE 2. THE PYOGENIC GROUP (SUBGROUP B) Members-

Streplococcus pneumoniae.

Micrococcus zymogenes.

Micrococcus gonorrheae.

M. gonorrheae is difficult to cultivate on labora. tory media. It is a parasite and requires special media for cultivation. For these reasons it is sufficient to study the characteristic morphology in smears made from gonorrheal pus. Methylene blue or Pappenheim's stain (p. 45) and Gram stains should be made.

Inoculate agar slants from laboratory cultures of Str. pneumoniae and M. zymogenes.

References ( $M$. zymogenes)-

MacCallum and Hastings, Jour. Exper. Med., I899, 4, p. 52 I.

Harris and Longcope, Centralbl. f. Bakt., rgor, 30, Abt. I, p. 353 (printed in English).

Birge, Johns Hopkins Hospital Bull., 1905, 16, p. 309.

I. Routine study.-Note the microscopic appearance of both organisms and the action of $\mathbf{M}$. zymogenes on milk and gelatin.

2. Special study.-The staining of capsules from a milk culture of Str. pneumoniae. Three methods may be applied for this stain:

First method (Friedländer's method) -

I. Prepare a stain by the following formula:

Glacial acetic acid............... I part

Saturated alcoholic solution of gentian violet................. 5 parts

Distilled water............... ro parts

2. Prepare a film in the usual manner from a 24hour-old culture in milk. 
3. Cover with the stain for Io to I 5 seconds.

4. Wash in water.

5. Dry and mount in balsam.

Second method (Welch's method) -

I. Prepare a film from a 24-hour milk culture by smearing a loopful thinly over a coverglass.

2. Cover with glacial acetic acid for $I 5$ to 20 seconds.

3. Wash the acetic acid off with carbol fuchsin.

4. Wash off the stain with 0.8 per cent $\mathrm{NaCl}$ solution.

5. Dry and mount in balsam.

Third method (Rosenow's method) (Jour. Am. Med. Assoc., I9I I, 56, p. 4I8)-

This method is applicable for staining capsules in tissues as well as cultures. If the material is too thick or viscid it must be diluted with a suitable amount of distilled water. Cultures from agar, blood serum, etc., should be mixed on a cover slip with a loopful of serum.

a) Prepare a thin film, and dry in the air.

b) When dry, cover with a 5 to ro per cent solution of tannic acid for Io to 20 seconds.

c) Wash in water and dry with blotting paper.

d) Cover with carbol gentian violet or anilin gentian violet for one-haif to one minute. Carbol gentian violet is prepared by mixing one part.saturated alcoholic solution of Grübler's gentian violet with 4 parts of an aqueous 5 per cent phenol solution.

e) Wash in water.

f) Stain with Gram's iodin solution for one-half to one minute.

g) Decolorize in alcohol. 
h) Stain with a saturated alcoholic (6o per cent) solution of Grüber's eosin.

i) Wash in water and blot.

j) Clear and mount in balsam.

Whichever method is applied, the capsule should appear as a lightly stained zone with a well-defined outline around the deeply stained cell. Capsules are rarely demonstrable unless the organisms are cultivated in media rich in proteins, or are mixed with serum previous to staining.

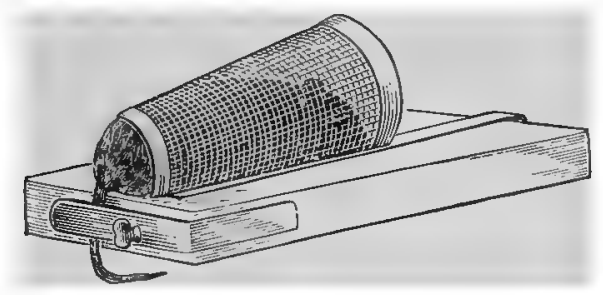

FIG. 32

Mouse Holder

Special study.-Inoculation of a mouse with Str. pneumoniae.

I. Fasten the mouse in the holder (Fig. 32).

2. Shave a place on the back above the tail.

3. Wash with a solution of mercuric chlorid (I: $1,0>0)$, followed by alcohol.

4. Inject 0.2 c.c. of a milk culture of Str. pneumoniae.

5. When dead, perform an autopsy, and study the lesions in the usual manner.

6. Make cultures in milk and on slant agar from the heart's blood or the spleen.

7. Make a capsule stain from the heart's blood, spleen, or other organs. 


\section{SECTION 3}

THE GROUP OF COLON-TYPHOID BACILLI

This chapter is devoted to the study of the group of intestinal organisms. This collective group may conveniently be subdivided into three subgroups:

Subgroup I : the colon group.-This group includes different varieties of Bacillus coli and B. aërogenes.

Subgroup 2: the B. enteritidis group.-This group includes B. suipestifer, B. paratyphosus, B. enteritidis, and B. icteroides. The term "intermediate" is assigned to this group, because it resembles in part the colon group and the typhoid group.

Subgroup 3: the typhoid-dysentery group.-This group includes B. typhosus, varieties of B. dysenteriae, and $\mathbf{B}$. fecalis alkaligenes.

\section{EXERCISE I. STUDY OF SUBGROUP I THE COLON GROUP}

Inoculate agar slants from laboratory cultures of B. coli, B. coli anaërogenes, ${ }^{\mathrm{T}}$ and $\mathrm{B}$. aërogenes. Also inoculate one tube of broth with $\mathbf{B}$. coli for the preparation of sugar-free broth.

\section{References-}

Smith, The Wilder Quarter Century Book, Ithaca, 1893; p. 187.

Smith, Amer. Jour. Med. Sci., I895, N.S. I ro, p. 283.

Rogers, L. A., Clark, W. M., and Davis, B. J., "The Colon Group of Bacteria," Jour. Inf. Dis., I4, p. 4II.

${ }^{2}$ There are many varieties of $B$. coli, distinguished from each other chiefly by their ability to produce gas from various carbohydrates. Most varieties produce gas from dextrose and lactose, some also from saccharose, and a few from dextrose only, while there is one variety, known as $B$, coli anaërogenes, which does not produce gas from any one of the three sugars. 
I. Routine study.-Observe carefully the growth on potato of B. aërogenes. This organism produces an amylolytic enzym, which manifests itself by gas production. Gas bubbles frequently appear in the growth on potato.

2. Special study.-In order to test the action of micro-organisms on various carbohydrates, it is necessary to eliminate the small amount of sugar in ordinary broth introduced into it by meat extract, which generally contains muscle sugar (glycogen). This is accomplished by adding to freshly prepared broth a culture of B. coli, which decomposes many carbohydrates, including muscle sugar. By this method a sugar-free broth is prepared, which may be used as a solvent for any sugar desired.

Preparation of sugar-free broth for the fermentation tube:

I. Dissolve by heat:

Extract of beef................ I. 5 grams

Pepton.................... 5 grams

in 500 c.c. water. Broth made from chopped beef (500 g. to I liter) may also be used for this purpose. One per cent pepton should be dissolved in meat infusion (see p. $3 \mathrm{I}$ ).

2. After cooling, inoculate with a broth culture of B. coli prepared 24 hours previously.

3. Set aside in the thermostat, for $18-24$ hours.

4. Boil 5 minutes (to kill B. coli), and filter repeatedly through the same paper until clear.

5. Adjust the reaction to I per cent acid.

6. Divide into three equal parts and dissolve I per cent dextrose, lactose, and saccharose, respectively, in each part, and filter again, if necessary. 
7. Fill fermentation tubes, taking care to Iabel each one properly, and sterilize in the arnold on 3 consecutive days for 20 minutes or in the autoclave for 5 minutes.

All gas must be carefully tilted out of the closed arm of the tube while the fluid is warm. When sterilization is completed, inoculate one set of the fermentation tubes with B. coli, another set with B. coli anaërogenes, and a third set with $B$. aërogenes. Inoculate with the straight or looped needle.

Directions for measuring gas formation in fermentation tubes and for analyzing the gas are given on p. 8I. The reaction in the closed arm is not always the same as in the bulb. This may be ascertained by adding a small amount of litmus solution by means of a suitably bent glass tube.

3. Special study.-Test for indol and nitrites.

a) Test for nitrites: Add to a culture in Dunham's solution, or, better, in sugar-free broth, successively I drop of each of the following solutions:

(I) Sulphanilic acid.............. 0.5 gram Acetic acid (25 per cent) ........ 150 c.c.

(2) a Naphthylamine chlorid........ $0.1 \mathrm{gram}$

Distilled water.............. 20 c.c.

Acetic acid (25 per cent)......... I50 c.c.

A yellowish-red or rose color shows the presence of nitrites.

b) Test for nitrites and indol combined.

(I) Add to a culture in Dunham's solution, or sugarfree broth, I or 2 drops pure sulphuric acid.

(2) Heat gently. Rose color shows the presence of nitrites and indol. If no reaction takes place, add- 
(3) A few drops of a solution of O.I g. potassium or sodium nitrite in $\mathrm{I}, 000$ c.c. water. Rose color then indicates the presence of indol only.

The appearance of indol red depends on the presence of $\mathrm{NO}_{2}$. This is liberated by sulphuric acid from nitrites, if these are produced by the organism. If nitrites are not produced, a small amount of a nitrite solution is added, which then furnishes the necessary material for production of $\mathrm{NO}_{2}$.

Perform these tests with all the organisms of the intestinal group, and make control tests in sterile Dunham's solution or sugar-free broth.

4. Special study.-Make a capsule stain of $\mathbf{B}$. aërogenes from 24-hour-old milk cultures. (For method see p. Iog.)

The study of B. coli is of special importance in connection with bacteriological analysis of water (see Part IV). The presence of this organism in large numbers indicates sewage contamination, and consequently bacteria such as B. typhosus and B. dysenteriae may be present.

\section{EXERCISE 2. STUDY OF SUBGROUP II}

THE HOG-CHOLERA, B. ENTERITIDIS, OR INTERMEDIATE GROUP

Inoculate agar slants from laboratory cultures of $\mathbf{B}$. suipestifer, B. enteritidis (Gärtner's bacillus), and B. paratyphosus.

References-

B. cholerae suis:

Moore, The Pathology of Infectious Diseases of Animals.

McFarland, Textbook of Bacteriology.

B.paralyphosus:

Buxton, Jour. Med. Res., I902, 7, p. 201. 
Wells and Scott, Jour Infect. Dis., I904, I, p. 72.

Cushing, Johns Hopkins Hospital Bull., 1900, p. I56.

Durham, Jour. of Exper. Med., Igoo-rgor, 5, p. 353.

I. Routine study.-Observe the bluish-green coloration of the cream ring in litmus milk, and make a test for indol in Dunham's solution or sugar-free broth.

2. Special study.-Inoculate plain sterile milk with B. suipestifer. After 8-10 days it will be observed that the milk is becoming transparent, due to a solvent action of the alkali produced by the organism upon the protein content.

3. Special study.--Inoculate fermentation tubes as with B. coli. Measure and analyze the gas. Compare the results with those obtained in the study of the colon group.

4. Special study.-Inoculation of a rabbit subcutaneously with B. suipestifer. Subcutaneous inoculations of rabbits are made in the following manner: An assistant, in a sitting position, places the rabbit back down in his lap. The head projects beyond the knees of the assistant. The ears and hindlegs are grasped, and the animal is thus held in position. The hair is then cut off on a portion of the abdomen, and the place is treated with mercuric chlorid and alcohol. The skin is then pulled up, the syringe inserted, and the material injected.

After the rabbit has died, study the lesions produced by the organism, and make smears from the site of the inoculation, the heart's blood, and other organs. Note the polar staining, i.e., stained portions at the two ends of the cell and an unstained area between. Make cultures on agar from the heart's blood and other internal organs. 
EXERCISE 3. STUDY OF SUBGROUP III THE TYPHOID-DYSENTERY GROUP

Use great care in handling members of this group. Inoculate agar slants from laboratory cultures of B. typhosus, B. dysenteriae (Shiga), and B. fecalis alkaligenes.

I. Routine study.-Study the reaction on milk, and test for indol. Preserve glucose agar cultures for two weeks for the observation of involution forms.

2. Special study.-Inoculate fermentation tubes in the, same manner as in the two preceding groups. Observe the absence of gas formation but note growth or absence of growth in both arms. Compare the results with those of the colon and intermediate groups.

3. Special study. -The staining of flagella.-To demonstrate the presence of flagella on B. typhosus, the following method will give good results (Löffler's method):

a) The mordant:

Tannic acid ( 20 per cent aqueous solution). Io parts

Ferrous sulphate (saturated aqueous solution) $\ldots \ldots \ldots \ldots \ldots \ldots \ldots \ldots \ldots \ldots \ldots \ldots \ldots$ parts

Fuchsin (saturated alcoholic solution).... I part

Add one part I per cent $\mathrm{NaOH}$ solution for each roo parts of stain.

b) 'Prepare several cover slips by flaming them, and place them side by side on a piece of filter paper. (This paper must be burned after using.)

c) Place 4 or 5 loopfuls of water on a clean slide.

d) Make a light suspension in this water of $\mathbf{B}$. typhosus from a 24-hour-old agar culture, taking care to stir the suspension as little as possible.

e) Place a loopful of water on each of the cover slips.

$f$ ) Carry over a loopful of the suspension on the 
slide to one of the cover slips and from this to each of the other cover slips.

g) Allow to dry in the air.

h) Cover with the mordant.

i) Heat over a small flame for $I \frac{1}{2}$ minutes while steam rises, or better, heat on a water bath for 5 minutes. Replace the evaporated mordant to prevent its drying on the cover slip.

j) Wash in water.

k) Drain the water off with blotting paper.

l) Cover with anilin gentian violet or carbol fuchsin.

$m$ ) Heat as before over a small flame for $\mathrm{I} \frac{1}{2}$ minutes, or better, on a water bath for 5 minutes.

$n$ ) Wash in water.

o) Dry and mount in balsam.

4. Special study.- Agglutination. - Dried-blood method of Johnston: A drop of blood of a typhoid fever patient is obtained by pricking the lobe of the ear, previously cleaned and washed with alcohol. The blood is taken up by a piece of sterile non-absorbent paper or on a sterile aluminum slide. This is sent to a laboratory, where the blood is dissolved in physiological salt solution in such a manner as to obtain an approximate dilution of $I: 25$. This solution is then tested with a suspension of typhoid bacilli, a young culture of which is constantly kept on hand for this purpose. A loopful of the diluted blood is mixed with a loopful of the suspension on a cover glass, this making a dilution of $\mathrm{I}: 50$. The cover glass is then inverted over a hollow slide like a hanging drop and observation made after two hours' incubation at $37^{\circ} \mathrm{C}$. For laboratory tests the serum of an animal (either a rabbit or a guineapig) which has been injected with cultures of B. typho- 
sus, previously heated for I hour at $60^{\circ} \mathrm{C}$., is used. This process kills the organisms, but the toxins remain active. The first injection is followed by another one with dead cultures after four to five days, and after the same intermission a culture of virulent bacilli is injected. By this time the agglutinative power of the blood is well developed. The animal is then bled in the following manner: One of the ears is shaved, and the skin is washed with alcohol. A small vein near the border is opened, and the blood is collected in a sterile glass vessel. If the animal is hung head down enough blood can be collected in a short time. The blood is placed in the ice chest, and the serum is collected after separation.

The method of procedure with serum obtained in the above-described manner is as follows:

a) Small quantities of the serum are diluted with sterile salt solution ( 0.85 per cent) so as to represent dilutions of $I: 5, I: 25$, and $I: 50$.

b) A suspension of a 24-hour-old agar culture of $\mathbf{B}$. typhosus in salt solution is prepared. This suspension should be uniform and not heavy. It is desirable to filter the suspension through absorbent cotton or sterile filter paper to remove clumps of bacteria.

c) Three hanging-drop preparations are made by mixing a loopful of this suspension with a loopful of the three serum dilutions, respectively. The final dilutions then are: I: IO, I: 50, and $I: I 00$.

d) Examine with the high power (dry lens), and observe the clumping of the bacilli, preceded by the loss of motility.

e) Tabulate the results as to time and completeness of reaction. 
f) Make a control hanging drop without serum to test the motility and the absence of clumps.

g) When the clumping is completed allow the drop to dry in the air without stirring or spreading, fix in the flame, or better with absolute alcohol, and stain with gentian violet. A permanent preparation can be obtained in this manner, showing the agglutinated bacteria.

Blood may also be obtained by puncturing the lobe of the ear and collecting the blood in a capillary glass tube with a small bulb. Hold the bulb down, fill three-fourths with blood, and seal the ends in the flame. In 45 minutes the serum will have separated, and may be tested.

The above-described method of an agglutination test is known as the microscopic test. Another method, in which larger amounts of serum and suspension are required, is known as the macroscopic method. Small test tubes are used, and. definite amounts of bazterial suspensions are introduced. by means of graduated pipettes. The serum is then added in varying amounts so as to effect the desired dilutions (see table in appendix, p. 197). The tubes are then incubated at $37^{\circ} \mathrm{C}$., usually for 2 hours. After this they are placed in an ice chest for sedimentation. If complete agglutination has taken place, the bacteria will have collected in clumps at the bottom, forming a sediment. The supernatant fluid is clear. By varying amounts of sediment and varying degrees of turbidity of the supernatant fluid, the degree of agglutination may be estimated. A control tube of a bacterial suspension without addition of serum serves as a guide. Controls with normal serum should also be made. 
5. Special study.-Make cover-slip preparations of B. dysenteriae from glucose agar cultures IO-I2 days old. Involution forms are then plentiful and can be studied.

\section{SECTION 4}

THE PROTEUS GROUP

Inoculate agar slants from laboratory cultures of Bacillus proteus, Proteus zenkeri, and Bacillus cloacae.

I. Routine study.-Observe the action on milk and gelatin.

2. Special study.-Make plates in gelatin and agar, and observe the colonies after 24,48 , and 72 hours. Note the appearance of the colonies of $\mathbf{B}$. proteus and of Prot. zenkeri on both media.

3. Special study.-Inoculate fermentation tubes and determine the percentage of gas formed and the gas formula. Compare the results with those of the intestinal bacteria.

Note.--In order to obtain a clear picture of the differential characteristics of the three groups of colon-typhoid bacilli and the proteus group, it is recommended to tabulate the results in columns, as outlined below. Express positive results by the sign +; negative, by -. Complete agglutination is expressed by ++ ; slight, by + . 
122 LABORATORY GUIDE IN BACTERIOLOGY

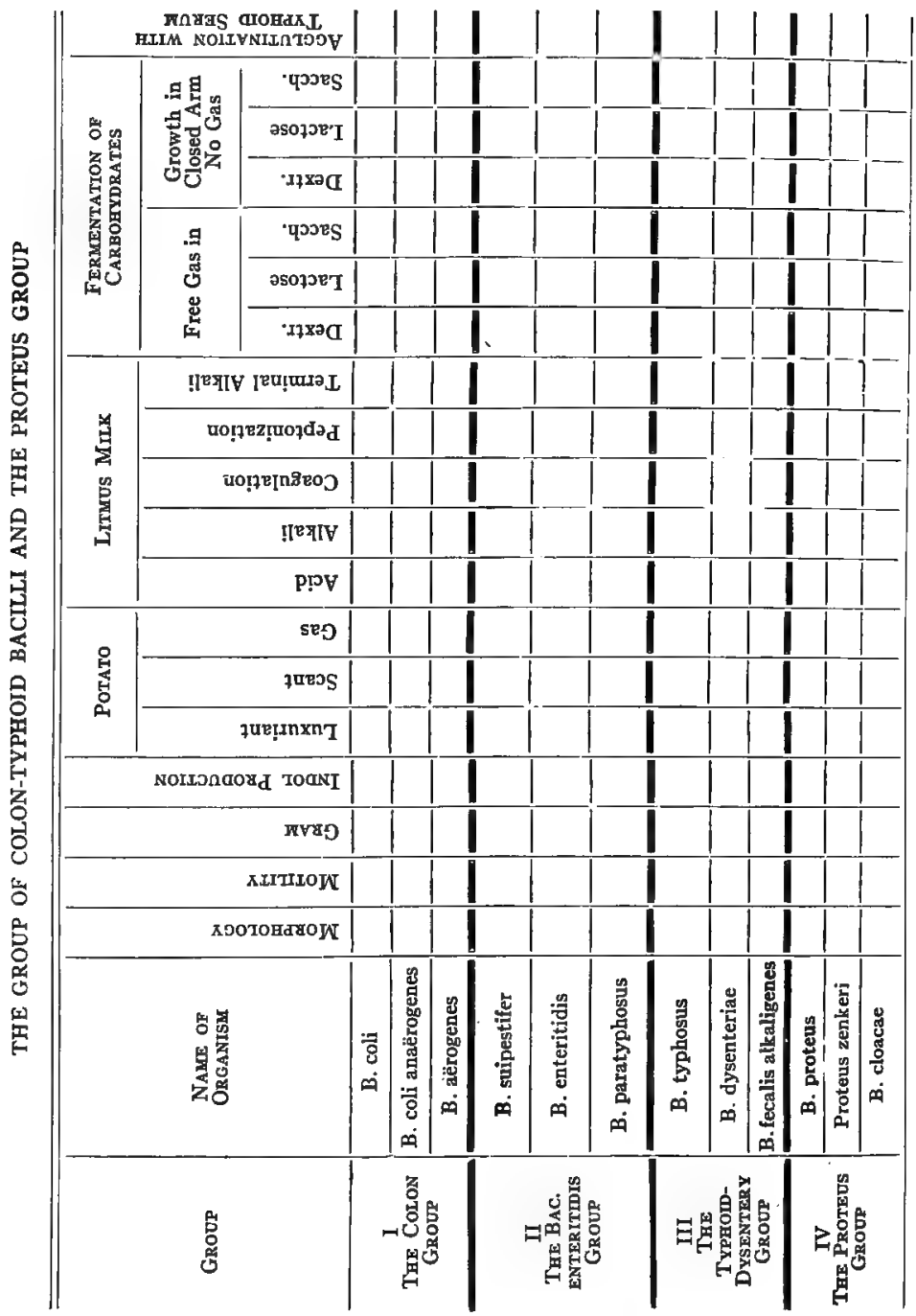




\section{SECTION 5 \\ THE CAPSULATED GROUP}

Members-

Bacillus capsulatus.

B. thinoscleromatis.

Reference-

Perkins, Jour. Infect. Dis., rgo4, I, p. 24 I.

Inoculate agar slants from laboratory cultures of B. capsulatus (Friedländer's pneumo-bacillus) and B. rhinoscleromatis.

I. Routine study.-Observe the viscous condition of cultures on solid media, the consistency of liquid media, and the gas formation on potato.

2. Special study.-Staining of capsules from 24hour-old milk cultures (see p. rog).

3. Special study.-Intraperitoneal inoculation of a rabbit with B. capsulatus.

Method of intraperitoneal inoculation. - The rabbit is held in the same manner as described on p. Io6. The hair is clipped close over the left lower abdominal quadrant. Then (after washing with mercuric chlorid I : I, , oo and alcohol) pass the needle at first beneath the skin, then, holding it at about a right angle to the abdominal surface, push it through the abdominal wall, which is usually made tense by the resistance of the animal. Successful passage of the abdominal wall can be felt by the sudden loss of resistance to the needle's pressure. Then make the injection, and withdraw the syringe. If the contents of the needle have been emptied into the peritoneal cavity, no swelling takes 
place, as is noticed in subcutaneous inoculations. Care is necessary not to puncture the intestines.

When the animal has died, perform an autopsy and study the lesions. Make cultures from the heart and internal organs in the usual manner, and make capsule stains from the heart's blood.

\section{SECTION 6}

\section{THE DIPHTHERIA GROUP}

Members-

Bacillus diphtheriae.

B. hofmannii.

B. xerosis.

Use great caution in handling B. diphtheriae.

Inoculate agar slants from laboratory cultures of B. diphtheriae and B. hofmannii.

I. Routine study.-Stain B. diphtheriae with Löffler's methylene blue instead of gentian violet. The staining may be facilitated by the application of mild heat. Observe the darkly stained granules and make sketches of some of the bacilli.

2. Special study.-

Neisser's Granule Stain (Gin's Modification)-

I. 5 per cent alcoholic solution. Methylene blue (Grübler)............ 20 c.c. 5 per cent glacial acetic acid...... r,000 c.c.

2. 1o per cent alcoholic solution. Crystal violet (Höchst) ............. I0 c.c. Distilled water............. 300 c.c.

Two parts of I with one part of 2 ; call solution $a$. $b$. Acid lactic.................. I c.c. Lugol's solution............... 99 c.c.

c. Chrysoidin (I gram in hot water).... 300 c.c. 
Stain film for 2 seconds with solution $a$ and wash. Apply solution $b$ for 3 to 5 seconds and wash well. Apply solution $c$ for 3 to 5 seconds, wash, dry, mount.

3. Special study.-Test for acid formation in a culture, in neutral glucose broth, one week old, by addition of a few drops of litmus solution, or by titration with $\mathrm{N}_{\frac{1}{2} \sigma} \mathrm{NaOH}$ solution.

4. Special study.-Cultivation of B. diphtheriae on eggs (method of Wyatt Johnston).

Note. - This method is recommended as an emergency culture test, the egg taking the place of Löfler's blood serum.

a) Sterilize over the flame an empty meat extract pot, or any other vessel of suitable size.

b) Wash a hard-boiled egg in mercuric chlorid solution, followed by alcohol, and break the shell at the blunt end with sterile forceps, without rupturing the membrane lining the shell.

c) Flame the exposed part, and free the coagulated albumen from the membrane.

d) Inoculate by rubbing some culture or throat swab on the exposed egg-albumen.

e) Invert and set in the sterilized pot.

f) Incubate at $37^{\circ} \mathrm{C}$.

g) Observe the appearance and make a stained preparation after 24 hours.

\section{Special study-}

\section{Experiment I-}

a) Clip the hair over a small area on the surface of the abdomen of a guinea-pig or rabbit.

b) Cut a small opening in the skin, and separate the skin from the muscles below by pushing in sterile 
scissors. Expand these slightly and after closing remove. This forms a small pocket.

c) Carry I loopful of a 24-hour-old agar culture into this pocket.

Experiment 2-

a) Heat a 24-hour-old broth culture in the water bath for 30 minutes at $60^{\circ} \mathrm{C}$.

b) Inject 0.25 c.c. of this heated culture subcutaneously into another guinea-pig (or rabbit).

Observe and compare in both animals the results by taking note of the ante-mortem phenomena and the lesions post-mortem.

\section{Experiment 3-}

Prepare two guinea-pigs and inject subcutaneously into one a lethal dose of diphtheria toxin and into the other the same amount of toxin neutralized with a sufficient amount of antitoxin. Compare the results in the two guinea-pigs.

6. Demonstration of methods employed in municipal laboratories for the diagnosis of diphtheria.

7. Study of B. xerosis. Obtain mucus from the inner angle of the eyelids by stroking with a platinum loop. Make two film preparations, stain one by Gram's method and the other with methylene blue. Make a culture on slant agar and if impure, plate out. Transfer cultures to all media from colonies on the plate and study these in the usual manner. 


\section{SECTION 7}

\section{THE HEMORRHAGIC SEPTICEMIA GROUP}

Members-

Bacillus pestis (bacillus of bubonic plague).

$B$. cuniculicida (bacillus of fowl cholera, bacillus of rabbit septicemia, Bacillus der Rinderseuche, Bacillus der Schweineseuche, etc.).

Reference-

Moore, The Pathology of Infectious Diseases of Animals.

Inoculate agar slants from a laboratory culture of B. cuniculicida or another organism of this group. On account of the enormous infectiousness of $\mathbf{B}$. pestis it is not desirable to study this organism in classwork.

I. Routine study.-Stain with Löffler's methylene blue and anilin gentian violet. Observe "polar staining."

2. Special study.-Inoculation of a rabbit subcutaneously or by scarification. When dead, study in the usual manner, and observe the hemorrhages produced in the serous membranes. Make cultures from the heart's blood, where large numbers of bacilli will be found. Also make a stained preparation from the heart's blood, and note the typical polar staining.

\section{SECTION 8}

THE ANTHRAX GROUP

Members-

Bacillus anthracis.

B. subtilis.

Great caution is necessary in handling B. anthracis. Inoculate agar slants from laboratory cultures of B. anthracis and B. subtilis. 
I. Routine study.-Observe the colonies formed on agar plates. Also prepare gelatin plates and study the colonies.

2. Special study.-Make an "impression prepara tion" (Klatschpräparat) from a surface colony on a gelatin plate.

Method-

a) Clean and flame a cover slip.

b) Place on a colony of suitable size, and gently press down, taking care not to press so hard as to disturb the characteristic shape of the colony.

c) Lift the cover slip with the forceps.

d) Dry, fix, and stain with methylene blue or by Gram's method.

e) Examine under low and high power (dry lens).

3. Special study.-Staining of spores.

Möller's method:

a) Prepare several (five or six) films from agar or potato cultures of B. anthracis (or B. subtilis).

b) Place in chloroform for 2 minutes.

c) After drying in the air, cover with a 5 per cent solution of chromic acid for 2 minutes.

d) Wash in water.

e) Cover with carbol fuchsin and heat for 5 minutes on a water bath, or over a small flame.

f) Decolorize with I per cent sulphuric acid for $25^{-}$ 30 seconds.

g) Wash in water.

h) Counterstain with methylene blue for Io-I5 seconds without heat.

i) Wash, dry, and mount in balsam.

Note.-The body of the cell should appear blue; the spore, red. 
4. Special study.-Demonstration of filament formation.

a) Spread a loopful of a broth culture of $\mathbf{B}$. anthracis or B. subtilis on a cover glass.

b) Dry and fix in the flame.

c) Cover with strong acetic acid ( 80 per cent) for 5-Io seconds.

d) Wash in water.

e) Stain with gentian violet.

f) Wash in water, dry, and mount in balsam.

.5. Special study.-Inoculate a guinea-pig subcutaneously with 0.2 c.c. of a 24 -hour-old broth culture of B. anthracis, or insert a loopful of a 24-hour-old agar culture in a "pocket" under the skin. When the animal is dead, perform an autopsy, and observe the hemorrhagic and gelatinous edema under the skin; also the enlarged spleen and the hemorrhagic adrenals. Make a stained preparation from the heart's blood, and observe the lack of spores, and also the presence of capsules and degenerate forms, which do not stain well. Make a culture on agar from the heart's blood or from the spleen and study the culture in the ușual manner.

\section{SECTION 9}

\section{THE SPIRILLUM GROUP}

Members-

Spirillum of Finkler and Prior.

Sp. metchnikovii.

Sp. tyrogenum.

And a number of spirilla indigenous to water.

Inoculate agar slants from laboratory cultures of Sp. of Finkler and Prior, and Sp. metchnikovii. The spirillum of Asiatic cholera is studied in Section I IB. 
I. Routine study.-In addition to the usual media, inoculate an extra tube of Dunham's pepton solution from each organism. Observe from day to day the action of these two organisms on gelatin, and compare the results by tabulation. Observe the formation of coccoid involution forms on agar after 3 days. Also make plates in gelatin, observe the colonies from day to day, and compare.

2. Special study.-Test for the nitroso-indol or cholera-red reaction. (See test for indol, p. II4.) Make two tests, using one of the cultures in Dunham's solution after 24 hours, the other after 6 days. Compare the results of these two tests.

3. Special study.-Stain for flagella by Löffler's method (see p. II7).

4. Special study.-Schottelius' enriching method, designed to demonstrate the presence of spirilla in water.

a) Prepare a solution of 2 grams Witte's pepton and 0.5 gram sodium chlorid in roo c.c. of water.

b) Distribute in three small Erlenmeyer flasks, and sterilize in the autoclave.

c) Inoculate one of these flasks with Sp. metchnikovii and B. suipestifer or any other motile bacillus.

d) Incubate at $37^{\circ} \mathrm{C}$. for $18-24$ hours.

e) After that time, take one loopful from the surface, inoculate the second flask, and incubate as before. Also make a stained preparation from the surface of the solution.

- f) After I8-24 hours, make a stained preparation from the surface of the second flask, and examine for spirilla. 
g) Transfer a loopful from the surface of the second flask to the third one, and incubate as before.

h) After 18-24 hours, again stain and examine for spirilla. By this time a film has formed which contains the spirilla practically in pure culture.

5. Special study. - Inoculate a pigeon intramuscu. larly with 0.5 c.c. of a broth culture of Sp. metchnikovii. The breast of the pigeon is laid bare, washed with mercuric chlorid and alcohol, and the syringe plunged into the muscle fibers and discharged. After death, note the peculiar appearance, resembling that of boiled beef. Make stained preparations from the blood and muscle juice, and examine for spirilla.

\section{SECTION Io}

THE GROUP OF ACID-PROOF BACILLI

\section{Members-}

Bacillus tuberculosis.

B. leprae.

B. smegmae.

Möller's grass bacillus, and a number of bacilli found on grass, dung, in butter, milk, etc.

Cultural studies of $\mathbf{B}$. tuberculosis consume a great deal of time and are, therefore, impracticable in an elementary course.

For comparison, the culture characteristics of Möller's grass bacillus are instructive.

Inoculate an agar slant from a laboratory culture of Möller's grass bacillus.

r. Routine study. 
2. Special study.-Method of staining acid-proof bacilli.

a) Pick out purulent matter from the sputum of a tuberculous patient and spread carefully on a cover glass.

b) Dry and fix as usual.

c) Heat with carbol fuchsin over a small flame for one minute or on a water bath for two minutes.

d) Decolorize with acid alcohol ( 2 per cent $\mathrm{HCl}$ in 80 per cent alcohol) until the film has lost almost all its color.

e) Wash in water and counterstain with methylene blue for Io seconds (cold).

f) Wash again and mount in balsam.

NoтE.-Make a second preparation, substituting anilin gentian violet for carbol fuchsin, and Bismarck brown for methylene blue.

3. Special study.--Stain Möller's grass bacillus from an agar culture by the same method, omitting the counterstain.

4. Special study.-Make a smear from a culture of Möller's grass bacillus in milk and stain this smear for acid-proof bacilli.

\section{SECTION IIA}

MISCELLANEOUS ORGANISMS: BACILLUS MALLEI, BACILLUS MELITENSES, BLASTOMYCES DERMATITIDIS

B. mallei has been the cause of more accidents among bacteriologists than any other organism, and it is therefore not prudent to study this organism in the laboratory unless there is thorough supervision. 
The virulence of $\mathbf{B}$. mallei seems not to diminish in laboratory cultures, and careless handling may affect all those who are engaged in work in the same place. Those who desire to study this organism will find directions in the following section.

Inoculate agar slants from laboratory cultures of B. melitensis and Blastomyces dermatitidis.

Carry these cultures through the usual routine.

\section{SECTION IIB}

In this section the following organisms have been included: Spirillum cholerae, Bacillus mallei, Bacillus influenzae, Micrococcus meningitidis (meningococcus).

A separate section has been devoted to these organisms so as to enable the instructor to omit them if he deems it advisable. The Sp. cholerae and B. mallei are dangerous organisms to be manipulated by elementary students, and unless there is sufficient supervision accidents of grave consequences are liable to happen. The Sp. cholerae may be studied in the usual routine manner and the test for the so-called cholera-red reaction (indol reaction) and Schottelius enriching method (see p. I30) added. B. mallei should also be studied in the usual manner and a demonstration of its infectiousness made on guinea-pigs.

B. influenzae requires special media for study, blood agar being the most suitable. The meningococcus grows to some extent on ordinary media. Stains with methylene blue and according to Gram's method " are instructive, showing the resemblance of this organism to the gonococcus. 


\section{SECTION 12}

\section{PATHOGENIC TRICHOMYCETES}

\section{Members-}

Actinomyces bovis (hominis) and Actin. asteroides.

Leptothrix.

Cladothrix.

Nocardia.

I. Inoculate broth and potato from laboratory cultures, and make descriptions and stained preparations as usual. Other media need not be inoculated.

2. Special study.--Suspend a small amount of the potato culture in physiological salt solution, and examine under the low power.

3. Special study.-Examine a sample of actinomycotic tissue (bovine) in the fresh state, for so-called "sulphur granules." Crush some of the material in salt solution under cover slips and search for "clubs," using the low and high power dry lenses, and stain by Gram's method; counterstain with eosin or Bismarck brown.

\section{SECTION I3}

THE GROUP OF ANA ËROBIC BACILLI

Members-

Bacillus tetani.

B. edematis.

B. welchii.

B. chauvei.

$B$. botulinus.

And others.

Anaërobic cultivation involves the growth in an atmosphere devoid of oxygen. This is accomplished by removing the oxygen from air by chemicals, or 
consuming the oxygen by burning paper, or by substituting hydrogen gas for air. The following methods are most commonly in use.

I. Park's method.

a) Boil three tubes of dextrose agar vigorously for 5 minutes, to drive out the dissolved oxygen.

b) Cool to $43^{\circ} \mathrm{C}$. and inoculate from laboratory cultures of B. tetani, B. edematis, and B. welchii.

c) Solidify rapidly by immersion in cold water.

d) Cover the medium with a thin layer of liquid paraffin or sterilized mineral oil.

e) Incubate at $37^{\circ} \mathrm{C}$.

NotF.-The layer of paraffin or oil excludes atmospheric oxygen which is inhibitory to the growth of anaërobes. The oxygen necessary for their multiplication is derived from carbohydrates in the medium.

2. Wright's modification of Buchner's method.

a) Liquefy, as before, six dextrose agar tubes, plugged with absorbent cotton. Cool three to $43^{\circ} \mathrm{C}$. and inoculate while fluid. Let the other three become solid, and make stab cultures.

b) Sterilize the cotton stoppers in a flame, and with the forceps, sterilized in a flame, push the stoppers into the test tubes for the distance of about $\mathrm{I}$ inch $(2-3 \mathrm{~cm}$.).

c) Pour into the tubes (upon the cotton stoppersy 2 c.c. of a saturated solution of pyrogallic acid in water, followed by 2 c.c. of a 2 per cent solution of $\mathrm{NaOH}$.

d) Cork the tubes immediately with rubber stoppers, and keep upside down.

e) Incubate at the required temperature. Pyrogallic acid in alkaline solution absorbs oxygen, leaving the cultures in an atmosphere of nitrogen. 
3. Cultivation by Buchner's method, using fruit jars.

a) In a Mason fruit jar of ordinary type deposit Io g. of pyrogallic acid.

b) Smear vaselin around the mouth of the jar.

c) Pour into the jar roo c.c. of a I per cent solution of $\mathrm{NaOH}$.

d) Deposit in the jar culture tubes previously inoculated.

e) Fasten the cover of the jar, and incubate at $37^{\circ} \mathrm{C}$. for $48-72$ hours.

4. Cultivation in hydrogen gas.

a) Inoculate all media from laboratory cultures.

b) Fit up apparatus as shown in Fig. 33 .

c) Place culture tubes in a Novy jar (Fig. 33,a).

$d$ ) Open the faucet $(b)$ of the gas generator $(c)$, containing zinc and hydrochloric acid. The hydrogen gas generated is purified by passing through two jars, one of which contains concentrated sulphuric acid $(d)$, the other a ro per cent solution of sodium hydrate $(e)$. Gradually the Novy jar is filled with hydrogen gas, which can be ascertained by holding a culture tube over the opening $(f)$ and then over a burning match or gas flame. As long as a detonation takes place the hydrogen is mixed with atmospheric oxygen. When the hydrogen in the Novy jar is pure, close it off by turning the stoppers $(g)$ and $(b)$, and place the jar in the incubator. The whole process occupies Io or 15 minutes.

5. A simple and effective method of anaërobic cultivation is as follows: Culture tubes, after inoculation, are placed in a desiccation jar or any other jar with 
tight-fitting cover. Vaselin is smeared on the top of the jar to insure a tight fit of the cover. A small piece of absorbent paper wetted with a few drops of alcohol is placed inside of the jar, the paper is lighted, and the cover replaced. The burning paper absorbs the oxygen, leaving the cultures in an atmosphere of nitrogen.

When growth has been obtained by any of the above methods, transfers should be made to milk, and gentian

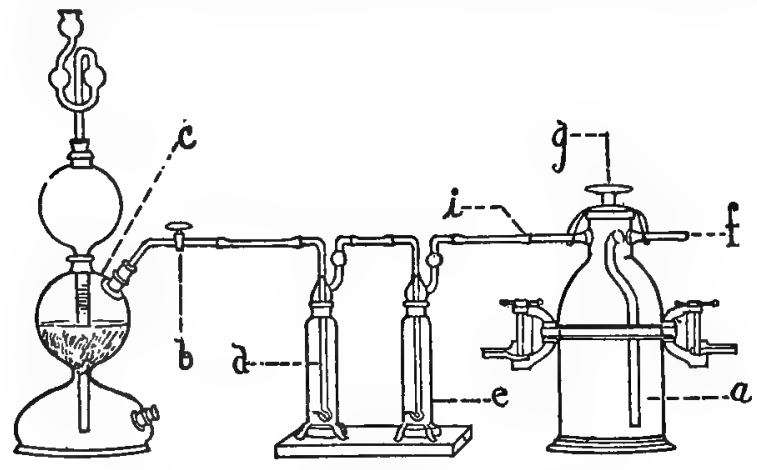

FIG. 33

Anaërobic Cultivation in Hydrogen Gas
a. Novy jar
e. Sodium hydrate solution
b. Glass cock
f. Opening of Novy jar
c. Gas generator
g. Stopper

d. Sulphuric acid

violet and Gram stains prepared. Motility should be determined by preparing a hanging drop. Anaërobic bacteria in a hanging drop will concentrate toward the center of the drop away from the oxygen of the air.

6. Special study.-Inoculation of a rabbit with B. welchii.

a) Shave the ear of the rabbit.

b) Wash with mercuric chlorid solution and alcohol. 
c) Inoculate intravenously with 0.5 c.c. of a 24 hour-old milk culture of $\mathbf{B}$. welchii.

d) After the culture has been distributed in the circulation, which takes at the most 3 minutes, kill the rabbit by a blow on the back of the neck.

e) Put the rabbit in a warm place--on top of the thermostat-for I 8 hours, or from 6 to 8 hours inside of the thermostat.

f) After this time has elapsed, perform an autopsy. Note the crackling, on pressure, over the axillary or inguinal regions. The rabbit is swollen to a great extent. Skin the animal, without opening the abdominal cavity; then quickly puncture the abdominal wall and bring a flame to the opening. Note that the escaping gas will burn with a blue flame. Also note the disorganized condition of the liver, spleen, and kidney.

g) Make capsule stains from the heart's blood or organs by Welch's method (modified). The modification of Welch's method is as follows: Proceed in the manner indicated on p. IIO, and, after washing the acetic acid off with the stain (carbol fuchsin or gentian violet), dry with filter paper and heat the specimen for 5 to Io seconds before washing. Then proceed as before.

7. Special study.-Staining of spores of B. tetani and B. edematis from 3-day-old glucose agar cultures (see p. I 28).

8. Special study.-Inoculation of a white mouse or guinea-pig with B. tetani or its toxin (0.oI c.c.) in the hind-leg or over the root of the tail (if a mouse). Note daily the condition of the animal, and when dead 
make cultures and cover-slip preparations from the site of the inoculation.

9. Special study. - Inoculate a white rat with garden earth subcutaneously or in a pocket above the root of the tail. Note the condition of the animal daily. When dead, make cultures and cover-slip preparations from the site of the inoculation.

\section{SECTION I4}

ISOLATION OF UNKNOWN BACTERIA FROM A MIXTURE

I. Make hanging-drop, stained, and Gram preparations from the mixture. Note observations and results.

2. Melt five or six agar tubes, and cool to $43^{\circ} \mathrm{C}$.

3. Transfer 5 or 6 loopfuls of the mixture to a tube of liquid agar, from this to a second, and so on until all the melted tubes are inoculated.

4. Pour into sterile petri dishes, and mark them with successive numbers and the date. Place in the thermostat at $37^{\circ} \mathrm{C}$.

5. After 24 hours examine the colonies under the low power, describe them in the usual manner, and transfer to agar slants all those which appear different.

6. Transfer to dextrose agar and litmus milk and incubate at $37^{\circ} \mathrm{C}$. for 24 hours. Retain dissimilar cultures and proceed with the usual routine study. Make hanging-drop, stained, and Gram preparations, transfer to all media, describe the culture characteristics, and make sketches.

7. Special tests may become necessary after 24 or 48 hours. Such tests may consist of- 
I40 LABORATORY GUIDE IN BACTERIOLOGY

Capsule stain.

Spore stain.

Stain for acid-proof bacilli.

Fermentation tests of all those which produce gas in dextrose agar.

Test for acid in neutral broth.

Test for agglutination.

Test for indol.

Anaërobic cultivation.

Inoculation of animals.

For final diagnoses the systematic works of Migula, Matzuschita, and Chester should be consulted. 


\section{PART IV}

THE BACTERIOLOGICAL EXAMINATION OF WATER AND SEWAGE 



\section{INTRODUCTORY}

This work is designed to follow the physical, chemical, and microscopic examination of water. The physical examination usually applies to odor, color, and turbidity. The chemical examination determines the oxygen consumed, dissolved oxygen, free and albuminoid ammonia, nitrites, nitrates chlorin, and hardness. The microscopic examination refers to algae, protozoa, etc. Many factors influence the results obtained by any of these examinations, and in order to gain a clear insight into existing conditions judgment on the quality of water should not be passed unless all these examinations and a bacteriological examination have been completed.

References-

Savage, The Bacteriological Examination of Water Supplies, London, 1906.

Horrocks, The Bacteriological Examination of Water, London, Igor.

Prescott and Winslow, Elements of Water Bacteriology, New York, I9 14 .

Ohlmüller and Spitta, Die Untersuchung and Beurteilung des Wassers und Abroassers, Berlin, тgго.

Kinnicut, Winslow, and Pratt, Sewage Disposal, New York, Igro.

Hazen, The Filtration of Public Water Works, New York, Igoo.

Standard Methods for the Examination of Water and Sewage. American Public Health Association, 755 Boylston Street, Boston, Mass.

Bacteriological Standards for Drinking Water. Reprint No. $23^{2}$ from the Public Health Reports, I9I4, Washington, D.C., Government Printing Office, 1914. 


\section{I44 LABORATORY GUIDE IN BACTERIOLOGY}

Whipple, The Microscopy of Drinking Water, New York, John Wiley \& Sons, I9I4.

Jackson, Biological Studies by the Pupils of W. T. Sedgrick, I906, p. 292.

Fuller and Johnson, Jour. Exper. Med., I899, 4, p. 61о.

Don, Chisholm, Modern Methods of Water Purification, London, IgII.

Apparatus needed in addition to the list given on p 5 .

Two hundred culture tubes.

Four wire baskets.

Twenty fermentation tubes.

Twelve Erlenmeyer flasks, about I50 c.c. each.

Six wide-mouth glass-stoppered bottles of about i 25 c.c. capacity.

Twenty petri dishes.

Twenty-five I c.c. pipettes.

Ten ro c.c. pipettes.

\section{SECTION I \\ PREPARATION OF CULTURE MEDIA AND OF DILU- TION FLASKS}

Dextrose or lactose agar-50 tubes. Thirty-five tubes should contain ro c.c. of agar for plating; the others about 7 c.c.

Nutrient gelatin-20 tubes. This gelatin should contain I2 per cent gelatin. This percentage is reduced to Io per cent after the contents of a tube has been mixed with the litmus solution and the water used for plating if ro c.c. gelatin are filled into each tube.

Litmus solution-20 tubes.

Lactose bile fermentation tubes-30. 
Dilution flasks, filled with roo c.c. filtered tap water or better I00 c.c. 0.8 per cent $\mathrm{NaCl}$ solution. After sterilization in the autoclave these flasks are assumed to contain 99 c.c. each.

Sugar-free meat infusion broth in bulk for fermentation tubes and in tubes- 20 .

In addition to these media the media listed on p. I05 should be prepared.

The reaction of all media should be adjusted to I per cent acid to phenolphthaleïn.

\section{SECTION 2}

\section{BACTERIOLOGICAL EXAMINATION OF WATER}

EXERCISE I. COLLECTION OF SAMPLES

I. Tie a piece of filter paper or lead foil over 6 glassstoppered bottles of about 125 c.c. capacity. Sterilize these in the hot-air oven for one hour at $160^{\circ} \mathrm{C}$.

2. Before taking the sample from surface waters remove the paper cap, dip the bottle about $\mathrm{I} 2$ inches below the surface, remove the stopper under water, replace the stopper as soon as the bottle is filled, wipe dry with a clean cloth or absorbent cotton, and replace the paper cap.

-3. Pack the samples in ice in a suitable container. They should be kept on ice until ready for examination either in the laboratory or in the field.

4. Samples from pumps should be collected after several pails of water have been wasted.

5. Samples from hydrants should be taken after the water has been running freely for at least I5 minutes. 
EXERCISE 2. EXAMINATION OF SURFACE WATERS

I. Secure three samples of surface waters from different sources.

2. Shake the samples and prepare dilutions.

Dilution I. I: Io; remove ro c.c. from a dilution flask containing 100 c.c. sterile water, and replace these ro c.c. by ro c.c. of the sample.

Dilution 2. I: roo; add I c.c. of the sample to a dilution flask.

Dilution 3. I : I,ooo; add I c.c. of the dilution I : Io to another dilution flask.

3. Melt a number of dextrose or lactose agar tubes in a water bath and cool to $43^{\circ} \mathrm{C}$.

4. Place I c.c. of sterile litmus solution on each of I2 petri dishes.

5. Place I c.c. of the sample and I c.c. of each dilution on the same petri dishes.

6. Pour the contents of a tube of the liquefied agar on each of the petri dishes and mix.

7. After the agar has solidified incubate at $37^{\circ} \mathrm{C}$.

NoTE.-If working in pairs, it will be instructive to have one student incubate the agar plates at $37^{\circ} \mathrm{C}$., and the other student at room temperature. The period of incubation at $37^{\circ} \mathrm{C}$. is 48 hours, at room temperature 72 hours. It is also instructive to plate the same samples and dilutions in gelatin, incubating these at $20^{\circ} \mathrm{C}$. for 48 hours, and comparing the number of colonics with those appearing on agar.

8. After the plates have been removed from the incubator count the colonies, using a colony counter. Make differential counts of acid-forming colonies, recognized by the reddening of the litmus, and nonacid-forming colonies. 
EXERCISE 3. QUALITATIVE AND QUANTITATIVE DETERMINATION OF B. COLI AND STREPTOCOCCI

I. Take one sample and inoculate ro fermentation tubes, containing dextrose or lactose broth, each with I c.c. of the sample. Similarly inoculate ro fermentation tubes with I c.c. of each of the dilutions.

Note.-This experiment requires 40 fermentation tubes and may be divided among several students. This same experiment should be repeated with lactose bile in place of dextrose or lactose broth and the results compared.

2. Incubate the fermentation tubes at $37^{\circ} \mathrm{C}$.

3. Measure the amount of gas in the closed arm after 24 hours and replace in the thermostat.

4. Measure the gas again after 48 hours and determine the composition. See p. 8r for directions.

5. Make smears of each tube and apply Gram's stain to determine the presence of streptococci.

6. Calculate the number of B. coli and streptococci present according to the formula given on p. 86. Substitute the number of tubes containing streptococci for the letter $\mathrm{N}$ in the formula to determine the number of streptococci.

Nore.-Each fermentation tube containing gas in the closed arm shows the presence of $B$. coli. On the assumption that at least one of the organisms is present in the tube the approximate number in I c.c. of water is calculated.

\section{EXERCISE 4. EXAMINATION OF WELL WATERS}

Secure three samples of well water, make dilutions of $\mathrm{I}$ : Io and $\mathrm{I}: 100$ and examine in the same manner as directed in Exercises 2 and 3. Compare the results with those obtained in Exercise 3. 
EXERCISE 5. EXAMINATION OF RAIN WATER, SNCW, AND ICE

Secure samples of rain water or snow, and of ice. Examine these samples, making dilutions up to $I: 1,000$ in the manner directed.

\section{SECTION 3 \\ EXAMINATION OF SEWAGE}

I. Secure two samples of sewage. Place one of these in an ice chest. Examine the other sample in the same manner as directed for water, with this

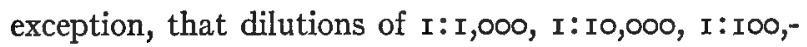
$\infty, 0$, and $I: I, 000,000$ are to be used for plating and inoculation of fermentation tubes, omitting the lower dilutions.

2. Keep the first sample of sewage in your locker.

3. After seven days examine both samples, i.e., the one kept in the locker and the one kept in the ice chest, in the same manner as the fresh sewage was examined. Note the difference in the results of this examination as compared to that of fresh sewage.

4. Replace the samples in the locker and ice chest and examine again after seven and after 14 days.

NotE.-If possible a chemical examination for free and albuminoid ammonia and for nitrites and nitrates should be made simultaneously with the bacteriological examination. This will help to give a clear understanding of the changes which have taken place during the three weeks. 


\section{SECTION 4}

DETERMINATION OF ANAËROBES IN SEWAGE

I. Prepare dilutions of sewage, I:I00, I:I,000, and $\mathrm{I}: \mathrm{ro}, 000$.

2. Inoculate a series of ro litmus milk tubes for each dilution with $\mathrm{I}$ c.c. of each dilution.

3. Heat these tubes in a water bath at $80^{\circ} \mathrm{C}$. for I5 minutes.

4. Incubate at $37^{\circ} \mathrm{C}$. for $4^{8}$ hours, in an anaërobic jar (see p. 137).

5. Determine the number of anaërobes present.

NorE.-Heating the tubes at $80^{\circ} \mathrm{C}$. kills all vegetative forms of bacteria, leaving only the spores alive. These develop the thermostat and their presence is recognized by violent gas formation and breaking-up of the milk curd. The number of anaërobes is determined by the same formula as the number of $B$. coli, substituting the number of milk tubes showing growth of anaërobes for the letter $\mathrm{N}$ in the formula.

\section{SECTION 5}

\section{STUDY OF B. COLI AND STREPTOCOCCI}

Isolate colonies of B. coli and Streptococcus by plating from the fermentation tubes in lactose litmus agar. Carry the two organisms through all the media and determine whether their characteristics are typical according to the rules laid down in the Committee Report of the American Public Health Association. If they are not typical, they must be rejuvenated according to Fuller and Johnson's method. This 
consists in transferring the cultures for three consecutive days in broth and incubating at $20^{\circ} \mathrm{C}$. From the third transfer they are plated in gelatin and a colony from this transferred to slant agar, from which subcultures are made.

\section{SECTION 6}

\section{ISOLATION OF B. TYPHOSUS FROM WATER}

I. Prepare ro tubes each of Endo's medium, Drigalski and Conradi's medium, aesc. bile-salt agar (p. 33).

2. Prepare plates from water containing $\mathbf{B}$. typhosus from both of these media.

3. Incubate at $37^{\circ} \mathrm{C}$. for 24 hours and isolate the colonies.

4. Carry the colonies through all media and apply the agglutination test with typhoid immune serum.

\section{SECTION 7}

STUDY OF REACTION OF BACTERIA ON NEUTRALRED BROTH

Prepare a number of fermentation tubes with dextrose or lactose broth and add enough of a I per cent neutral-red solution until a decided red color has been imparted. Inoculate these tubes with a variety of colonies from water or sewage plates and note the difference in color reaction after 24 and 48 hours' incubation. 


\section{PART V}

\section{THE BACTERIOLOGICAL EXAMINATION OF}

MILK 



\section{INTRODUCTORY}

This work is designed to follow the physical and chemical examination of milk. The physical examination usually consists in the determination of the specific gravity, sediment, odor, and general appearance. The chemical examination determines the fat percentage, total nitrogen, casein, albumin, milk sugar, acidity, total solids, solids not fat, and preservatives, chiefly formalin. To determine the exact character of milk, physical, chemical, and bacteriological examinations should be made.

References-

Farrington and Woll, Testing of Milk and Its Products, Madison, I908.

Russell and Hastings, Oullines of Dairy Bacteriology, tenth edition, Madison, Wis., H.L. Russell, I9I4.

Ward, Pure Milk and the Public Health, Ithaca, I909.

Hygienic Laboratory Bulletin No. 56, "Milk and Its Relation to the Public Health, Washington, I909.

"Report of the Committee on Standard Methods of the Bacterial Analysis of Milk," American Journal of Public Heallh, 755 Boylston Street, Boston, Mass.

Lafar, Handbuch der technischen Mykologie, Jena, I905 to I908.

Additional apparatus needed.-The outfit given for. the bacteriological examination of water (p. I43) is to be used in this work, with the addition of ten 5 c.c. pipettes. 


\section{SECTION I}

PREPARATION OF CULTURE MEDIA AND OF DILU.TION FLASKS

The same culture media will be used as in the bacteriological examination of water (see p. I44), with this difference, that dextrose agar only is to be prepared, instead of lactose agar. In addition about ten tubes of whey agar are to be prepared.

\section{SECTION 2}

QUANTITATIVE BACTERIOLOGICAL EXAMINATION OF MILK

I. Secure samples of raw market milk, of pasteurized market milk, of certified milk, and of cream.

2. Prepare dilutions as follows:

Raw market milk, I: I,000 and I: 10,000.

Pasteurized market milk, I: I00 and I: I,000.

Certified milk, r: 100.

Cream, I: 1,000 and $\mathrm{I}: \mathrm{I0}, 000$.

3. Plate these in dextrose litmus agar, making duplicate plates from each dilution.

4. Incubate one set at $37^{\circ} \mathrm{C}$., the other set at $20^{\circ} \mathrm{C}$. The incubation period at $37^{\circ} \mathrm{C}$. is 48 hours, at $20^{\circ} \mathrm{C}$. 72 hours.

5. Count the colonies and express the results in numbers of bacteria per cubic centimeter of milk.

6. Make a differential count of acid-forming colonies and non-acid-forming colonies. 


\section{SECTION 3}

EXAMINATION OF MARKET MILK FOR TUBERCLE BACILLI

I. Secure a sample of milk and centrifugalize for 30 minutes at a speed of about 1,200 revolutions per minute.

2. Mix the sediment and the cream in a sterile tube; if too thick add a sufficient amount of sterile $0.8 \mathrm{NaCl}$ solution.

3. Make stains of the mixture for acid-proof bacilli.

4. Divide the mixture into three parts and inject subcutaneously into three guinea-pigs.

Three weeks is about the shortest time in which tuberculosis will develop. The guinea-pigs should be watched closely after this time, and if any of them die, postmortem examinations of the lesions should be made and smears from the affected organs should be stained to demonstrate the presence of tubercle bacilli. Three guinea-pigs are used for an experiment of this nature, because it is impossible to avoid injecting other bacteria present in milk, which may cause the death of one or more of the guinea-pigs before tuberculosis has developed.

\section{SECTION 4}

A STUDY OF THE ACID FERMENTATION OF MILK

I. Secure three samples of milk, one of raw milk, one of pasteurized milk, and one of certified milk.

2. Divide each sample into three parts, and keep one 
set in an ice chest, one set in the locker, and the third set in a thermostat at $37^{\circ} \mathrm{C}$.

3. Prepare plates in dextrose litmus agar from the original three samples and incubate these at $37^{\circ} \mathrm{C}$.

4. Remove every day, with a sterile 5 c.c. pipette, 5 c.c. of the milk from all samples, determine the acidity by titration with $\mathrm{I} / 20 \mathrm{~N} \cdot \mathrm{NaOH}$ and phenolphthaleïn as indicator. When the acidity becomes constant titrations may be omitted.

5. Prepare plates from all samples every day for one week, or until the numbers do not increase materially. It will be necessary to carry the dilutions up to a million after a day or two of market milk, after three - or four days of pasteurized milk, and toward the end of the week of certified milk.

6. Differential counts of acid-forming and non-acidforming bacteria should be made when this is possible.

7. After the week has passed, allow the samples to stand for two weeks longer and make titrations and plates every three days until the acidity and the number of colonies are constant.

The results of this study should be tabulated, as they will illustrate the process of "natural souring" of milk.

If milk is kept at $37^{\circ} \mathrm{C}$. for three weeks or longer the acidity often reaches more than 2 per cent and even up to 3 per cent. This is due to the activity of a group of bacteria wholly different from the ordinary lactic acid bacteria. These bacteria grow poorly on ordinary media. Their presence may be demonstrated by plating the sour milk in beerwort agar, or better, in whey agar (see p. 36 ). 


\section{SECTION 5}

DETERMINATION OF B. COLI AND STREPTOCOCCI IN MILK

I. Inoculate a series of ten dextrose broth fermentation tubes with I c.c. of market milk diluted I: IO, another series of ten fermentation tubes with a dilution of $I: I 00$, another series $I: I, 000$.

2. Incubate these tubes at $37^{\circ} \mathrm{C}$.

3. Measure the gas formed after 24 and 48 hours and determine the composition of the gas after 48 hours. Directions for this work are given on p. $8 \mathrm{r}$.

4. Determine the number of B. coli present in I c.c. of the milk according to the formula on p. 82 .

5. Make smears from each fermentation tube and stain with Gram stain.

6. Examine these smears for streptococci and determine the number according to the same formula, substituting the number of tubes containing streptococci for the letter $\mathrm{N}$ in the formula.

7. Plate out one of the fermentation tubes containing both B. coli and streptococci and carry some of the colonies through all media.

Note.-The work of this exercise should be repeated with pasteurized and certified milk. For pasteurized milk the undiluted sample and dilutions of $I$ : Io and $I: 100$ should be used, for certified milk the undiluted sample and a dilution of $\mathrm{I}: \mathrm{IO}$.

Estimation of numbers of $\mathbf{B}$. coll in milk may be made by inoculation of fermentation tubes containing dextrose broth with falling amounts of milk, i.e.. 1 c.c.. 0 . I c.c.. 0. or c.c., etc. 


\section{SECTION 6}

A COMPARATIVE STUDY OF THE EFFECTS OF PASTEURIZATION AND SO-CALLED STERILIZATION OF MILK ${ }^{2}$

I. Mix three quarts of raw milk and pour plates to determine the number of bacteria and the number of acid-forming bacteria.

2. Divide the mixed milk into three parts. Heat one-third for 20 minutes at $65^{\circ} \mathrm{C}$, , boil one-third for several minutes, and place all parts in an ice chest.

3. As soon as cooled, prepare plates of the milk heated to $65^{\circ} \mathrm{C}$. (pasteurized) and of the boiled milk. Note the "cooked" taste and odor of the boiled milk.

4. Check the keeping qualities of the three kinds of milk by preparing plates on three successive days, and after that every other day for six days.

It is of importance to make differential counts and determine the ratio of acid-forming and non-acidforming bacteria in all plates.

\section{SECTION 7}

A QUALITATIVE AND QUANTITATIVE STUDY OF ANAËROBES IN MILK

I. Secure a sample of raw milk, one of pasteurized milk, and one of certified milk.

2. Prepare dilutions of the raw milk $\mathrm{I}: \mathrm{IO}, \mathrm{I}: \mathrm{I} 00$, and

I The term "sterilized milk" is commonly used for boiled milk. In a bacteriological sense boiled milk is not always sterile, some of the spores being able to survive boiling. 
I: I,, 00 ; of the pasteurized milk I: Io and I: I00, and of the certified milk I: Io.

3. Inoculate a series of Io litmus milk tubes with I c.c. each of the raw milk, a series of Io milk tubes with I c.c. each of the dilution I: Io, and the same with the other dilutions and the other milks.

4. Heat these tubes in a water bath to $80^{\circ} \mathrm{C}$. for 15 minutes.

5. Incubate anaërobically for 48 hours at $37^{\circ} \mathrm{C}$.

6. Anaërobes will give evidence of their presence by the breaking-up of the curd formed, and by violent evolution of gas. The number may be determined according to the formula given on p. 86 by substituting the number of milk tubes with growth for the letter $\mathrm{N}$ in the formula.

\section{SECTION 8}

A STUDY OF SOME ORGANISMS CAUSING ABNORMAL FERMENTATIONS IN MILK

I. Place about 50 c.c. certified milk in each of 5 Erlenmeyer flasks.

2. Sterilize these flasks in the autoclave for 5 minutes.

3. Inoculate these flasks with laboratory cultures of B. prodigiosus, B. cyanogenes, B. viscosus, Sarcina lutea, and Torula amara.

4. Allow these to remain in the locker or in an incubator at $20^{\circ} \mathrm{C}$. for three days; examine the conditions as to color and consistency. 


\section{SECTION 9}

EXAMINATION OF MILK FOR MOLDS AND YEASTS

I. Prepare plates in beerwort agar from undiluted milk and from dilutions of $I: I 0$, and $I: I 00$.

2. Incubate these at $37^{\circ} \mathrm{C}$. and examine for molds and yeasts.

\section{SECTION IO}

\section{EXAMINATION FOR LEUKOCYTES IN MILK}

Examination for leukocytes in milk is carried on in many laboratories and the test was formerly considered of much value. Recent work, however, has cast doubt on its significance, since it has been found that milk of unquestioned purity and soundness may contain as high as $1,000,000$ leukocytes per cubic centimeter, and with modern methods it is not possible to distinguish between leukocytes and pus cells. Leukocytes are always present in milk in variable numbers. Some observers believe that the presence of leukocytes and streptococci together in large numbers indicate pus in the milk. The reliability of this test, however, has not been sufficiently demonstrated.

\section{EXERCISE I. STOKES' METHOD}

I. Centrifugalize ıoo c.c. of milk.

2. Smear the sediment on a cover glass.

3. Examine under the oil-immersion lens and record the number of leukocytes and streptococci. 
More than five cells in a field are sufficient to condemn the milk.

EXERCISE 2. STEWART'S METHOD, MODIFIED BY SLACK

I. Fill 2 c.c. of milk into a tube provided for the purpose.

2. Centrifugalize at a speed of 2,500 to 3,000 revolutions a minute.

3. The stopper is then removed and the sediment smeared on a slide so as to cover 4 square centimeters.

4. Examine the slide under the oil-immersion lens and count the cells and streptococci.

More than 50 cells are sufficient to condemn the milk.

EXERCISE 3. DOANE-BUCKLEY METHOD, MODIFIED BY RUSSELL AND HOFFMANN

I. Heat sample of milk for I minute at $85^{\circ} \mathrm{C}$.

2. Centrifugalize ro c.c. for 20 minutes.

3. Remove cream and milk, leaving 0.5 c.c. milk.

4. Mix and place in a blood counter.

5. Allow to settle for 2 minutes.

6. Count the cells in several hundred squares. The average number of cells per square is multiplied by 200,000 to arrive at number of cells per c.c. of milk.

EXERCISE 4. PRESCOTT AND BREED'S METHOD

I. Remove with capillary pipette with rubber bulb one drop (o.or c.c.) of the shaken sample of milk.

2. Spread over I square centimeter of a glass slide.

3. Dry by gentle heat.

4. Dissolve out the fat with xylol.

5. Fix smear in alcohol for a few minutes.

6. Overstain with methylene blue.

7. Decolorize with alcohol. 


\section{I62 LABORATORY GUIDE IN BACTERIOLOGY}

\section{SECTION II}

A STUDY OF GROUPS OF BACTERIA IN MILK

(Ayers and Johnson)

I. Prepare plates from a sample of milk.

2. Pick off all colonies from a suitable plate and inoculate each colony in a tube of litmus milk.

3. Incubate for 2 weeks at $37^{\circ} \mathrm{C}$.

4. Note all reactions and classify in groups as follows:

a) Acid-coagulating group.

b) Acid-forming without coagulation.

c) Inert group, i.e., no change in the milk.

d) Alkali-forming group.

e) Peptonizing group.

This experiment should be made with raw milk and the same milk pasteurized. The results should be compared. 


\section{PART VI}

THE BACTERIOLOGICAL EXAMINATION OF SOIL 



\section{INTRODUCTORY}

For this work a knowledge of elementary bacteriology and quantitative and qualitative chemistry is indispensable.

\section{References-}

Lafar, Handbuch der technischen Mykologie, Jena, Ig05 to Igo8.

Bulletin 94, Iowa Experiment Station (Soil Samplers).

Apparatus needed in addition to the list given on p. 5:

Two hundred culture tubes.

Twelve Erlenmeyer flasks, I50 c.c. each.

Six Erlenmeyer flasks, 500 c.c. each.

Twelve fermentation tubes.

One mortar and pestle (wedgewood or porcelain).

One soil sampler.

The media required may be made up as the work requiring them comes up. Besides the special media which will be needed a set of media similar to those given for medical bacteriology will be used. See p. I05.

\section{SECTION I}

QUANTITATIVE DETERMINATION OF BACTERIA AND SPORES IN SOIL

EXERCISE I. SECURING SAMPLES OF SOIL

Soil samplers are used and cylinders of soil removed from the upper eight inches of soil. Cylinders of soil should be taken in various parts of the field so as 
to obtain an average representation of the soil. The cylinders are wrapped in sterile paper provided for that purpose and taken to the laboratory. Take samples in this manner from various kinds of soil, viz., garden soil, sand, loam, clay, manured fields, etc.

EXERCISE 2. PREPARATION OF SAMPLES FOR BACTERIOLOGICAL EXAMINATION

I. The samples from the same kind of soil are mixed in a sterile mortar.

2. Place part of each of these composite samples in a sterile glass tube.

3. Weigh accurately io grams from each composite sample and dry in a hot-air oven for one hour at $100^{\circ} \mathrm{C}$. Cool and place in a desiccator. After 24 hours weigh again and calculate the percentage of dry matter present.

EXERCISE 3. PREPARING SOIL SUSPENSIONS AND DILUTIONS AND POURING PLATES

I. Prepare sterile dilution flasks. Fill roo c.c. water in Erlenmeyer flasks of about I50 c.c. capacity. Sterilize these in the autoclave for ro minutes. As there is a loss by evaporation during the process of sterilization the remaining amount is approximately 99 c.c.

2. Weigh the tube containing the sample of soil.

3. Remove about Io grams by shaking the tube or by means of a sterile knife or spatula. Place in a sterile mortar.

4. Weigh the tube again and determine the precise amount of soil removed.

5. Grind the soil sample in the mortar with some 
sterile water from one of the dilution flasks for one minute.

6. Add some more water, so that the final volume is roo c.c. The suspension should be perfectly uniform.

7. Shake the suspension vigorously for three minutes.

8. Prepare dilutions from this suspension in the following manner: Add I c.c. suspension to a flask with 99 c.c. sterile water. Shake well. Remove Io c.c. water from another flask and add Io c.c. of the dilution of I: roo to this flask. This makes a dilution of I: I,000. Then add I c.c. of the dilution of I: 100 to another flask, making a dilution of $I: I 0,000$. I c.c. from the dilution $I: I, 000$ added to another flask makes a dilution of $\mathrm{r}: \mathrm{r} 00,000$. Finally add $\mathrm{r}$ c.c. of the dilution $I: I 0,000$ to another flask, making a dilution of I : I, $, 00,000$.

9. Pour duplicate agar plates from all dilutions and incubate for four days at room temperature. Plates should be prepared in both agar and gelatin.

Io. Examine the gelatin plates daily, and count the colonies earlier than four days if there are many liquefiers present.

II. After counting the colonies on both agar and gelatin calculate the number present in one gram of dry soil.

I2. Examine the colonies and determine as near as possible the group to which they belong according to Chester's Determinative Bacteriology. In most cases stained preparations and hanging drops will give this information. If not, cultures on slant agar must be prepared and the organisms studied in the usual manner by making subcultures. 
EXERCISE 4. DETERMINATION OF THE NUMBER OF SPORES IN SOIL

I. Add I c.c. of the soil suspension I: 1,000 to a tube of melted gelatin.

2. Heat the tube in a water bath to $80^{\circ} \mathrm{C}$. for Io minutes.

3. Pour the gelatin on a petri dish and incubate at room temperature for three or four days.

4. Count the colonies and calculate the number for one gram dry soil.

Each colony represents one spore originally present in the soil.

\section{SECTION 2}

A STUDY OF THE PEPTONIZATION OF PROTEINS BY SOIL BACTERIA

EXERCISE I. DIGESTION OF BLOOD SERUM

I. Place 200 c.c. blood serum in a 500 c.c. flask and sterilize in the autoclave.

2. After cooling, add 5 c.c. of a suspension of garden soil in water.

3. Incubate at $37^{\circ} \mathrm{C}$. until all of the serum has been liquefied.

EXERCISE 2. DETERMINATION OF THE CHANGES PRODUCED IN BLOOD SERUM

I. Add a suitable quantity of distilled water to the liquefied blood serum.

2. Filter to remove bacterial masses and impurities.

3. Neutralize with $\mathrm{NaOH}$, using litmus as indicator. 
4. Boil the solution. If a precipitate forms, it is due to undigested albumins.

5. Filter and add ammonium sulphate to the filtrate to saturation. Albumoses will be precipitated.

6. Allow the mixture to stand over night, then filter.

7. Dissolve the precipitate in distilled water.

8. Add to the dissolved precipitate an excess of $\mathrm{NaOH}$ and a few drops of copper sulphate solution. This will produce the characteristic color of the biuret reaction for the albumoses present.

9. Add to the filtrate left from No. 6 an excess of $\mathrm{NaOH}$ and a few drops of copper sulphate solution. This will give the biuret reaction for peptons.

\section{EXERCISE 3. THE DIGESTION OF GELATIN}

I. Prepare gelatin plates with a dilution of garden soil suspension.

2. Isolate one of the liquefying colonies by transferring it to slant agar. Make subcultures and determine the species.

3. Sterilize 200 grams of gelatin in a 500 c.c. flask and inoculate this heavily with a culture of the liquefying organism obtained in the previous experiment.

4. Incubate at room temperature until the gelatin is completely liquefied.

5. Determine the composition in the same manner as in Exercise I.

\section{EXERCISE 4. THE DIGESTION OF CASEÏN}

I. Precipitate the casein in a quantity of milk by means of dilute acetic acid.

2. Filter. 
3. Wash the precipitate with dilute acetic acid until the milk sugar has been removed.

4. Place in a 500 c.c. flask and add 300 c.c. distilled . water.

5. Neutralize with $\mathrm{NaOH}$ and sterilize in the autoclave.

6. Inoculate with soil suspension.

7. Incubate at $37^{\circ} \mathrm{C}$. until all the caseïn has been dissolved.

8. Determine the composition of the solution as in Exercise I.

9. Make plates in gelatin and isolate the organisms.

Nore. - The precipitated caseĩn has to be washed in order to remove all traces of milk sugar, otherwise acid-forming bacteria will multiply rapidly and crowd liquefiers out.

\section{SECTION 3}

THE FORMATION OF AMIDO COMPOUNDS AND AMMONIA

EXERCISE I. THE FORMATION OF INDOL

I. Prepare 200 c.c. Dunham's solution and place in a 500 c.c. flask.

2. Sterilize in the autoclave.

3. Inoculate with a pinch of garden earth and incubate at $37^{\circ} \mathrm{C}$. for one week.

4. Remove a small amount with a sterile pipette and add a few drops sulphuric acid. Follow this up with a few drops of a 0.00 I per cent solution of potassium or sodium nitrite.

The appearance of a red color indicates the presence of indol. 
EXERCISE 2. THE FORMATION OF AMMONIA

Experiment 1.-Formation of ammonia from pepton-

I. Test the remainder of the solution in Exercise I for ammonia.

2. Make a quantitative determination of ammonia by distillation and nesslerization.

Experiment 2:-Formation of ammonia from urea-

I. Prepare a solution as follows:

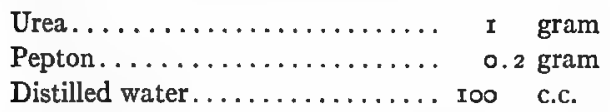

This solution must not be sterilized, as heat breaks up urea into ammonia and carbon dioxid.

2. Inoculate with some garden earth.

3. Incubate at room temperature for one week.

4. From time to time moisten a piece of filter paper with Nessler's solution and pour a few drops from the flask on the paper. A yellow or brown color indicates the formation of ammonia.

\section{SECTION 4}

THE FORMATION OF NITRITES FROM AMMONIA AND ISOLATION OF NITRJTE BACTERIA

EXERCISE I. THE FORMATION OF NITRITES

I. Prepare five flasks and place 50 c.c. of the solution on p. $3^{8}$ in each. Number these flasks consecutively.

2. Inoculate flask I with soil, and incubate at room temperature. 
3. As soon as growth has appeared transfer some of the growth from the first flask to the second.

4. As soon as growth has appeared in the second flask transfer some of the growth to the third flask.

5. Repeat the procedure until all five flasks have been inoculated. This method of transferring repeatedly gradually weeds out all bacteria but those which are able to grow in the solution, and these may thus be obtained in pure culture.

6. Examine these bacteria by making stains, hanging drop, spore stain, etc.

7. Test each flask for nitrites with the starch iodin test as follows. Prepare the following solutions:

a) Dissolve 2 grams starch in roo c.c. of water by boiling.

b) Dissolve one gram potassium iodid in roo c.c. of distilled water.

The potassium iodid solution must be freshly prepared. Ádd a few drops of diluted $\mathrm{H}_{2} \mathrm{SO}_{4}$ to liberate nitrous acid. Then add I c.c. of each of the solutions to 5 c.c. of the fluid to be tested. If nitrous acid is present, iodin will be liberated and will give a blue reaction with starch.

EXERCISE 2. ISOLATION OF NITRITE BACTERIA

Experiment 1.-Agar method-

I. Prepare the agar medium described on p. 38 .

2. Fill ro tubes, and sterilize in the autoclave.

3. Pour plates from this medium inoculated with the contents of the flasks prepared in Exercise $I$ in various dilutions.

4. Incubate at room temperature until growth has appeared. 
5. Transfer some of the colonies to slanted agar prepared as described on p. 38 .

6. Study the colonies by stains, hanging drop, etc., and identify the organism.

Experiment 2.-Silica jelly method-

I. Prepare some tubes with silica jelly as described on p. 38 .

2. Melt these tubes, inoculate several with a soil suspension, others with the contents of the flasks prepared in Exercise I, others with colonies obtained by the washed agar method.

3. Incubate the plates at room temperature and study the colonies in the usual manner.

Collodion sacs for the dialysis of silica are made in the following manner:

Depending on the size desired a culture tube or an Erlenmeyer flask or any other suitable glass vessel can be used. The finished sac is always much smaller than the vessel used and this shrinkage must be considered in choosing the right size of vessel. Celloidin is dissolved in a mixture consisting half of ether and half of alcohol in such quantity that the solution contains 6 per cent celloidin. Celloidin usually is covered with water. This must be washed off with alcohol before the celloidin is dissolved. A quantity of the celloidin solution is then poured into the flask and the flask rotated until the whole inside surface is covered with the solution. The flask is then inverted and the celloidin allowed to drain off so that a thin coat remains on the sides of the flask. The flask must then be rotated and air blown into it until the celloidin is almost dry. The process is then repeated so that the 


\section{I74 LABORATORY GUIDE IN BACTERIOLOGY}

inside surface of the flask is covered with two coats. For large sacs three coats should be applied. When the celloidin is nearly dry water should be run into the flask until filled. This water should be changed several times. Commencing at the top of the flask the film is separated from the glass and by means of a smooth instrument, for instance, a glass rod which has been rounded off at the end, the film is slowly removed from the glass. As soon as there is a fairly large part of the film separated, the water may be emptied out and water run in between the film and the glass. In this manner the film is gradually removed from the glass. If the celloidin is too dry before the flask is filled with water, it will crack and will be difficult to remove from the glass. The technic is not difficult and with some practice and care sacs can be made which will be large enough to hold two liters of liquid.

\section{SECTION 5}

THE FORMATION OF NITRATES FROM NITRITES, AND ISOLATION OF NITRATE BACTERIA

EXERCISE I. THE FORMATION OF NITRATES FROM NITRITES

I. Prepare a solution as described on p. 39 .

2. Prepare a series of five flasks and place 50 c.c. of the solution in each.

3. Sterilize in the autoclave.

4. Inoculate the first flask with soil and incubate at room temperature.

5. As soon as growth has appeared inoculate a second flask, from this one a third, etc., as in Exercise I, 
Section 4. The bacteria will finally appear in pure culture.

6. Determine the presence of nitrates. For this determination proceed as follows:

a) Preparation of phenol sulphonic acid: 30 grams phenol are dissolved in $37^{\circ}$ grams concentrated sulphuric acid in a round-bottom flask. Immerse completely in a water bath and heat for six hours.

b) Dissolve 20 grams KOH in 20 c.c. distilled water.

c) Evaporate a small amount of the culture to dryness on a water bath.

d) Add to the residue one c.c. phenol sulphonic acid and rub with a glass rod.

e) Add enough $\mathrm{KOH}$ solution to make the solution alkaline.

f) Dilute with distilled water.

If nitrates are present this will be indicated by the appearance of a yellow color.

EXERCISE 2. ISOLATION OF NITRATE BACTERIA

These bacteria may be isolated with agar or silica jelly in the same manner as in Section 4, Exercise 2.

\section{SECTION 6}

THE ASSIMILATION OF FREE ATMOSPHERIC NITROGEN AND ISOLATION OF THE BACTERIA

EXERCISE I. BY LEGUME BACTERIA (TUBERCLE BACTERIA)

\section{Experiment I-}

I. Secure the roots of a clover plant, or any other legume. Note the appearance and distribution of the tubercles. 
2. Crush between two slides a small tubercle and a large one.

3. Make mounted preparations and examine them under the microscope.

\section{Experiment 2-}

I. Wash a number of tubercles in distilled water, then soak in mercuric chlorid solution $I: I, 000$ to sterilize the exterior of the tubercles.

2. Wash again in several changes of sterilized distilled water.

3. Crush in a sterile petri dish.

4. Plate in agar, prepared as described on p. 38 .

5. Incubate at room temperature.

6. After growth has appeared transfer to all ordinary laboratory media.

7. Study characteristics in the usual manner.

EXERCiSE 2. BY ORGANISMS OTHER THAN LEGUME BACTERIA

\section{Experiment I-}

I. Prepare 5 flasks and place 50 c.c. of the solution on p. 39 in each flask.

2. Sterilize in the autoclave.

3. After growth has appeared inoculate a second flask from the first, from the second to the third, etc.

4. Determine the gain in nitrogen by the Kjeldahl method. This determination should be repeated at regular intervals to determine the progress of nitrogen assimilation.

Experiment 2.- These organisms may be obtained in pure culture by plating in agar or silica jelly media. 


\section{SECTION 7}

THE REDUCTION OF NITRATES TO NITRITES AND ISOLATION OF THE BACTERIA

I. Prepare a flask of pepton broth and add 0.5 per cent potassium nitrate.

2. Inoculate with a small quantity of soil.

3. Incubate for several days at room temperature.

4. Test by the starch iodin method as described in Section 4, Exercise I.

5. Obtain pure cultures by plating on nutrient agar.

\section{SECTION 8}

- THE REDUCTION OF NITRATES TO FREE NITROGEN

I. Prepare several large fermentation tubes with the medium described on p. 40.

2. Inoculate the closed arm of the fermentation tubes with varying quantities of soil.

3. Incubate at $37^{\circ} \mathrm{C}$.

4. When gas evolution has ceased determine the percentage of gas.

5. Determine the composition of the gas.

6. These bacteria may be isolated by plating in agar, or better in a medium prepared by adding agar to the original solution used in the fermentation tubes.

7. Study the morphology of the bacteria in pure culture. 


\section{I78 LABORATORY GUIDE IN BACTERIOLOGY}

\section{SECTION 9}

GROWING LEGUMES IN SAND AND IN SAND INOCULATED WITH TUBERCLE BACTERIA

Secure some flower pots and fill them with sand. Plant some species of legume and soak the sand in half the number of pots with suspensions of legume bacteria. The difference in growth between those planted in pure sand and those planted in inoculated sand will be evident after a short time. 


\section{PART VII}

MOLDS, YEASTS, TORULAE, AND ACETIC-ACID BACTERIA 



\section{INTRODUCTORY}

References-

Klöcker, Die Gährungs Organismen (translated into English).

Hansen (translated by Miller), Practical Studies on Fermentation, London, 1896.

Jörgensen, Microörganisms and Fermentation, London, I9oo. Green, Soluble Ferments and Fermentation, Cambridge, Igar. Lafar, Handbuch der technischen Mykologie, Jena, I905 8. Marshall, Microbiology, Philadelphia, P. Blakiston, Son \& Co., IgI I.

Apparatus needed in addition to the list on p. 5:

Fermentation tubes................ 24

Erlenmeyer flasks, I 5o c.c. each.......... 24

Stender dishes................... Iо

Glass tumblers.................. 10

\section{SECTION I}

PREPARATION OF CULTURE MEDIA

Prepare 25 tubes of each of the following media:

Meat extract agar, partly for slants and partly for plating.

Dextrose agar.

Litmus milk.

Liquid beerwort.

Beerwort agar for plating.

Beerwort gelatin.

Also fill I2 Erlenmeyer flasks with 50 c.c. beerwort each, and

Meat extract broth 5 tubes.

Beerwort may be sterilized in a cask in the following manner: Fit a cork with two holes in the bunghole 
and insert two glass tubes through the holes. The tubes should reach to the bottom of the cask (see Fig. 35). The open ends of both tubes should be plugged with cotton and have a constriction below the cotton, to prevent it from slipping down. One of the tubes is connected with the air valve of an autoclave and steam passed through the wort for 30 minutes. The process is repeated on the two following days. Sterile wort may be obtained from the cask by blowing through the tube $e$ and collecting from the bent tube, which, when not in use, should be protected from contamination by a sterile test tube with a cotton plug.

\section{SECTION 2}

\section{A STUDY OF MOLDS}

EXERCISE I. COLLECTING MOLDS FROM THE AIR

I. Expose two plates of wort agar and two of meat extract agar to the air in different places.

2. Incubate at $37^{\circ} \mathrm{C}$.

3. After molds have appeared transfer three different colonies to slanted wort agar. Transfers are made by touching the ends of the hyphae with a platinum needle and streaking on the slanted surface of a tube of wort agar.

4. After full development transfer some of the spores to liquid wort or broth. This is done by touching the ends of the filaments with a platinum needle.

5. Examine a large loopful of this spore suspension under the microscope, using a low magnification. 
6. If the spores are numerous dilute the suspension until only a few appear in a loopful.

7. When the dilution is high enough to show but a few spores under the microscope transfer a large loopful to a cover slip.

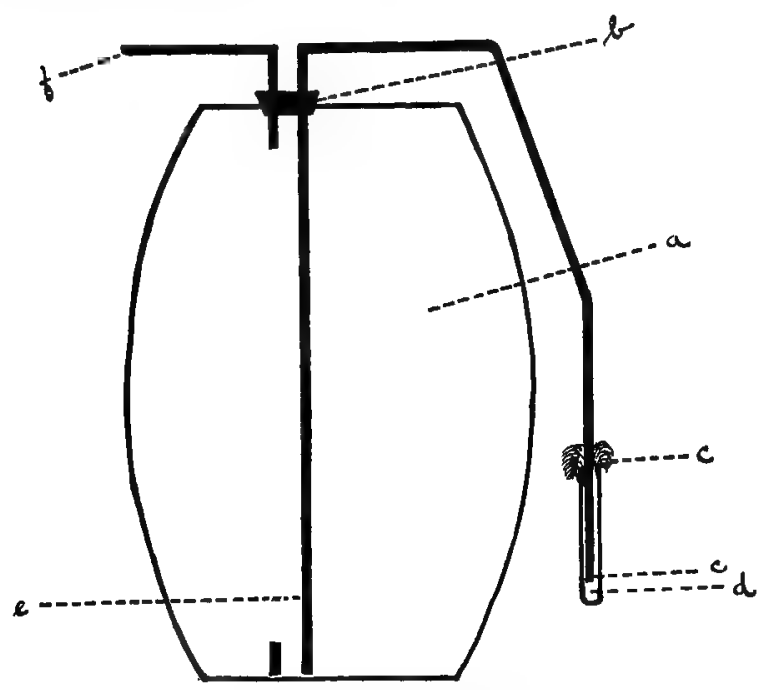

FIG. 34

Sterilizing Wort in a Cask
4. Cask
b. Rubber stopper
c. Cotton plugs
d. Test tube

$e$. Glass tubes $f$. Cotton stopper and connection with autoclave

8. Invert this cover slip over the ring of a Böttcher Moist Chamber (Fig. 35).

9. Incubate at $37^{\circ} \mathrm{C}$.

Io. Observe the hanging drop every day and make sketches. After 7 to ro days the cycle of development will be completed so that a new crop of spores has appeared. 
The Böttcher Moist Chamber consists of a slide, a cover slip, and a glass ring (see Fig. 35). The glass ring is held on the slide by a mixture of rosin and castor oil. A few drops of sterile water are placed in the bottom to maintain moisture in the hollow of the ring. The inverted cover slip with the hanging drop is held in position by smearng vaselin around the top of the glass ring.

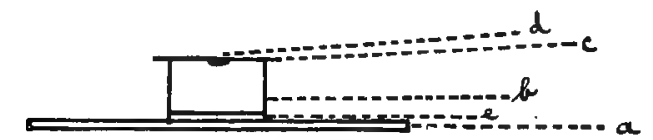

FIG. 35

Böttcher Moist Chamber
a. Slide
b. Glass ring
d. Hanging drop
c. Sterile water
ఒ. Cover slip

EXERCISE 2

Preparation of slides for microscopic study of molds, also stained preparations (see p. 79).

EXERCISE 3. STUDY OF MOLDS IN CHEESE

I. Secure some Roquefort and some Camembert cheese.

2. Pick out with a looped needle some of the dark spots in the Roquefort cheese and some of the mold on the Camembert cheese.

3. Make streaks of this material on wort agar plates.

4. Isolate the molds and study as in Exercises I and 2.

EXERCISE 4. STUDY OF THE AMYLOLYTIC ACTION OF MOLDS

I. Prepare cultures of Aspergillus oryzae.

2. Add some starch to liquid wort in a flask and sterilize. 
MOLDS, YEASTS, TORULAE, AND BACTERIA I85

3. Inoculate with the mold and test for sugar formation by the Fehling test from day to day.

EXERCISE 5. CULTIVATION OF MOLDS IN RAULIN'S SOLUTION

I. Preparation of Raulin's solution (see p. 42).

2. Place about 50 c.c. of the solution in three Erlenmeyer flasks and sterilize in the autoclave.

3. Inoculate the surface with molds from three species of molds.

4. Incubate at $37^{\circ} \mathrm{C}$.

5. After growth has appeared examine the molds and make sketches.

EXERCISE 6. A STUDY OF MOLDS FROM LABORATORY CULTURES

Study cultures of molds furnished in the same manner as outlined in the first five exercises of this section.

\section{SECTION 3}

\section{A STUDY OF YEASTS}

Note.-All yeast cultures are to be incubated at $25^{\circ} \mathrm{C}$. unless otherwise directed.

EXERCISE I. STUDY OF YEASTS FROM THE AIR

r. Expose two plates of wort agar to the air in different places, or if the plates exposed in the previous section have colonies of yeasts these may be used.

2. Transfer three colonies, which appear to differ from each other by microscopic examination, to tubes of slant wort agar, and incubate. 
3. After growth has taken place transfer from these agar slants to the following media: Meat agar slant, dextrose agar, litmus milk, wort gelatin, liquid wort.

4. After 24 hours' incubation make stains with gentian violet and by Gram's method, examine the unstained cells in water, and make sketches.

EXERCISE 2. A STUDY OF GAS EVOLUTION BY YEASTS

I. Prepare 2 per cent solutions of the following carbohydrates in wort: Dextrose, saccharose, lactose, mannit, levulose, maltose.

2. Fill three fermentation tubes from each of these solutions and sterilize for three consecutive days in the Arnold.

3. Inoculate each set with the three yeast cultures studied in Exercise I.

4. Measure the percentage of gas evolved after 24 and 48 hours.

5. Determine approximately the composition of the gas formed (see p. 82), using a 4 per cent $\mathrm{NaOH}$ solution.

6. Tabulate the results, stating the amount and composition of the gas formed from each carbohydrate by the three species of yeasts.

EXERCISE 3. A STUDY OF FILM FORMATION

I. Prepare cultures in liquid wort from three species of yeasts.

2. After growth has appeared inoculate three flasks containing sterile wort with each one of the yeasts. This should be done after pouring the supernatant liquid off, inoculating with a loop from the sediment.

3. Incubate these flasks as follows: One set at $37^{\circ} \mathrm{C}$., 
the second set at room temperature, and the third set at $25^{\circ} \mathrm{C}$.

4. Note which temperature is most favorable to film formation.

5. Examine under the microscope some cells from the film and some from the sediment, also make permanent stained preparations. It will be observed that there is a difference in morphology between the cells from the film and those from the sediment. Also note the decolorization of the wort.

6. Determine by distillation approximately the amount of alcohol produced.

EXERCISE 4. A STUDY OF SPORE FORMATION

r. Prepare cultures in liquid wort.

2. Prepare gypsum blocks as described on p. 80 .

3. After growth has taken place in the tubes pour off the supernatant fluid and smear the sediment on the surface of the gypsum blocks.

4. Incubate the gypsum blocks at $25^{\circ} \mathrm{C}$.

5. Examine a small amount from day to day until spores are present, and make sketches.

EXERCISE 5. PREPARATION OF PURE CULTURES OF YEASTS FROM ONE CELL

The preparation of pure cultures from one cell has become of vast importance in breweries. It is relatively difficult to prepare pure cultures of bacteria from one cell, these being smaller than yeasts and, therefore, more difficult to manipulate. Barber (Jour. Infect. Dis., rgo8, 5, p. 379) has succeeded in devising a practical method for isolating single cells of bacteria and preparing pure cultures from these. 
Experiment r.-The dilution method-

I. Prepare a culture of a species of yeast in liquid wort.

2. Examine a large loopful under the microscope and dilute the culture with sterile wort until there is an average of about one cell to the loopful.

3. Inoculate a series of ten tubes of liquid wort with a loopful each of the diluted culture, or inoculate with a drop from a sterile capillary pipette.

4. Incubate.

All those tubes in which growth has appeared contain a culture originating from one cell.

Experiment 2.-Hansen's gelatin method-

I. Prepare a culture of a mixture of two or three species of yeast.

2. After growth has appeared inoculate a tube with liquefied wort gelatin at a temperature of about 30 to $35^{\circ} \mathrm{C}$.

3. Examine under the microscope and dilute with liquefied gelatin until there are only one or two cells to each loopful.

4. Prepare cover slips in the following manner: Dip several cover slips into liquid paraffin. After the paraffin has solidified draw lines through the paraffin with a sharp steel needle, so as to form a number of squares. Mark each square with numbers or letters with the same needle. Dip the cover glass into hydrofluoric acid for a few seconds, wash in water, then chloroform, ether, and alcohol until the glass is clean and free from fat. The hydrofluoric acid will have etched the glass so as to show the marks permanently.

5. Cover the slip with a thin coat of the diluted wort gelatin containing the culture. 
6. After the gelatin has solidified, paint the top of the glass ring of a Böttcher Moist Chamber with vaselin and invert the cover slip, gelatin down. Do not neglect to place a small amount of water inside the moist chamber.

7. Examine under the microscope and make a sketch corresponding to the figures on the cover slip and make a mark for all single cells observed. It is possible then to find the cells again by comparing the cover slip with the sketch.

8. Incubate at room temperature.

9. Observe from day to day the growth of colonies from single cells.

Io. When the colonies are large enough to be picked up with a platinum needle, inoculate several tubes of liquid wort with the colonies.

II. Incubate at $25^{\circ} \mathrm{C}$. and after growth has appeared transfer the sediment from each tube to a flask containing liquid wort.

I2. Incubate these flasks and study the cultures by making microscopic examination and stains, study the film and the sediment separately, inoculate fermentation tubes with the various carbohydrates, and inoculate gypsum blocks. Also note the aroma, and determine the amount of alcohol formed.

\section{EXERCISE 6. A STUDY OF LABORATORY CULTURES}

Prepare cultures from Saccharomyces cerevisiae, Sacch. pastorianus, and Sacch. ellipsoideus on liquid wort. After 24 hours' incubation transfer to all media and study these yeasts in the same manner as described as to gas formation, film and sediment formation, spore formation, etc. 
EXERCISE 7. EXAMINATION OF BREWER'S YEAST

I. Secure some brewer's yeast.

2. Inoculate a tube of liquid wort and incubate at $25^{\circ} \mathrm{C}$.

3. Prepare pure cultures from this mixture according to Hansen's method.

4. When pure cultures have been obtained, study these in the same manner as previously directed.

\section{SECTION 4}

\section{EXAMINATION OF BAKER'S YEAST}

I. Prepare 5 flasks with Ioo c.c. sterile water.

2. Secure a cake of pressed yeast.

3. Prepare a suspension of I gram in roo c.c. sterile water.

4. Weigh out about one gram, evaporate on a water bath, place in a calcium chlorid desiccator over night, weigh again, and determine the percentage of moisture.

5. Remove Io c.c. water from a flask containing Ioo c.c. sterile water, and replace with ro c.c. from the suspension.

6. Transfer I c.c. of the suspension to another dilution flask.

7. Transfer I c.c. from the second flask to a third dilution flask. The dilutions prepared are $I: I 00$,

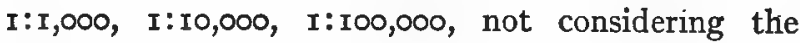
amount of moisture in the gram of yeast suspended.

8. Pour meat extract agar and wort agar plates from all dilutions.

9. Incubate the meat agar plates at $37^{\circ} \mathrm{C}$. and the wort agar plates at $25^{\circ} \mathrm{C}$. 
Io. After 28 hours count the number of colonies of bacteria and yeasts present on both plates. Calculate the numbers in a gram of dry yeasts.

Bacteria do not multiply well on wort agar, the acid reaction being unfavorable. The count on meat agar will, therefore, be higher than on wort agar.

II. Examine the yeast colonies under the microscope, make stains, examine in water, and transfer the different colonies to wort tubes.

I2. Study the cultures prepared as before.

SECTION 5
EXAMINATION OF YEAST OF SALT-RISING BREAD

I. Make smears and stains from the yeast.

2. Inoculate litmus milk and incubate at $37^{\circ} \mathrm{C}$. for two or three days.

3. Make gentian violet and Gram stains, and note the dark red color of the litmus.

4. Inoculate a flask containing 250 c.c. sterile milk and incubate for seven days at $37^{\circ} \mathrm{C}$.

5. Determine the amount of acid formed from day to day with $\mathrm{r} / 20 \mathrm{~N} \cdot \mathrm{NaOH}$ and phenolphthalein as indicator. Record the results.

6. Plate in meat extract agar and wort agar.

7. Study the colonies in both plates.

Meat extract agar is not suitable for the organism active in this yeast and probably no colonies will appear. Beerwort agar is more suitable. The active organism is a large bacillus, which forms an amount of lactic acid often as high as 3 per cent. When used for baking this acid combines with the soda added to 
salt-rising bread dough, and carbon dioxid is liberated, which causes the bread to rise.

\section{SECTION 6}

\section{A STUDY OF TORULAE}

\section{Experiment I-}

I. Transfer from laboratory cultures to wort agar.

2. Make stains, and transfer to all the other media.

3. Make descriptions of these organisms, and note the differences from yeasts.

Experiment 2-

I. Prepare three plates of wort agar.

2. Expose these to the air in different places.

3. Incubate at $25^{\circ} \mathrm{C}$.

4. After 48 hours fish for torula colonies, transfer these to all the media, prepare stains, and describe the cultures. Inoculate fermentation tubes with carbohydrates, and inoculate gypsum blocks. Some torulae produce gas from lactose; the true yeasts do not. Torulae do not form spores.

\section{SECTION 7}

A STUDY OF ACETIC-ACID BACTERIA

\section{EXERCISE I}

I. Secure some old vinegar with a film on top.

2. Prepare a suspension of the film in sterile water.

3. Plate out in wort agar, and incubate at $25^{\circ} \mathrm{C}$.

4. Transfer the colonies to slant agar.

5. Inoculate flasks containing about 50 c.c. wort and I per cent alcohol with the cultures. 
6. Incubate one flask at room temperature, one at $37^{\circ} \mathrm{C}$., and one at $40^{\circ} \mathrm{C}$.

7. Examine and note the degree of film formation at the different temperatures and the differences in morphology.

8. Add small amounts of alcohol from time to time.

9. Titrate daily with $\mathrm{I} / 20 \mathrm{~N} \cdot \mathrm{NaOH}$ and determine the amount of acid produced.

EXERCISE 2

Inoculate liquid wort to which 3 per cent saccharose has been added with an alcohol-forming yeast. After alcohol has been produced, inoculate with one of the acetic-acid cultures and note the amount of acid produced. 



\section{APPENDIX}





\section{APPENDIX}

\section{DILUTION TABLES FOR AGGLUTINATION}

\begin{tabular}{|c|c|c|c|}
\hline Number & Amount of Serum & $\begin{array}{c}\text { Amount of Salt } \\
\text { Solution }\end{array}$ & Final Di \\
\hline $\begin{array}{l}1 \ldots \ldots \ldots \ldots \\
2 \ldots \ldots \ldots \ldots \\
3 \ldots \ldots \ldots \ldots \\
4 \ldots \ldots \ldots \ldots\end{array}$ & $\begin{array}{l}\text { I part } \\
\text { I part of No. I } \\
\text { I part of No. } 2 \\
\text { I part of No. } 3\end{array}$ & $\begin{array}{l}9 \text { parts } \\
9 \text { parts } \\
9 \text { parts } \\
9 \text { parts }\end{array}$ & $\begin{array}{l}I: I 0 \\
I: I 00 \\
I: I, O C \\
I: I 0, C\end{array}$ \\
\hline
\end{tabular}

\begin{tabular}{|c|c|c|}
\hline Amount of Serum or Serum Dilution & Suspension & Final Di \\
\hline 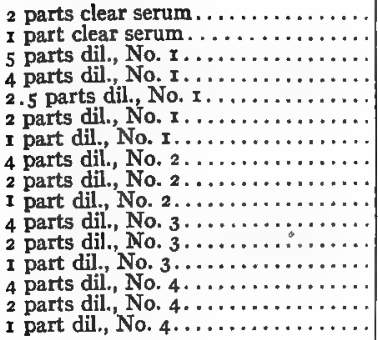 & $\begin{array}{l}\text { I8 parts } \\
\text { I9 parts } \\
\text { I5 parts } \\
\text { I6 parts } \\
\text { I7 } 5 \text { parts } \\
\text { I8 parts } \\
\text { Ig parts } \\
\text { I6 parts } \\
\text { I8 parts } \\
\text { I9 parts } \\
\text { I6 parts } \\
\text { I8 parts } \\
\text { I9 parts } \\
\text { I6 parts } \\
\text { I8 parts } \\
\text { I9 parts }\end{array}$ & $\begin{array}{l}I: I 0 \\
I: 20 \\
I: 40 \\
I: 50 \\
I: 80 \\
I: I 00 \\
I: 200 \\
I: 500 \\
I: I, 0 \\
I: 2,06 \\
I: 5,06 \\
I: I 0, C \\
I: 20, C \\
I: 50, C \\
I: I 00 \\
I: 200\end{array}$ \\
\hline
\end{tabular}

DILUTION TABLE FOR WATER OR MILK ANALYSI

\begin{tabular}{|c|c|c|c|}
\hline Number & Amount of Dilution & $\begin{array}{l}\text { Amount of } \\
\text { Sterile Water }\end{array}$ & Final Di \\
\hline 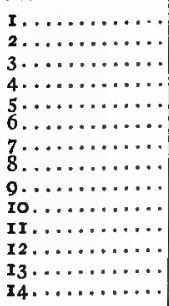 & $\begin{array}{r}\text { Original } \\
\text { roc.c. of No. I } \\
\text { rc.c. of No. I } \\
2 \text { oc.c. of No. } 3 \\
\text { Ioc.c. of No. } 3 \\
\text { 5c.c. of No. } 3 \\
\text { 2c.c. of No. } 3 \\
\text { rc.c. of No. } 3 \\
\text { 5c.c. of No. } 4 \\
\text { 2c.c. of No. } 4 \\
\text { Ic.c. of No. } 4 \\
\text { 5c.c. of No. } 7 \\
\text { 2c.c. of No. } 7 \\
\text { Ic.c. of No. } 7\end{array}$ & $\begin{array}{l}\text { goc.c. } \\
99 \mathrm{c.c} . \\
80 \mathrm{c.c} . \\
90 \mathrm{c.c} . \\
95 \mathrm{c.c} . \\
98 \mathrm{c.c} . \\
99 \mathrm{c.c} . \\
95 \mathrm{c.c} . \\
98 \mathrm{c.c} . \\
99 \mathrm{c.c} . \\
95 \mathrm{c.c} . \\
98 \mathrm{c.c} . \\
99 \mathrm{c.c} .\end{array}$ & $\begin{array}{l}I: I \\
I: I 0 \\
I: I 00 \\
I: 500 \\
I: I, 0 \\
I: 2, \propto \\
I: 5,06 \\
I: I 0, C \\
I: 20, C \\
I: 50, C \\
I: I 00 \\
I: 200 \\
I: 500 \\
I: I, 06\end{array}$ \\
\hline
\end{tabular}




\section{COMPARATIVE TABLES OF WEIGHTS AND MEASURES}

I inch $=2.54$ centimeters

I foot $=0.3048$ meters

1 yard $=0.9144$ meters

$I$ mile $=I .6$ I kilometers

I micromillimeter (micron, $\mu$ ) $=0.000001$ meters $=0.00003937$ in.

1 millimeter $=0.001$ meters $=0.03937$ in.

I centimeter $=0.01$ meters $=0.3937$ in.

1 decimeter $=0.1$ meters $=3.937$ in.

$I$ meter $=I$ meters $=39.37$ in. $=3.28$ feet $=I .0936$ yds.

1 kilometer $=1,000$ meters $=3,28 \mathrm{I}$ feet $=1093.6 \mathrm{yds}$.

I grain $\quad=0.0648$ grams

I ounce, avoirdupois $=28.35$ grams

I ounce, troy $=31.10$ grams

I pound, avoirdupois $=453.6 \quad$ grams

I pound, troy $=373 \quad$ grams

I gram $=15.43$ grains

I kilogram $=2.205$ pounds, avoirdupois

I kilogram $=2,679$ pounds, troy

I gallon, U.S. liquid $=3785$ cubic centimeters

I quart, U.S. liquid $=946$ cubic centimeters

I pint, U.S. liquid $=473$ cubic centimeters

I ounce, U.S. liquid $=29.57$ cubic centimeters

$\mathbf{1}, 000$ cubic centimeters $=\mathbf{1} .057$ U.S. liquid quarts

\section{CENTIGRADE AND FAHRENHEIT THERMOMETERS}

\begin{tabular}{|c|c|c|c|c|c|}
\hline C. & F. & C. & F. & C. & F. \\
\hline -I 8 & -0.4 & -6 & 21.2 & 6 & 42.8 \\
\hline$-I_{7}$ & I. 4 & -5 & 23.0 & 7 & 44.6 \\
\hline$-\mathrm{r} 6$ & 3.2 & -4 & 24.8 & 8 & 46.4 \\
\hline$-\mathrm{I}_{5}$ & 5.0 & -3 & 26.6 & 9 & 48.2 \\
\hline$-\mathrm{I}_{4}$ & 6.8 & -2 & 28.4 & IO & 50.0 \\
\hline$-I_{3}$ & 8.6 & $-\mathbf{I}$ & $3^{0.2}$ & I I & $5 \mathrm{~T} .8$ \\
\hline$-\mathrm{I} 2$ & 10.4 & 0 & 32.0 & I2 & 53.6 \\
\hline$-\mathbf{I} \mathbf{I}$ & I 2.2 & I & 33.8 & I3 & 55.4 \\
\hline-10 & 14.0 & 2 & 35.6 & 14 & 57.2 \\
\hline-9 & I5 .8 & 3 & $37 \cdot 4$ & 15 & 59.0 \\
\hline-8 & 17.6 & 4 & 39.2 & I6 & 60.8 \\
\hline-7 & I9. 4 & 5 & $4 \mathrm{I} .0$ & 17 & 62.6 \\
\hline
\end{tabular}




\section{APPENDDIX}

\begin{tabular}{|c|c|c|c|c|}
\hline C. & F. & c. & F. & C \\
\hline I8 & 64.4 & 46 & II 4.8 & 74 \\
\hline 19 & 66.2 & 47 & т I 6.6 & 75 \\
\hline 20 & 68.0 & 48 & II 8.4 & 76 \\
\hline $2 \mathrm{I}$ & 69.8 & 49 & I 20.2 & 77 \\
\hline 22 & 71.6 & 50 & I 22.0 & 78 \\
\hline 23 & 73.4 & $5 \mathrm{I}$ & I 23.8 & 79 \\
\hline 24 & 75.2 & 52 & I 25.6 & 80 \\
\hline 25 & 77.0 & 53 & I 27.4 & $8 \mathrm{I}$ \\
\hline 26 & 78.8 & 54. & I 29.2 & 82 \\
\hline 27 & 80.6 & 55 & I3I.O & $8_{3}$ \\
\hline 28 & 82.4 & 56 & $\mathrm{I}_{32} .8$ & 84 \\
\hline 29 & 84.2 & 57 & I 34.6 & 85 \\
\hline 30 & 86.0 & $5^{8}$ & I 36.4 & 86 \\
\hline $3 I$ & 87.8 & 59 & $\mathrm{I}_{3} 8.2$ & 87 \\
\hline 32 & 89.6 & 60 & 140.0 & 88 \\
\hline 33 & 9 I. 4 & $6 \mathrm{I}$ & 14 I. 8 & 89 \\
\hline 34 & 93.2 & 62 & I 43.6 & 90 \\
\hline 35 & 95.0 & $\sigma_{3}$ & 145.4 & $9 \mathrm{I}$ \\
\hline 36 & 96.8 & 64 & 147.2 & 92 \\
\hline 37 & 98.6 & 65 & I 49.0 & 93 \\
\hline $3^{8}$ & 100.4 & 66 & $\mathrm{I}_{50.8}$ & 94 \\
\hline 39 & 102.2 & 67 & I 52.6 & 95 \\
\hline 40 & 104.0 & 68 & I54. 4 & 96 \\
\hline $4 \mathrm{I}$ & 105.8 & 69 & $\mathrm{I}_{5} 6.2$ & 97 \\
\hline 42 & I07.6 & 70 & $\mathrm{I}_{5} 8.0$ & 98 \\
\hline 43 & I09. 4 & $7 I$ & I 59.8 & 99 \\
\hline 44 & $\operatorname{III} \cdot 2$ & 72 & I 6 I. 6 & 100 \\
\hline 45 & $\mathrm{II} 3.0$ & 73 & 163.4 & \\
\hline
\end{tabular}




\section{Endo's Medium-}

Pepton (Witte)............. Io grams

Extract of meat............ 3 grams

$\mathrm{NaCl} \ldots \ldots \ldots \ldots \ldots \ldots \ldots \ldots . . .6$ grams.

Distilled water............. I,000 c.c.

Dissolve by boiling. Titrate to 0.2 per cent acid to phenolphthaleïn. Place in autoclave at 15 pounds pressure for 6 minutes. Cool and filter off precipitate. Titrate again to 0.2 to 0.3 per cent acid.

Then add:

Agar threads.............. 30 grams

Boil until dissolved and make up to $\mathrm{I}, 000$ c.c.

Saturated solution of basic fuchsin.... 3 c.c.

Sodium sulphite solution ( 5 per cent anhydrous) .................23.3 grams

Lactose (dissolved in 50 c.c. hot water) Io grams

Tube and sterilize in autoclave for to minutes at Io pounds pressure.

\section{Russell's Medium-}

Make up I,000 c.c. broth (meat extract) and make reaction 0.9 per cent acid to phenolphthaleïn. Autoclave and filter. Add I5 grams thread agar and dissolve by boiling.

Add I per cent litmus solution in proportion of 5 per cent.

Add sufficient n. $\mathrm{Na}_{2} \mathrm{CO}_{3}$ to bring the solution to the neutral point of the litmus ( $12-15$ c.c.).

Add I per cent lactose and o. I per cent dextrose.

Tube and sterilize for to minutes at Io pounds pressure.

The amount of $\mathrm{Na}_{2} \mathrm{CO}_{3}$ must be accurate, as otherwise the medium will turn greenish after sterilizing. 
INDEX 



\section{INDEX}

Abnormal fermentation in milk, I59.

Acetic-acid bacteria, I92 .

Acid broth, 4I.

Acid fermentation in milk, 155 .

Acid-proof bacilli, I31, I32.

Actinomyces asteroides, $\mathrm{I}_{34}$.

Actinomyces bovis, 134 .

Actinomyces group, I34.

Actinomyces hominis, I34.

Aesculin bile-salt agar, 33 .

Agar-agar, 20.

Agar: beerwort, 32; bile-salt, 33; blood, 40; dextrose, 26; glycerin, 36 ; litmus dextrose, 35 ; litmus lactose, 35; mannit, 36 ; slants, inoculation of, 72 ; synthetic for plating, 38 ; standard method for preparing, 30; whey, 36.

Agglutination test, I 18 .

Air, bacterial examination of, 87, number of bacteria in, 87 .

Albuminoid, 62.

Alcohol formation by yeasts, 187 .

Alum carmin, 44; hematoxylin, 44.

Amido compounds formed by soil bacteria, I70.

Ammonia, formed by soil bacteria, I7I.

Ammonification, pepton solution for, 40 .

Amylase, 63 .

Amylolytic: action of molds, I84; enzym, 62.

Anaërobes: in milk, 158; in sewage, I49.

Anaërobic: bacilli, I34; cultivation, I34; Buchnner's method, 136; in hydrogen gas, 136;
Park's method, I35; V method, 135 .

Analysis of gas in ferme tubes, $8 \mathrm{I}$.

Anilin gentian violet, 43 .

Anthrax group, I27.

Arnold steam sterilizer, I2

Asiatic cholera, spirillum ,

Aspergillus oryzae, 184 .

Assimilation of atmospheri gen, 175 .

Autoclave, 14.

Autopsy, 107.

Bacilli: acid-proof, I3I; an: 1.34.

Bacillus: aërogenes, II2; cis, I27; botulinus, I34 vei, I34; suipestifer, IC II5; cloacae, IOI, I2] 95, IOI, II2; coli genes, xx 2; coli and s cocci in milk, 157; a streptococci in water, 8 149; cuniculicida, 127 ; genes, 159; der Rinc I27; der Schweineseuch diphtheriae, I24; dyse II2, II7; edematis, I34; itidis, II2, II5; fecalis genes, IOI, II2, II7; O ner, II5; hofmannii, I24 oides, 1I2; influenzae leprae, I3I; mallei, I3 melitensis. I32; Möller'؛ I3 I; capulatus, I23; of 1 plague, 127; of rabbit cemia, I 27; paraty Ir2, II5; pestis, I27; giosus, 97, 159; pyoc 97; rhinoscleromatis, I23 mae, I3I; subtilis, I 27; I34; tuberculosis, I3I; sus, 95, II $, I 17,150$; sus in water, 150; vir 


\section{LABORATORY GUIDE IN BACTERIOLOGY}

97; viscosus, I59; welchii, I34; xerosis, 124, I 26.

Bacteria: and spores in soil, 165 ; chromogenic, 97; from the air, 87 ; intestinal, rox; legume, I76; nitrate, I74; nitrite, I7I, I 72 ; number in air, 87 .

Bacterial examination: of air, 87 ; of milk, 88 , I5I; of soil, I6 3 ; of water, $84,14 I$.

Bacteriological technic, I.

Baker's yeast, Igo.

Beerwort: agar, 32; gelatin, 32; hopped, 32; liquid, 32; media, 32.

Berkefeld filter, ro, 92 .

Bile-salt agar, 33; broth, 33.

Bismarck brown, 44 .

Blastomyces dermatitidis, $\mathbf{1 3 2}$.

Blood agar, 40.

Blood serum, 3r.

Böttcher's moist chamber, 183 .

Bouillon, I8.

Bread paste medium, 4r.

Brewer's yeast, Igo.

Broth: acid, 4I; bile-salt, 33; calcium carbonate, 4I; glycerin, 36; meat, 3I; nitrate, 4I; pepton, I8; sugar-free, I0I, II3; standard method of preparing, 30.

Brownian movement, 76.

Buchner's method of anaërobic cultivation, 136 .

Budding of yeasts, 80 .

Calcium carbonate broth, 4r.

Capaldi's egg medium, 37 .

Capaldi's medium, 35.

Capsulated group, 123.

Capsule stain, rog; Friedländer's, rog; Rosenow's, r ro; Welch's I Io; Welch's modified, I38.

Carbol fuchsin, 43.

Carbolic: gentian violet, 45 ; thionin blue, 44.
Carmin: alum, 44; lithium, $45^{\circ}$

Caseīn, 62 .

Chart, culture, 59 .

Cheese, Camembert, I84; molds in, I84; Roquefort, 184 .

Cholera red reaction, I30.

Chromogenic group, 97.

Cladothrix, I34.

Cleaning: of glassware, 8; mixture, 8 .

Coagulation of milk, 62 .

Coagulative enzym, 62 .

Collecting: micro-organisms from the air, 70; molds from the air, 78,182 ; yeasts from the air, 78 , I 82 ; torulae from the air, 78 , I92.

Collection of water samples, 84, I 45 .

Collodion sacs, I73.

Colonies, estimation of, 85 .

Colony, 72 ; counter, 85 .

Comparative table: of Centigrade and Fahrenheit thermometers, I98; of weights and measures, I98.

Condensation water, 72,99 .

Conidia, 79.

Conradi's medium, 34 .

Cotton filter, 92.

Counter, colony, 85 .

Cultivation, anaërobic, 134; of molds, I 82 .

Culture chart, 59 .

Culture media, I8; filtration of, 21 ; preparation of, 18 ; reaction of, I8; titration of, 18 .

Culture of yeasts from one cell, 187.

Culture tubes, 9; plugging of, 9; potato, 28 .

Cultures, egg, 125; method of describing, 53.

Death-point, thermal, 96 .

Decolorization of litmus milk, 63 . 


\section{INDEX}

Delafield's hematoxylin, 44 .

Denitrification, solution for testing, 40.

Describing cultures, 53 .

Determination: of anaërobes in milk, 158 ; of anaërobes in sewage, I49; of B. coli and streptococci in milk, I57; of B. coli and streptococci in water, $86, I_{47}, I_{49}$; of bacteria and spores in soil, 165 ; of species in water, 86; of spores in soil, 165 .

Dextrose: agar, 26; litmus agar, 35; litmus gelatin, 36 ; yeast water, 33 .

Diastase, 63.

Differentiation of B. typhosus and B. coli, media for, 33 .

Digestion: of blood serum by soil bacteria, 168 ; of caseîn by soil bacteria, 169; of gelatin by soil bacteria, I6g.

Dilution tables, r97.

Diphtheria: antitoxin, I26; bacillus, I24; group, I24; toxin, I26.

Directions for filling out culture charts, 58 .

Discontinuous sterilization, II.

Disinfectants, 94 .

Doane-Buckley method, I6r.

Dog's blood serum, 33 .

Dorset's egg medium, 37.

Drigalski and Conradi's medium, 34.

Dry beat sterilization, II.

Dunham's pepton solution, I8.

Dysentery bacillus, II2, II7.

Effect: of pasteurization of milk, 88; of sterilization of milk, 88 .

Egg media, 37 .

Ehrlich's anilin gentian vio'et, 43 .

Endo's medium, 200

Enriching method of Schottelius, I30.
Enzym, 62; amylolytic, coagulative, 62; diastatic gelatinolytic, 62 ; inver 63; production, 62; $\mathrm{pr}$ lytic, 62: rennet, 63 .

Erienmeyer flask, 7.

Estimation of colonies, 85 .

Examination: of air, 87; of r48; of milk, 88, 15I; of for B. coli and streptococci, of milk for leukocytes, I6c milk for tubercle bacilli, of molds, I84; of rain w I48; of sewage, I48; of I63; of water, 86; of water, 'I 47 .

Exercises on infection and st zation, 9I.

Fermentation: abnormal, in 1 I59; chart, back cover; t 6; tube, gas production $8 \mathrm{I}$.

Filament formation, I 29 .

Filling culture tubes, 22.

Film formation by yeasts, I:

Filter: Berkefeld, ro, 92; co 92; folding of paper, 22.

Filtration of culture media,

Finkler and Prior, spirillun I29.

Flagella stain, II7.

Formation: of alcohol, 187 amido compounds, 170; ammonia, I7I; of film yeasts, I86; of indol, II4, of nitrates, 174; of nit I7I; of spores by bacteria, of spores by molds, 83 . spores by yeasts, 80,187 .

Formula for determining number of $B$. coli, streptoc and anaërobes in milk water, 86.

Fowl cholera, bacillus of, I2: Friedländer's capsule stain, : Friedländer's pneumobacillus, Frost's culture chart, 59. 


\section{LABORATORY GUIDE IN BACTERIOLOGY}

Fuchsin, carbol, 43.

Fuller and Johnson's rejuvenation method, 149 .

Gärtner's bacillus, II5.

Garden earth, inoculation with, I39.

Gas: analysis, $8 \mathrm{I}$; evolution by yeasts, 186; formula, 82 ; generator, I37; production, $8 \mathrm{r}$.

Gelatin, 26; beerwort, 32; dextrose, 36 ; digestion of, 62 ; liquefaction of, 62 ; litmus dextrose, 36 ; litmus lactose, 36 ; pepton, 26; standard methods of preparing, 30; whey, 36 .

Gelatinoid, 62.

Gelatinolytic enzym, 62 .

General bacteriology, 67 .

General directions, 5 .

Gentian violet: anilin, 43; carbolic, 45 .

Germination of mold spores, 83 .

Giltay solution, 40 .

Glanders, I32.

Glassware: cleaning of, 8 ; sterilization of, II.

Glycerin: agar, 36; broth, 36; egg medium, 37; media, 36 .

Glycerinated potato, 37 .

Glycogen, II3.

Gonococcus, rog.

Gonorrheal-pus, rog.

Gram's iodin solution, 43; stain, 77.

Granule stain, I24.

Granules, sulphur, I34.

Grass bacillus, I3I.

Group: actinomyces, 134; anthrax, 127; capsulated, I23; chromogenic, 97; colon, colontyphoid, II2; diphtheria, I24; enteritidis, II2-I5; hemorrhagic septicemia, 127; hog cholera, II 2-I5; intermediate, II 2-I5; of acid-proof bacilli, I3I; of anaërobic bacilli, I34; proteus,
121; pyogenic, ro5; typhoiddysentery, II2, I 7 .

Groups of bacteria in milk, 162 .

Growing legumes in sand, 178 .

Gruber-Widal test, Ir8.

Gypsum blocks, 80 .

Hand lens, 7.

Hanging drop, 75 .

Hansen's method of pure culture of yeasts, 187 .

Hay infusion, 4I.

Heat, influence of, on bacteria, 94 .

Hematoxylin: alum, 44; Delafield's, 44 .

Hemorrhagic septicemia group, I27.

Hesse's medium, 35 .

Hill's test rods, 94 .

Hiss's plating medium, 34; tube medium, 34 .

Hog cholera group, II5.

Hopped beerwort, 32 .

Horse's blood serum, 33 .

Hot-air sterilizer, II.

Hydrogen gas generator, 137 .

Ice, examination of, $\mathrm{I}_{4} 8$.

Impression preparation, I 28 .

Incubator, 5 I.

Indol, II4; formation of, II4, 170; test for, II4, I7O.

Infection, phenomena of, gr.

Influence: of disinfectants, 94; of moist heat, 94; of sunlight, 96.

Inoculation: of agar slants, 72; of animals (see various heads).

Inspissator, Koch's, I7.

Intermediate group, II2, II 5 .

Intermittent sterilization, I I.

Intestinal group of bacteria, II 2 .

Intramuscular inoculation, I3I.

Intraperitoneal inoculation, 123. 


\section{INDEX}

Intravenous inoculation, Io6.

Inverting enzym, 63 .

Involution forms, II7, I 2 I.

Iodin: solution, Gram's, 43; starch test, 172.

Isolation: of B. typhosus in . water, I5o; of legume bacteria, 176; of nitrate bacteria, 175; of nitrite bacteria; I72; of unknown bacteria, I39.

Jar, Novy, 137.

Jordan's non-protein medium, 42.

Klatschpräparat, I28.

Koch's inspissator, 17 .

Kühne's methylene blue, 45 .

Laboratory rules, 3 .

Lactalbumin, 62.

Legume, bacteria, 176 .

Leptothrix, 134.

Leukocytes in milk, I6o.

Liquefaction of blood serum, 57; of casein, 62 ; of gelatin, 62 .

Liquid beerwort, 32 .

Lithium carmin, 45 .

Litmus: decolorization of, 63 ; dextrose agar, 35; dextrose gelatin, 36; lactose agar, 35; lactose gelatin, 36; mannit agar, 36 ; milk, 27 ; solution, 35 ; whey, 36 .

Löffler's flagella stain, II 7 .

Löffler's methylene blue, 43.

MacConkey's bile salt agar, 33 .

MacConkey's bile salt broth, 33 .

Malachite green media, 35 .

Maltose, 63.

Mannit agar, 36.

Measures and weights, I98.

Meat: broth, 3I; press, $3 \mathrm{I}$.

Media: adjusting reaction of, I8; beerwort, 32; culture, I8; egg, 37; filling in tubes of, 22; filtering, 22; for differe tion of B. typhosus an! coli, 33; for the study of bacteria, 37; for water milk examination, 35 ; gly، 36 ; miscellaneous, 40 ; nit $4 \mathrm{r}$; non-protein, 42; ph 34; preparation of, 18 ; rea of, I8; standard method of paring, 30; synthetic, titration of, I8; whey, 36

Medium: bread paste, 4r; C di's, 35; Dorset's egg, Drigalski and Conradi's, Endo's, 33; glycerin egg Hesse's, 35; Hiss's plating Hiss's tube, 34; Jordan's protein, 42 ; ox bile, 35 ; Us sky's, 42; wine must, $4 \mathrm{I}$.

Meningococcus, I 33 .

Method: of describing cult 53; of making Gram stair. of making plates, 98 ; of ing stained preparations, of microscopic examinatic molds, 79; of preparing standard, 30 ; of prep broth, standard, 30 ; of paring gelatin, standard,

Methylene blue: Kühne's, Lö̈fler's, 43.

Micrococcus gonorrheae, meningitidis, I33; tetrage I05; zymogenes, IOg.

Micro-organišms from the ai Microscope, 45.

Milk: abnormal fermentatic I59; acid fermentation I55; acid-proof bacilli in anaërobes in, 158; bac examination of, 88 ; B. col streptococci in, I57; $\mathrm{CO} 2$ tion of, 63; examinatio for tubercle bacilli, 89 ; li 27; leukocytes in, 160; 1 and yeaşts in, I60; pa ized, 89, 158; reaction o sterilized, 158; sugar, 62 .

Miscellaneous: mẹdia, 40; $c$ isms, 132 . 
Möller's grass bacillus, I3I.

Möller's spore stain, I 29.

Moist chamber, Böttcher's, I83.

Mold spores, germination of, 83 .

Molds, I82; amylolytic action of, 184 ; in cheese, 184 ; in milk, I60; microscopic examination of, I84; yeasts, torulae, and acetic-acid bacteria, 179 .

Molecular movement, 75 .

Mouse: holder, III; microscopic examination of, II $\mathrm{r}$.

Muscle sugar, ror.

Must, wine, $4 \mathrm{r}$.

Natural souring of milk, 156 .

Needles, platinum, 6 .

Negative Gram stain, 78 .

Neutral-red agar, 33.

Nicolle's carbolic gentian violet, 45; carbolic thionin blue, 44 .

Nitrate: bacteria, I74; broth, $4 \mathrm{I}$; formation, I74; media, $4 \mathrm{I}$; solution, 4I.

Nitrates, test for, I75.

Nitrite: bacteria, I7I, I72; formation, I7I.

Nitrites, țest for, II4.

Nitrogen, assimilation of, $\mathbf{1 7 5}$.

Nitroso-indol reaction, $\mathbf{1} 30$.

Nocardia, I34.

Non-protein media, 42.

Normal solution, 20.

Novy jar, I37.

Ox-bile medium, 35 .

Ox-blood serum, 33.

Parietti's solution, 34 .

Park's method of anaërobic cultivation, 135 .

Pasteurizing milk, 89, r58.

Pedesis, 76 .

Pepton: broth, 18; gelatin, 26; solution, Dunham's, I8, solution for anmonification, 40.

Peptonization, 62, I68.
Petri dishes, 7.

Phenol: media, 34; sulphonic acid, I75.

Phenolphthaleīn, ro.

Phenomena: of infection, 9r; of sterilization, $9 \mathrm{I}$.

Pigments, I00.

Plate cultures, 98.

Plating medium, Hiss's, 34 .

Plugging culture tubes, 9 .

Pneumobacillus, I23.

Pocket inoculation, I25.

Polar staining, II6, I27.

Positive Gram stain, 78.

Potato, 28; glycerinated, 37 ; substitute for, 29 ; tube, 28 .

Preparation: Gram, 77; hanging drop, 75; impression, 128 ; of agar-agar, 20; of blood agar, 40; of blood serum, 3I; of bouillon, I8; of broth, I8, 31; of culture media, I8; of dextrose agar, 26; of Dunham's pepton solution, I 8; of egg media, 37; of gelatin, 26; of glycerin media, 36 ; of litmus milk, 27; of media for soil examination, 37; of media for water and milk examination, 35 ; of non-protein media, 42; Prescott and Breed's method, I6I; of silica jelly, 38 ; of soil samples, I66; of soil suspensions, 166 ; of staining solutions, 43 ; of sugar-free broth, ror; of whey media, 36 ; stained, 76 .

Proteolysis, 62 .

Proteolytic enzym, 62.

Proteus: group, r2I; vulgaris, I2I; zenkeri, I2I.

Pure culture: of bacteria, 187; of yeasts, I87.

Pus, gonorrheal, rog.

Pyocyanin, roo.

Pyogenic group, 105.

Rabbit septicemia, 127.

Rain water, I48. 


\section{INDEX}

Raulin's solution, 42, I85.

Reaction: indol, II4, I 70; nitrites; II4, I70; nitroso-indol, I30; of bacteria on neutral red broth, 150 ; of culture media, I8; of milk, 62.

Reduction of nitrates, 177 .

Rejuvenation of cultures, I49.

Rennet enzym, 62.

Rinderpest, I27.

Roquefort cheese, I84.

Rosenow's capsule stain, IIO.

Russell's medium, 200

Saccharomyces: cerevisiae, 78 , I89; ellipsoideus, I89; pastorianus, $I 89$.

Sacs, collodion, I73.

Safranin, 44.

Samples of water, collection of, 84 .

Salt rising bread, Igi.

Sarcina lutea, $97, \mathbf{r} 59$.

Scheme for routine study, 50 .

Schottelius enriching method, I 30.

Schweineseuche, 127 .

Sewage: anaërobes in, 149; contamination of, 86; examination of, I 48 .

Sketches of streak and stab cultures, 64,65 .

Silica jelly, 38 .

Snow, examination of, 148 .

Soil: bacteria and spores in, 165 ; examination of, I63; samples, I65; samplers, I65.

Solution: Dunham's pepton, 18; for assimilation of atmospheric nitrogen, 39; for denitrification of nitrates, 40; for formation of nitrates, 39; for formation of nitrites, 38; Giltay, 40; Gram's iodin, 43; litmus, 35; nitrate, 4I; normal, 20; Parietti's, 34; pepton for ammonification, 40; Raulin's, 42; Winogradsky's, 37.

Solutions, staining, 43 .
Species determination is 86.

Spirillum: cholerae, 133 I29; metchnikovii, asiatic cholera, I33; o and Prior, I 29; tyrogen

Spore: formation of ye. I87; staining, 128 .

Spores: germination of, soil, I68; of bacter of molds, 83; of yeasts

Stain: flagella, II7; Friec capsule, 100; Gram, 77; flagella, 109; Pappenh Rosenow's capsule, I Is 228; Welch's capsul Welch's capsule, modif

Stained preparation, 76 .

Staining: acid-proof bac capsules, 109; solutior

Standard method: for $F$ agar, 30 ; for preparin 30; for preparing gelat

Staphylococcus: albus, reus, $95,100,105$.

Starch iodin test, $\mathbf{1 7 2 .}$

Steam sterilizers, II.

Sterilization, ro; by cl II; by dry heat, II; heat, II; discontinu intermittent, II; 0 serum, I6; of glassw and pasteurization of 1 I58; of milk, 89 , I5 nomena of, $9 \mathrm{I}$.

Sterilized milk, 158 .

Sterilizer: Arnold stea hot-air, II.

Streptococci: in milk, water, 86 .

Streptococcus: lacticus, ogenes, I05. pneumeae

Study: of acetic-acid I92; bacterial, of milk, of molds, 83 ; of molds and torulae, 78; of $\mathrm{p}$ roo; of soil bacteria, yeasts, 79 .

Subcutaneous injection, I 
Substitute for potato, 29.

Sugar-free broth, Ior.

Sulphur granules, 134 .

Sunlight, influence of, 98 .

Surface water, 146 .

Suspension of soil, I 66 .

Synthetic: agar for plating, 38 ; media, 42 .

Table: of Centigrade and Fah. renheit thermometers, I98; of weights and measures, I98.

Tables, dilution, I97.

Technic, bacteriological, $\mathbf{I}$.

Tẹst: agglutination, $x$ I 8 ; for indol, II4, I7O; for indol and nitrites, I14, I70; for nitrates, I75; for nitrites, II4; GruberWidal, I 8 ; rods, Hill's, 94; starch iodin, I72; Widal, II8.

Thermal death-point, 96 .

Thermostat, 5I.

Thionin blue, 44 .

Titration of media, I8.

Torula amara, 159.

Torulae, 78 , 192.

Trichomyceies, I34.

Tube: culture, 9; termentation, 7; medium, Hiss's, 34; potato, 28.

Tubercle: bacilli in milk, 89; bacieria, 175 .
Typhoid-dysentery group, II 2, II 7 .

Ultramicroscopic bacteria, 92 .

Uschinsky's medium, 42.

Water: and milk examination, media for, 35; and sewage, bacterial examination of, 84 , I4I; bacterial examination of, 84 ; bath, 70; of condensation, 72 ; samples, collection of, 84 ; species determination in, 86.

Weights and measures, 198.

Welch's capsule stain, Iro; modified, 138 .

Well water, I47.

Whey, 62; agar, 36; gelatin, 36; litmus, 36 ; media, 36 ;

Widal test, II 8.

Wine must, 4r.

Winogradsky's solution, 37 .

Yeast: baker's, 190; brewer's, I90; of salt-rising bread, IgI; water, 32; water, dextrose, 33 .

Yeasts, 78, I85; alcohol formation, 187 ; budding of, 80 ; film formation of, I86; from the air, 78 , I 85 ; gas evolution of, I86; spore formation of, 80, 187 .

Ziehl-Neelsen's carbol fuchsin, 43. 



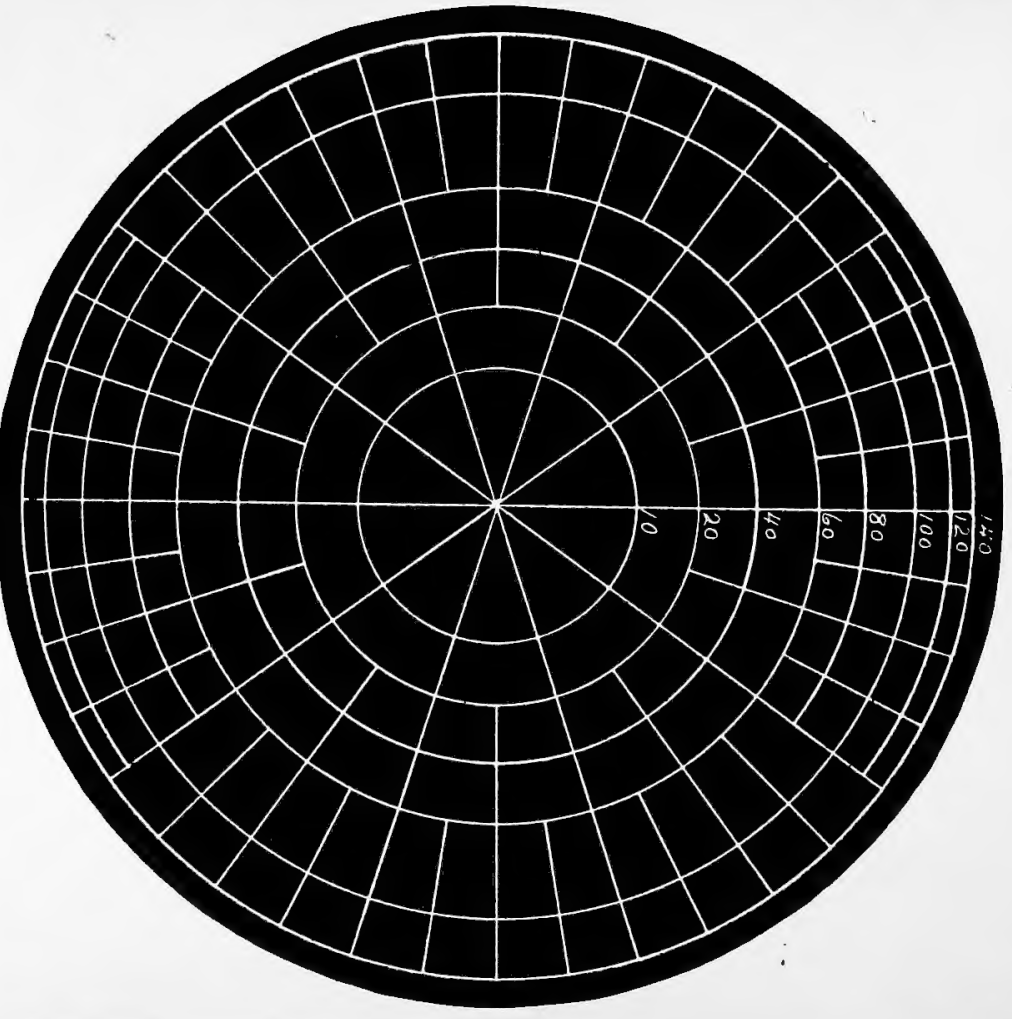




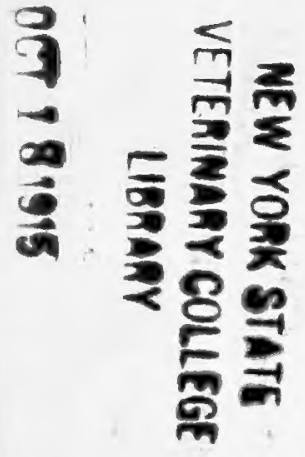


